\title{
Diaspora's Dialect: Cultural Exchange and the Transformation of Jamaican Patois in the Greater Toronto Area
}

\author{
by \\ Raven-Paige Wilkinson
}

A thesis submitted to the Faculty of Graduate and Postdoctoral Affairs in partial fulfillment of the requirements for the degree of

Master of Arts

in

Communication

Carleton University

Ottawa, Ontario

(C) 2019, Raven-Paige Wilkinson 


\section{Abstract}

Patois, the unofficial language of Jamaica, has been hybridized since its inception due to the slavery, violence, and subversion that took place during colonialism, and is thus influenced by various cultures, styles, and identities. Over time, its significance has surpassed the borders of the Caribbean and influenced numerous localities such as the Greater Toronto Area (GTA), which has incorporated many aspects of Jamaican culture and language. As such, this project asks, in what ways is Patois, a language long used to define Jamaican culture, now contributing to cultures in locations abroad, through various processes and connections?

Using an online survey and interviews, this empirical project weaves postcolonial thought together with cultural studies and personal narratives to provide new insights on the ways in which Patois has connected Jamaica with the Toronto community, and what it means for a language to transform significantly throughout space and time. This research contributes a fresh perspective to the wider discourse on social and cultural exchange in the modern age. 


\section{Acknowledgements}

I would like to thank my supervisor, Professor Merlyna Lim for her guidance and support throughout my thesis. When I took her class the year prior to starting my thesis, I was exposed to numerous critical thinkers, theories, and concepts that have played a significant role in my understanding and development of my research project. As my supervisor, she has helped to demystify thesis writing and demonstrated the ways in which I can make my project original and personal, while still adhering to the expectations of the program. I would also like to thank Professor Karim Karim, my second reader, for contributing new perspectives and helping to refine the final draft. I am also thankful to have received the SSHRC award, which has not only helped me financially, but to also feel more confident in my academic work. Finally, I would like to thank my close loved ones, especially my mom, for their continued love, encouragement, and support throughout this journey. 


\section{Table of Contents}

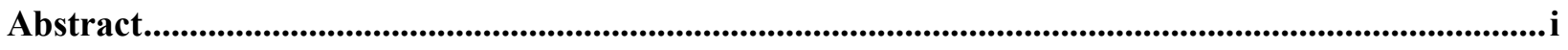

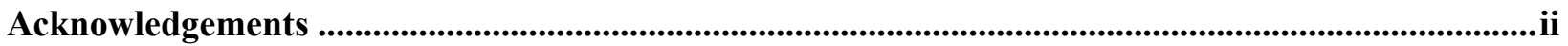

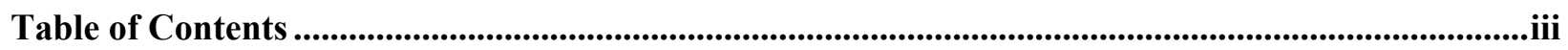

List of Tables ...................................................................................................................................................... vii

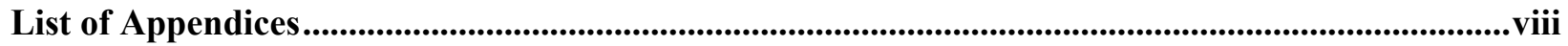

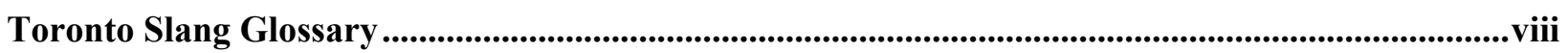

Chapter 1: Introduction..................................................................................................................................... 1

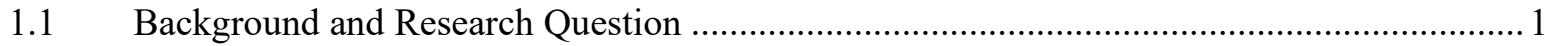

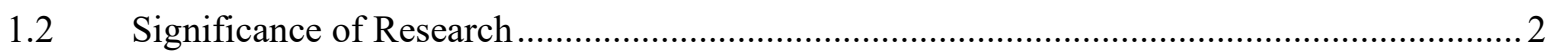

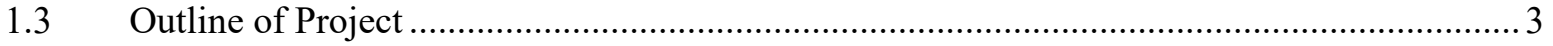

Chapter 2: Review of the Literature............................................................................................................4

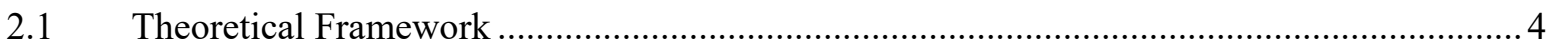

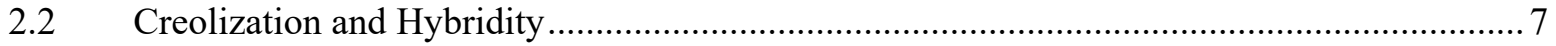

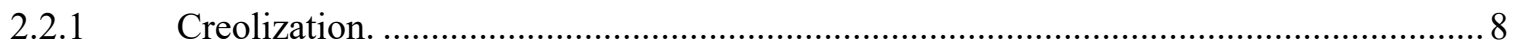

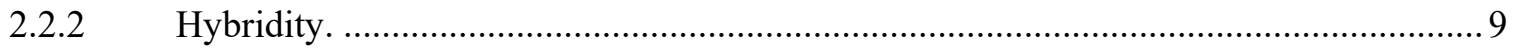

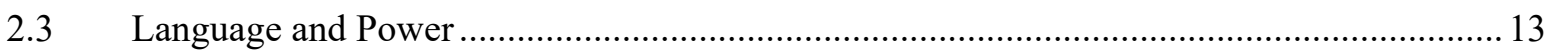

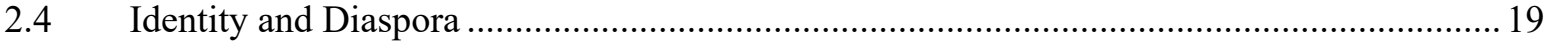

2.4.1 Présence Africaine and Présence Européenne: origins of identity.............................. 20

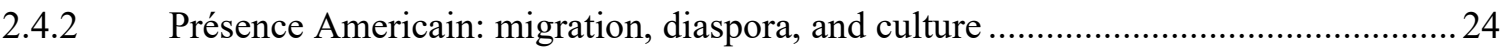

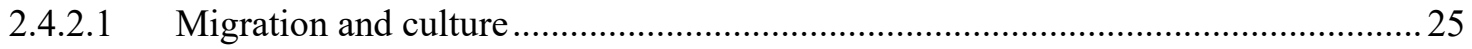

2.4.2.2 Visibility of Patois in Toronto slang and culture …............................................... 28

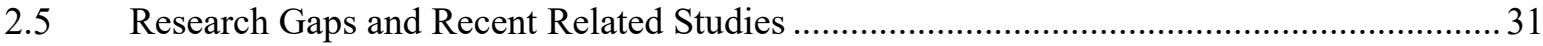

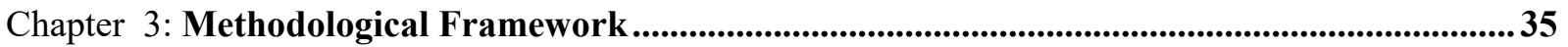

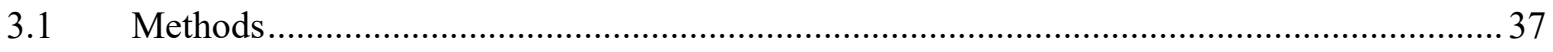




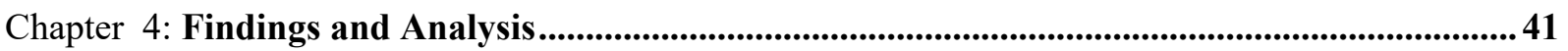

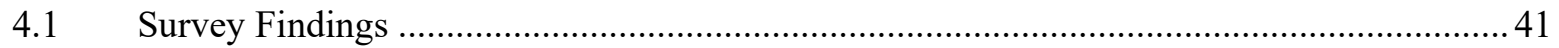

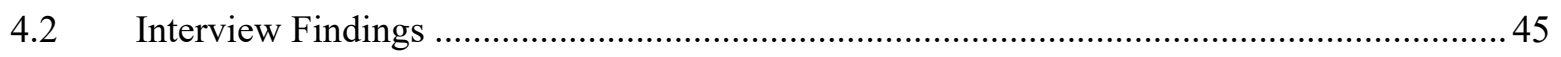

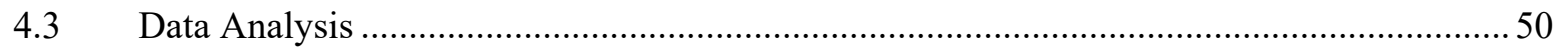

4.3.1 Connections to and views of Jamaican culture ......................................................... 51

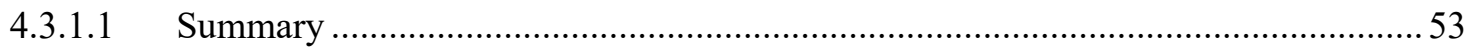

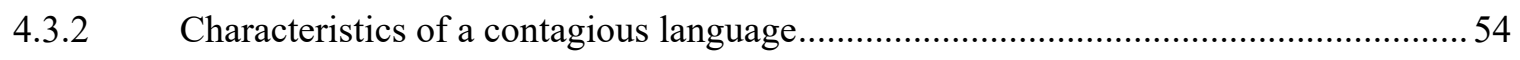

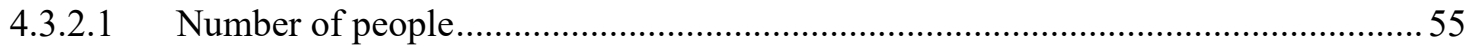

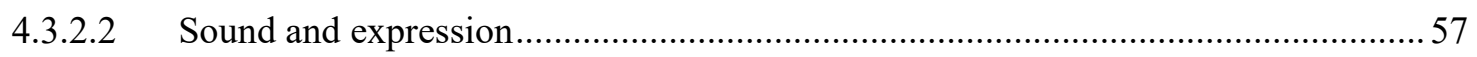

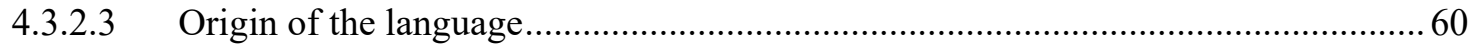

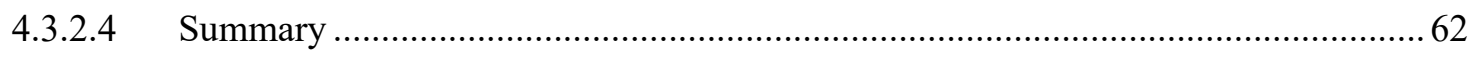

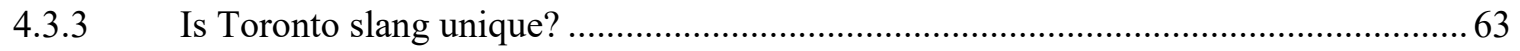

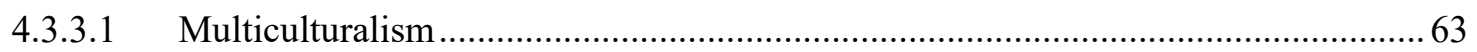

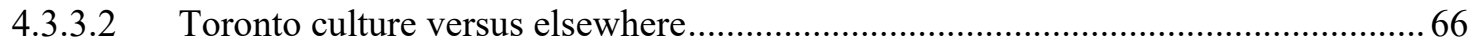

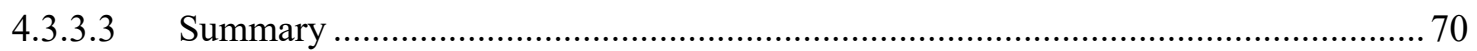

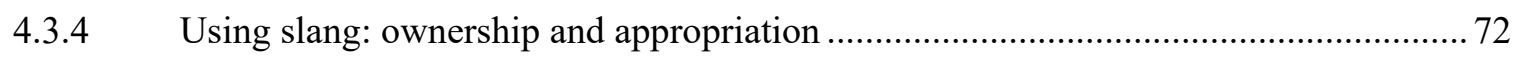

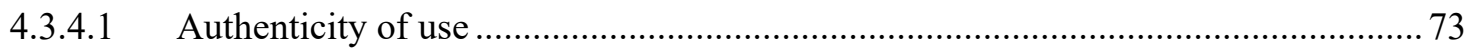

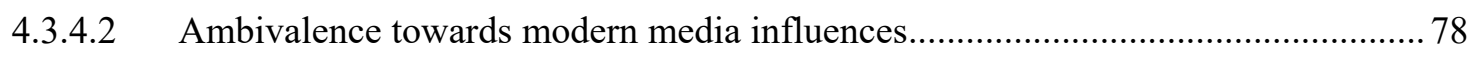

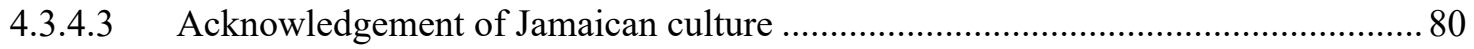

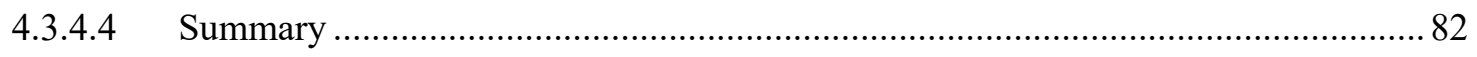

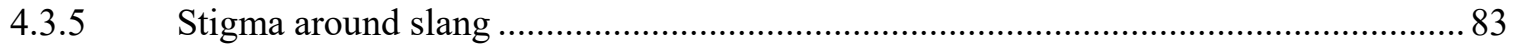

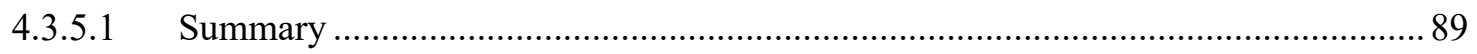

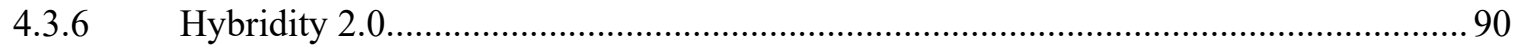

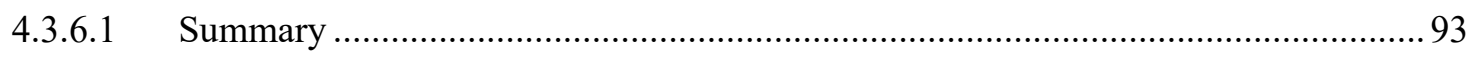

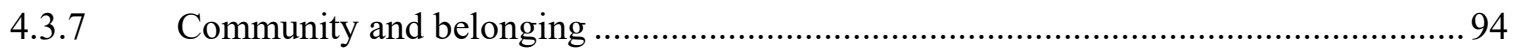

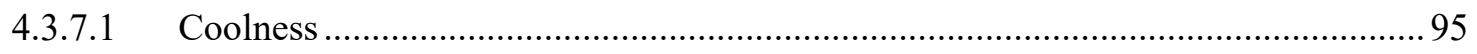

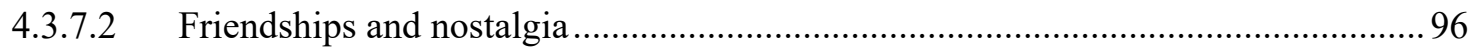

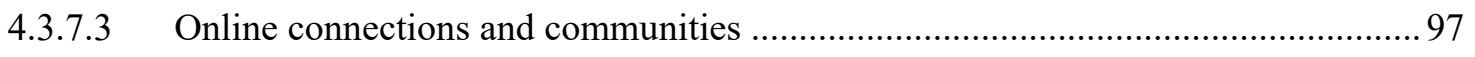




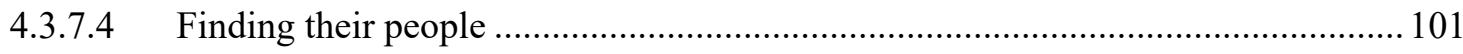

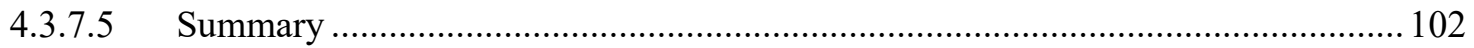

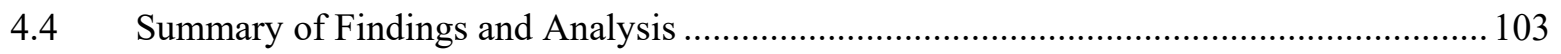

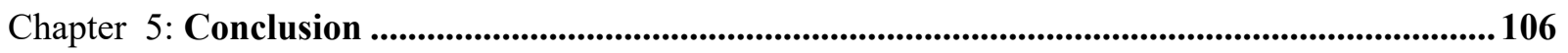

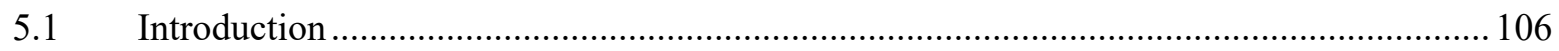

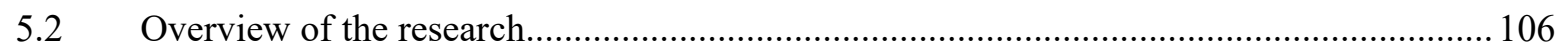

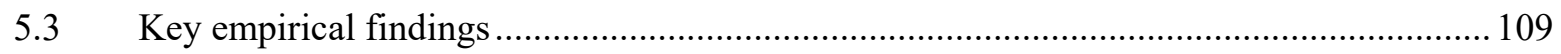

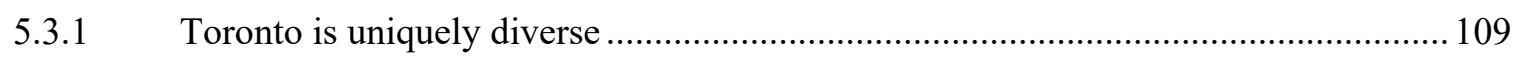

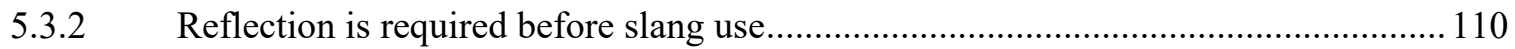

5.3.3 Toronto slang and culture are gaining recognition ................................................ 110

5.3.4 Toronto slang evokes feelings of community and nostalgia .................................... 111

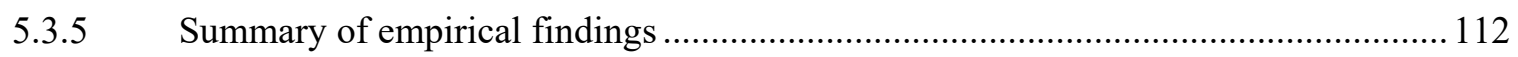

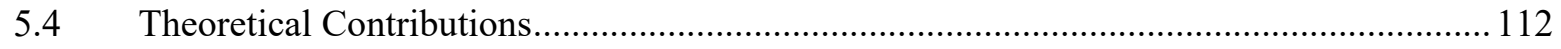

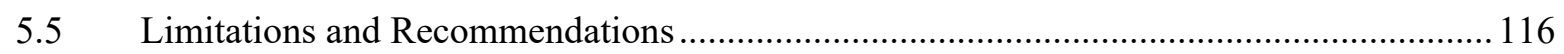

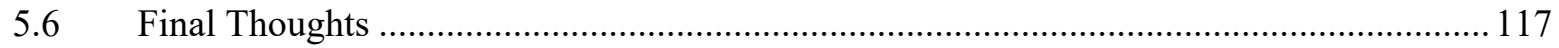

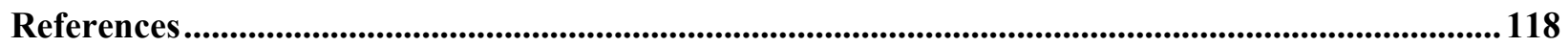

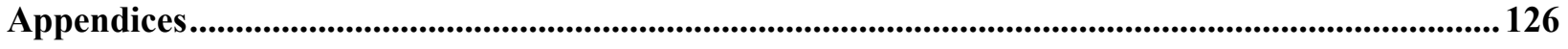




\section{List of Tables}

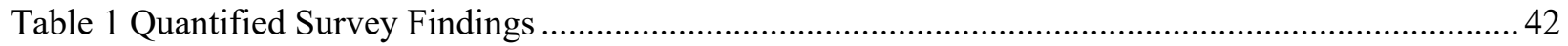

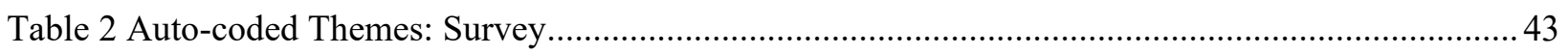

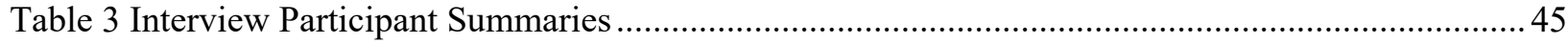

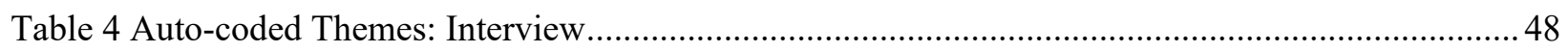




\section{List of Appendices}

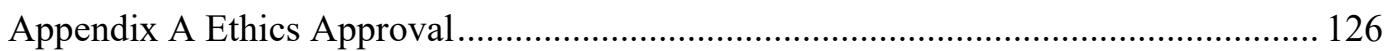

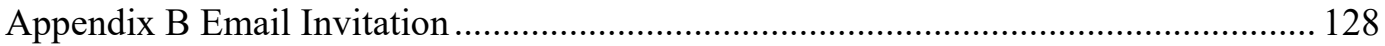

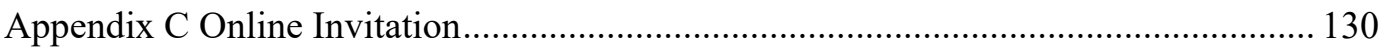

Appendix D Social Media Script ............................................................................... 131

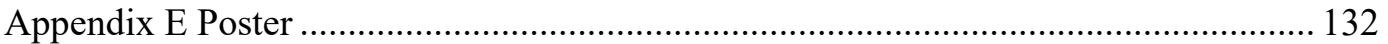

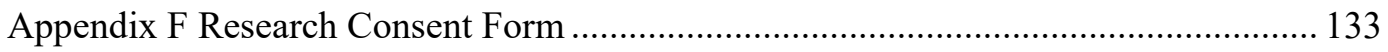

Appendix G Online Survey Research Consent .............................................................. 137

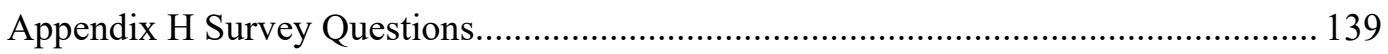

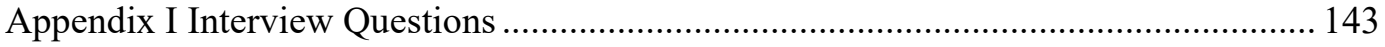




\section{Toronto Slang Glossary}

Ahlie can mean 'Really?' 'Is that true?', or as an affirmation such as 'I know, right?'

Bare used when describing 'a lot' of something

Brejin brethren, friend, comrade

Dukes refers to one's parents

[Toronto] Hoodman(s) a man who may or may not engage in illegal dealings, but has a heavy Toronto accent and primarily uses Toronto slang when he speaks

Kissing teeth sucking hair through the teeth with pursed lips; done to show annoyance, disapproval, or dissatisfaction with a person or situation

Mandem often refers to one's friends

Mans often refers to oneself, as well as the plural form of 'man'

Pree to eavesdrop or be nosy

The Six, The 6ix, T-dot Toronto

Ting thing

Wha gwaan a greeting among people, meaning 'What's up?' or 'How are you?' 


\section{Chapter 1: Introduction}

"Alright, so. *Kisses teeth* Ah wah gwaan. Mans woke up this morning, took a one-two shower, ate a one-two piece of pizza. Then, like, my dukes wanted me to drop them at work, so, like, had to follow wit her real quick. Scooped off the whip, dropped off my dukes, came back home. *Kisses teeth* One of the mandem wanted to roll through to take some pics for their 'gram, so I was like "alright". He forwarded to my crib, mans went out, ate bless. After that, bare snow started falling, so I was like, "Nah, it's not even one of those ones", so mans just came back home and I'm kick up, still." (Participant 11, Personal Communication, November $15,2018){ }^{1}$

\subsection{Background and Research Question}

The above quote is a story told by an interview participant who was asked to describe his day in Toronto slang. As a content creator of Jamaican and Congolese descent who has spent most of his life in the Greater Toronto Area (GTA), Toronto slang is a dialect he can use instinctively. He enjoys the element of comedy and entertainment related to slang and is also able to connect with those who grew up with and relate to the vernacular.

Toronto has been the most popular destination for West Indian migrants to Canada since the 1960s, with most immigrants travelling from Jamaica (Foner, 2009). After changes to Canadian immigration legislations, people from the Caribbean and Bermuda were the second largest non-European and non-American immigrant groups in Canada after Eastern Asia (Statistics Canada, 2018b). And as of 2016, the GTA had a population of 5,928,040. Of this population, 346,530, or, approximately six percent

1 "Alright, so. *Kisses teeth* What's up? I woke up this morning, took a shower, ate a piece of pizza. Then, like, my mom wanted me to drop her at work, so, like, had to go with her real quick. Took the car, dropped off my mom, came back home. *Kisses teeth* One of my friends wanted to come over to take some pics for their Instagram account, so I was like "alright". He came over, we went out, and then we ate good food. After that, a lot of snow started falling, so I was like, "I'm not going to bother with this", so I came back home and I'm relaxing now." 
had Caribbean origins, with 200,330 people, or, 58\% originating from Jamaica (Statistics Canada, 2018a). As such, Toronto and the GTA have been influenced by many aspects of Jamaican culture through migration and diaspora.

Jamaican Patois, the unofficial language of the island, has been influenced by various cultures, and is a fusion of "relatively distinct forms, styles, or identities" (Kraidy, 2005, p. 5). This hybridized language has been spoken and spread throughout the Jamaican diaspora in various ways, and by both Jamaicans and non-Jamaicans. The language has since contributed to the language spoken in diverse neighbourhoods in the GTA, and over time, this influence and the ways in which residents would incorporate and combine Standard English and Patois, became known as Toronto slang. Observably, through slang, Patois' vibrant and contagious nature has long been integrated into the linguistic and cultural fibre of the GTA. However, residents may choose to use slang with little to no knowledge of Jamaica, or Patois' history of violence, oppression, and cultural tension.

My research looks at the new ways in which Patois has heavily contributed to a culture and age unlike that in which it originated, primarily because of migration. I explore what it means for a resistive language such as Patois to be used in the West, how this usage is interpreted by both Jamaicans and nonJamaicans, and its significance to GTA culture. Particularly, I ask, in what ways is Patois, a language long used to define Jamaican culture, now contributing to cultures in locations abroad, through various processes and connections?

\subsection{Significance of Research}

Past research has focused primarily on Jamaican migration to cities in England or the United States (Hewitt, 1986; Sebba, 1993; Bryan, 2004; Thomas, 2007; Sebba, \& Dray, 2012). Few analyze Jamaican diasporic experiences in Toronto to discover the culture's effect and influence on Canada, and the GTA specifically. Furthermore, since many related studies are outdated, this research contributes to a 
wider discourse on social and cultural exchange in the modern age. This empirical project contributes to the scholarship by weaving postcolonial thought together with cultural studies and personal narratives, to provide new insights on how Patois has connected Jamaica with the Toronto community. It is also timely because of the use of Patois, slang, and reggae beats in videos and social media content, as well as music

produced by GTA-grown musical artists such as Drake, which have resulted in a new rise in circulation of this hybrid dialect.

\subsection{Outline of Project}

This project is organized into five chapters. Following the introduction, Chapter 2 discusses the project's theoretical framework and reviews relevant literature to discuss its significance and potential research gaps. Postcolonial theory is used to explore the development of Patois within the colonial context, as well as the ways in which the language has evolved and transformed due to processes such as hybridity, diaspora, Third Space, and identity formation. Chapter 3 outlines the methodological approach and methods used to collect relevant data. I discuss the constructivist and transformative paradigms upon which my project is grounded, and the ways in which it aligns closely with these worldviews. I also discuss my online survey and interview research methods and their importance to this project, which relies heavily on personal stories and experiences. Chapter 4 discusses and analyses the survey and interview findings to identify prevalent themes, ideas, and quotes. I link the findings within each theme to relevant literature in order to demonstrate objectivity, validate the responses, and further situate the research results within previous studies. Chapter 5 concludes the project by providing an overview of the research, key findings, theoretical contributions, and limitations and recommendations for further projects. I end with final thoughts and a reiteration of this project's significance to both the academic and non-academic world. 


\section{Chapter 2: Review of the Literature}

I examine Jamaican language as a product of slavery, colonization and resistance, as well as an influence on communities that interact and intersect with members of the Jamaican diaspora. As a result, the country's deep connection to colonialism makes postcolonial theory the appropriate theoretical framework through which to address my research question.

\subsection{Theoretical Framework}

Colonialism has existed for many centuries, with ancient empires conquering and expanding their territories and claiming power over distant lands. That said, modern European colonialism was "distinctive and by far the most extensive of the different kinds of colonial contact that have been a recurrent feature of human history" (Loomba, 2005, p. 2; xiii). In fact, by the 1930s, 84.6\% of global land mass was covered by existing and former colonies (Loomba, 2005). Modern European colonialism wiped out entire cultures, disrupted economic processes, and developed biological and racial hierarchies that placed Europeans at the top, and forced black people to the lowest and most inferior ranking.

However, during this period of European imperialism arose an unexpected development: the "immensely prestigious and powerful imperial culture" became appropriated in "projects of countercolonial hybrid processes of self-determination" to confront, dissolve, and unseat the massive power of imperial knowledge (Ashcroft et al., 1995, p. 1, emphasis in the original). Therefore, postcolonial literatures are a "result of this interaction between imperial culture and the complex of indigenous cultural practices" (Ashcroft et al., 1995, p. 1). Furthermore, postcolonial theory emerged when colonized people were able to reflect on the tension that occurred from the "problematic and contested, but eventually vibrant and powerful mixture of imperial language and local experience” (Ashcroft et al., 1995, p. 1). 
Postcolonial theory holds that "imperialism and colonial domination have affected the whole world" (Burney, 2012, p. 173). It is based on the "'historical fact' of European colonialism and the diverse material effects to which this phenomenon gave rise" (Ashcroft et al., 1995, p. 2). The 'post' in postcolonial theory does not indicate the period after colonialism or imply that it is over. Instead, it signifies "the contestation of colonial domination and the legacies of colonialism" (Loomba, 2005, p. 12). This is because all postcolonial societies remain impacted by the lasting effects of colonialism and neocolonial domination, including racism, cultural and linguistic discrimination, imperialism, capitalism, and other unjust systems and unequal power relations (Ashcroft et al., 1995).

Said (1978) believed knowledge and power were the "two invisible foundations of imperial authority", which resulted in the exportation of European languages, literature, and learning, and a "civilising mission which involved the suppression of a vast wealth of indigenous cultures beneath the weight of imperial control" (Ashcroft et al., 1995, p. 1). Imperial language, literature, and culture have played a crucial role in colonization and resulted in the "silencing of the postcolonial voice" (Ashcroft et al., 1995, p. 4). This makes language a central aspect of postcolonial inquiry (Burney, 2012). Many indigenous groups were introduced to language and culture, "from outside", via literature by Dickens, Jane Austin, Kipling, and "that sacred gang" (Lamming, 1960, p. 27). Additionally, questions about whether the subaltern is able to speak (Spivak, 1988; Said, 1978; Bhabha, 1994), to what extent (Bhabha, 1985; 1994; Brathwaite, 1979/1981; 1984; Kincaid, 1988; Hall, 1994), and in which language (Achebe, 1965; Fanon, 1967; Ngũgĩ, 1972; Brathwaite, 1984; Glissant, 1989; Hall, 1994), have been crucial to postcolonial studies.

Postcolonial theory involves discourse on a number of concepts and issues as a consequence of the colonial encounter. These include migration, slavery, suppression, resistance, representation, race, gender, and "master discourses of imperial Europe such as history, philosophy and linguistics, and the fundamental experiences of speaking and writing" by which these topics exist (Ashcroft et al., 1995, p. 2). 
Furthermore, when the idea of 'postcolonial' includes as subjects people such as African Americans or those of Asian or Caribbean origin living in the West, who have been "geographically displaced by colonialism", it allows us to "incorporate the history of anti-colonial resistance with contemporary resistances to imperialism and to dominant Western culture" (Loomba, 2005, p. 12).

Although a number of countries and regions were severely affected by the colonial encounter, the West Indian, unlike the African, was "wholly severed from the cradle of a continuous culture and tradition" (Lamming, 1960, p. 34). During colonialism, the black Africans transported to the Americas experienced a rupture in their historical trajectory and had to deal with the shock and trauma that accompanied enslavement. The Caribbean people had no choice but to fuse the different cultures together to make something new, which required "absolute dependence on the values in that language of his coloniser" (Lamming, 1960, p. 35). Therefore, since colonialism is the "base and structure of the West Indian cultural awareness", postcolonial theory aids my investigation of how Jamaica has engaged with and challenged "colonialism's discourses, power structures, and social hierarchies" to form its widespread culture and language (Lamming, 1960, p. 35; Gilbert \& Tomkins, 1996, p. 2).

I am interested in exploring how postcolonial theories and approaches may be used to deal with questions of creolization and hybridity; language and power; identity formation; and migration and diaspora. These themes appropriately address the ways in which language and culture transport and transform through time; can be used to subvert and challenge oppression and authority; contribute to self expression; and create ties between ethnicities and immigrant communities, respectively. In this thesis, I apply these themes and concepts to today's society, to explore their significance to ideas relating to Patois-derived Toronto slang. My research draws from, aligns with, builds on, and challenges theorists' arguments pertaining to these themes, in order to demonstrate the ways in which my work contributes to the scholarship in a new light. 
In the following sections, I discuss existing scholarly works that are central to my research and, at the same time, position my research vis-à-vis these works. First, Creolization and Hybridity details the hybrid nature of Caribbean and particularly Jamaican culture, and the ways in which terms such as creolization, hybridity, and Third Space have been perceived as powerful and empowering by some scholars and overused and ineffective by others. Next, Language and Power discusses the ways in which Creole and Patois have been used to undermine traditional power structures during slavery, in order to subvert Standard English. Toronto slang is seen as an extension of these efforts to challenge what it means to speak English today. The third section, Identity and Diaspora, discusses the primary 'presences' that contribute to the Caribbean diasporic identity. Présence Africaine and Européenne demonstrate the origins of identity formation following decolonization, and Présence Americain explores the ambiguity of the diasporic identity, its relation to migration, and the cultural production that has resulted from Jamaican's migration to the GTA. Finally, Research Gaps and Recent Related Studies examines previous studies related to Jamaican language and culture in Canada and elsewhere. I point to the gaps within which my research seeks to fill and the ways in which this project contributes to the scholarship.

\subsection{Creolization and Hybridity}

Creolization, hybridity, and Third Space are central concepts that help to explain the process of cultural blending in the Caribbean. The process of cultural mixing is said to be a historical reality, having existed since the beginning of human beings (Bentley, 1993, cited in Kraidy, 2005). Creolization and hybridity are processes used to describe the "distinctiveness of Caribbean cultures", their mixed character, "complex, troubled unfinished relation to history", themes of voyage and exile in their narratives, and "the unrequited trauma of violent expropriation and separation" (Hall, 2015, p. 16). Said (1994) addresses and appreciates hybridity as a universal process for all cultures, stating that none are pure or homogeneous (Kraidy, 2005). In fact, he says cultures include more foreign elements and differences than 
they consciously exclude. This relates to Brathwaite's (1971) and Hall's (2015) arguments that hybridity and creolization were key processes in the development of the Caribbean islands and their unique qualities.

\subsubsection{Creolization.}

Although 'créolité' (Glissant, 1989; Bernabé, Chamoiseau, \& Confiant, 1990) and creolization are not commonly used in Anglophone Caribbean countries, Hall (2015) argues that creolization is still an appropriate term to use in the Anglophone context, as it is aligned with hybridity, openness, and diversity. Furthermore, Glissant's (1989) general definition of creolization resonates with the ideas presented in this project, that is, the "process of cultural and linguistic mixing which arise from the entanglement of different cultures" forced to cohabitate in the colonial context (Hall, 2015, p. 15). Each Caribbean country differs in their ethnic origins, genetic and physical features, personal characteristics, languages, and cultural expressions, due to the various qualities of their respective colonizers (Hall, 2001). As such, although they survived similar events, every island is unique in its cultural practices. Creolization, then, demonstrates the ways in which there are always traces of cultural and linguistic origins that remain untranslated throughout the process, and thus prevent total cultural closure. Although various elements are incorporated into a creolized culture, the "logic of diffèrance"- - which allows the culture to continue to operate on a spectrum instead of on binary terms - remains (Hall, 2015, p. 16). Considering this concept, one can understand why there still exists African terms in Patois, and Patois terms in Toronto slang.

Kraidy (2005) believes hybridity is the most appropriate term to describe cultural mixing because of it is broadness: terms such as syncretism, mestizaje, and creolization focus on specific elements of cultural mixing (religion; nationalism and race; and language, culture, and birthplace; respectively), whereas hybridity considers meanings related to culture, race, language, and ethnicity (Kraidy, 2005). I argue that creolization remains important to the understanding of the cultural entanglements that exist in 
the Caribbean. Its aspects of nationalism and race, language, and culture are pertinent to my project. Additionally, its ideas of linguistic mixing and cultural spectrums align closely with my arguments on Toronto slang's development and the ways in which Patois has taken on new meanings within the GTA context. That said, creolization, as mentioned, is related more closely to Francophonic and Caribbean settings and encompasses only certain elements of cultural merging. Therefore, I consider creolization not as a separate concept, but as a part of the discourse on hybridity, and use hybridity as the most effective term to address themes of language, ethnicity, culture, and race.

\subsubsection{Hybridity.}

Kraidy (2005) defines hybridity as involving "the fusion of two hitherto relatively distinct forms, styles, or identities" (p. 5). Spaces that experience cross-cultural contact via movement of cultural products or people — whether by choice or by force — are essential to hybridity (Kraidy, 2005). Bhabha $(1985,1993,1994)$ moves beyond ideas of cultural fusion and mixing in his theorization by arguing that hybridity is a tool through which colonized groups can subvert and reappropriate dominant discourses and imperial power. He asserts that repetition of "discriminatory identity effects" reverses the effects of disavowal, and instead allows rejected knowledges from the margins to enter the dominant discourse and "estrange the basis of authority" (Bhabha 1985, p. 156). Through mimicry, the "native" creates a "qualitatively different thing-in-itself, where misreading and incongruities expose the uncertainties and ambivalences of the colonialist text and deny it an authorizing presence" (Parry, 1987, in Ashcroft, Griffiths \& Tiffin, 1995, p. 42). Evidently, Bhabha believes colonized groups are afforded agency through productive strategies of hybridity and mimicry, which undermine authoritative colonial representation to reveal the ambivalence of colonial discourse (Bhabha, 1985).

Bhabha (1994) also describes hybridity as the 'Third Space' where the colonized subject forms its identity through iteration and translation. He explains that Third Space is the required passage through which production of meaning is mobilized. The Third Space challenges the idea that cultures are 
homogeneous and unified and reveals the contradiction and ambivalence within cultural statements and systems. In fact, Bhabha (1994) holds that the Third Space, "which constitutes the discursive conditions of enunciation...ensure that meaning and symbols of culture" have no inherent unity or fixity at all (p. 21). Hence, if a cultural symbol has no fixed origin, it is free to be appropriated, reinterpreted, and translated in new and different ways. Similarly, Hall (2015) explains the process of cultural transculturation and its production of a Third Space, which prevents both the colonizer and the colonized to retain their cultural purity or authenticity. This Third Space is a native vernacular space "marked by the fusion of cultural elements drawn from all originating cultures, but result in a configuration in which these elements, though never equal, can no longer be disaggregated or restored to their originary forms" because they have been "permanently "translated”" (Hall, 2015, p. 15).

Bryan (2004) discusses the ways in which "the speech of the children of that Jamaican diaspora, up to the third generation, blends with the local languages of the English working class and newer migrant populations" (p. 653). These ideas contribute to my discussion on negotiated identities. I explore the ways in which the fusion of traits from originating cultures result in an unequal and inseparable configuration. I also explore whether Patois can be considered a linguistic Third Space where other positions and structures could emerge during colonialism, and if, through Toronto slang, signs and symbols used within Jamaican culture have experienced further iterations and taken on new meanings.

Gilroy (1993) describes the inescapability of hybridity and the mixture of ideas by using the analogy of the ship: the ship illustrates the ways in which, through slavery, flows of people, ideas, and cultures between "departure and destination", are transported to various locations in the West, namely, the Caribbean, the United Kingdom, and the United States (Kraidy, 2005, p. 58). He cautions against the notion of cultural and racial purity, acknowledging and appreciating the hybridity that exists across different groups. Brathwaite $(1971 ; 1979 / 1981)$ also focuses on the ways in which the intersection of British and West African culture in Jamaica contributed to the formation of a creole society with its own 
distinctive character and identity. He also believes the process of cultural encounter and entanglement continued with various groups over time.

Hybridity is a continuous process that allows people, through the Third Space, to "negotiate and translate their cultural identities in a discontinuous intertextual temporality of cultural difference" (Bhabha, 1998, p. 22). I draw from these sentiments to discover if the hybridization of settlers and slaves before they inhabited Jamaica means that all languages can be considered hybrid - especially one like Jamaican Patois. Moving beyond slavery and colonization, I look at whether culture and language continue to evolve, producing new forms and practices as the older ones continue to exist (Ashcroft, Griffiths \& Tiffin, 1995).

That said, hybridity has experienced criticism and critique for a number of reasons. First, it has been used to define several processes within numerous fields and contexts. Consequently, its meaning gets diluted and lacks a solid understanding across a wide array of disciplines. Critics argue that this results in the term garnering no meaning at all (Kraidy, 2005). Next, some contend that positive perceptions of hybridity disregard its relationship to hegemony (Chow, 1993; Toumson, 1998). This perspective holds that under the guise of hybridity, the least controversial elements are selected from indigenous and minority cultures and incorporated into the dominant society to appear as if these cultures have been embraced. However, the dominant ideologies regarding religion, politics, and other institutions are still imposed on these minorities (Kraidy, 2005).

Additionally, whereas Bhabha (1998) argues for hybridity's function in the resistance of the colonized, Spivak (1988) holds that subaltern groups - those considered below the elite and outside of the hegemonic power structure - have little power within the colonial context. She states that through dominant ideologies and the normalization of imperial narratives, Western thinkers only speak to other Western thinkers about subaltern groups through Western viewpoints. In other words, while Bhabha (1998) is optimistic about the colonized people's ability to write themselves back into history and be 
heard, Spivak (1988) argues that there is little opportunity for them to speak when the knowledge produced in literary texts works to reinforce colonial philosophies, and when the Other is essentialized and seen as a homogeneous group. In Orientalism (1978), Said also demonstrates this view, arguing that the Imperial West constructs problematic ideas of the Other in order to differentiate itself from nonEuropean countries and appear superior. This negative binary depiction of the Other is internalized and incorporated into the dominant ideology, thus giving the West control over nearly all aspects of everyday life (Said, 1978). In fact, even when non-Western groups attempt to resist the hold of the Imperial West, the powerful countries barely even notice-it is of little effect (Kraidy, 2005). In addition, although Said (1994) acknowledges in his later work, the value of hybridity, as well as the impure and mixed nature of historical and cultural experiences, he does so by critically analyzing this process in relation to power, oppression, and the imperial attitudes that continue to prevail in the modern day.

Finally, within the context of the Caribbean and black culture, créolité and Négritude hold polarizing beliefs about hybridity: while those identifying with créolité embrace hybridity as a way to think about the cultural encounters that have undoubtedly taken place, Négritude rejects the idea of hybridity. In contrast to scholars such as Brathwaite (1971; 1979/1981) and Hall (2015), Négritude founder, Césaire (1956) believed in the preservation of the distinct African identity, and thus argued that hybridity weakened a civilization's national and cultural uniqueness. In Discourse on Colonialism (1972), Césaire argues that colonialism was not the best way of establishing contact among civilizations. A critic of colonialism and capitalism, he argues that while colonization is said to have brought progress, he instead sees "societies drained of their essence, cultures trampled underfoot, institutions undermined, lands confiscated, religions smashed, magnificent artistic creations destroyed, extraordinary possibilities wiped out" (Césaire, 1972, p. 43, emphasis in original text). He acknowledges Europe's influence on him and his work, but ultimately holds that contact between the colonizer and colonized has resulted primarily in destruction, domination, and submission (Césaire, 1972). Hall (2015) also notes that since creolization 
does not involve an equal and peaceful exchange of cultural elements, this process is always one of inequality, hierarchization, control, resistance, and "issues of domination and subalternity" (p. 16). Furthermore, creolization and hybridity are deeply connected to Jamaicans' lack of easily traceable roots and "brutal rupture with the past", due to a "regime founded on racism and institutional violence" (Hall, 2015, p. 16).

Although vital to the development of Jamaican culture, it is important to situate the process of hybridity and all other cultural encounters resulting from colonialism within the context of a "painful and difficult history", rooted in slavery, colonialism, rape, and racism (Prabhu, 2007). Brathwaite (1971) states that the creolization caused by friction and confrontation in the Caribbean was cruel, but creative. I keep this in mind as I describe the positive elements of these concepts, so as not to be complicit and disregard these disturbing histories. Therefore, while I use the idea of hybridity in a positive light, I do so with critical reflection and acknowledgement of its relation to power imbalances, racism, and oppression.

\subsection{Language and Power}

Creole languages developed in the Caribbean in the mid $17^{\text {th }}$ to $18^{\text {th }}$ centuries (Glissant, 1989). The intrusion of European culture after Columbus' 'discovery' of the Caribbean brought about the imperial languages of English, French, Dutch, and Spanish - languages of oppression (Bailey, 1966; Brathwaite, 1979/1981). These linguistic influences were infused into the languages of the West African people who were imported to the islands to perform slave labour. Caribbean slaves had their own traditions, using dance, music, and other cultural expressions to communicate feelings of fear, sorrow, and joy, among others (Braithwaite, 1971). West African folk traditions were foreign to the white observers; colonizers called the language of the Negro "drawling, dissonant gibberish", their practices were considered noise, and their culture was eventually denied, ignored, and forgotten by both master and slave (Braithwaite, 1971, p. 302). Suppression also occurred when it came to native languages. Overseers 
"banded slaves of different tribes together on the plantations so that cultural links with Africa were effectively severed" (Hebdige, 1976, p. 136).

Hebdige (1976) explains that "the expulsion of the black from the wider linguistic community meant that a whole culture evolved by a secret and forbidden osmosis" (p. 136). The slaves' lack of "any legitimate cultural exchange" caused them to develop "an excessive individualism and a set of cultural artefacts which together represent the vital symbolic transactions which had to be made between slavery and freedom, between his material condition and his spiritual life, between his experience of Jamaica and his memories of Africa" (Hebdige, 1976, p. 136). Therefore, while the people of the island continued to speak the master's English, there existed the submerged language of the slave that began as primarily African, but became increasingly influenced by the European languages, in the same way European languages were being influenced by their new environments (Brathwaite, 1979/1981). In Jamaica, this process resulted in what is now called Patois. Patois is the product of the various nations and global flows that influenced Jamaica's development. It reflects the pain, trauma, and infectious spirit of Jamaicans' ancestors, as well as the tactics used to subvert, appropriate, and mimic the colonial language, allowing slaves to hide meaning in plain sight (Bhabha, 1994; Glissant, 1989). The use of Patois also "challenges the standardizing impulses of modernity, resisting homogeneity in a variable and multi-layered process of change" (Bryan, 2004, p. 641). It is the Third Space where identities are negotiated through shared experience.

Slaves were forbidden to learn how to read and write, which explains the oral nature of Creole. With its blast of sound and rhythmic breathing, Brathwaite (1979/1981) explains that 'nation language', the language of the Caribbean people, is a "total expression" that requires the participation of sounds and noise of the entire community - if one ignores the noise, they also miss part of the meaning the noise signified (p. 273). I refer to Patois as a language in agreement with Brathwaite's (1984) assertion that to 
refer to nation language as a dialect is to think of it as bad or inferior English, and to distort people of their dignity. Referring to Patois as a language gives it power and its users pride.

Many black postcolonial scholars have grappled with the question of whether Standard English is an appropriate language in which to express non-European culture. For example, Kincaid (1988) discusses the ways in which England made millions of people orphans with "no motherland, no fatherland, no gods... and worst and most painful of all, no tongue" (p. 31). She also questions the ways in which she was made to adopt the language of the criminal, stating that the "language of the criminal can contain only the goodness of the criminal's deed" (Kincaid, 1988, p. 31). Additionally, Ngũgĩ (1981), one of the most vocal scholars who oppose the use of English, argues that writers are "obsessed with taking from his mother-tongue to enrich other tongues", instead of enriching their own (p. 8). Ngũgĩ (1981) also critiques African conferences and programs that exclude the works of those who write in African languages. And as English further penetrated education systems in the colonized world, it became perceived as the language of power and the benchmark for all levels of intelligence, ability, progress, and achievement (Kachru, 1986; Ngũgĩ, 1981).

For Ngũgĩ (1986), language is the “collective memory bank of a people's experience in history" (p. 15). It also carries, through storytelling and oral practices, the entire body of values by which we come to perceive ourselves and our place in the world. However, by using colonial languages, he believes we are further separated from ourselves and our origins and are instead taken to other selves and other worlds. This has been exemplified by the emphasis on teaching 'proper' English in schools in formerly colonized countries. Similar to Brathwaite's observation that Caribbean children could write more confidently about snow than hurricanes, Ngũgĩ comments on the disconnect between the words African children write in school, and "world of his immediate environment in the family and the community" (Ngũgĩ, 1981, p. 17). The colonial child then comes to view the world not through his lived experience, but through the lens and in the language of imposition. 
Ngũgĩ (1972) holds that literature in African languages is the only genuine voice for Africans. He questions why other cultures cannot be viewed in relationship to African literature instead of the other way around, arguing for the abolition of an English department at the University of Nairobi. And in his book, Decolonizing the Mind (1981), he says his farewell to English and declares he will only write in Gikuyu or Kiswahili from that point on. Ngũgĩ writes in the African context and examines the separation between African culture and the language used. However, this severance is heightened further when applied to the Caribbean, as the West African slaves were separated both literally and figuratively from their history and culture. Following the imposition of colonization and slavery, the Caribbean people were left with no language to call their own.

Although Ngũgĩ (1981) makes a solid argument for the termination of English, Fanon (1967) explains why the Caribbean person values speaking in imperial languages. Fanon (1967) holds that to speak, means to "assume a culture, to support the weight of a civilization" (p. 17-18). Many other scholars agree that language is more than words and syntax, but a direct reflection of one's culture (Okara, 1963; Ngũgĩ, 1981; Ashcroft, 1989; Brathwaite, 1984; Hall; 1990). To speak the language of the colonial regime resulted in the formerly colonized people feeling elated "above his jungle status" and assimilating to more civilized cultural standards (Fanon, 1967, p. 18). In the first chapter of one of his seminal works, Black Skin, White Masks, Fanon (1967) discusses the ways in which the Antillean black man strives to sound like the Frenchman. The Antillean looks down upon those which are less 'civilized', and through its national language, its schools, and its lifestyle, the society does its best to emulate French culture. As a result, when the white man assumes the black man is more comfortable speaking a 'pidgin' language, this frustrates the black man, and feelings of inferiority and the infantile exchange resurfaces (Fanon, 1967). Fanon even quotes French writer, Michel Leiris' opinion that "Creole seems already predestined to become a relic eventually" (Fanon, 1967, p. 27). Adopting a new language does not only 
change one's dialect, but one's entire way of thinking and perceiving the world. Therefore, to abandon Creole and adopt a European language is to perceive oneself as equal to the European (Fanon, 1967).

Ngũgĩ (1981) and Fanon (1967) both point out the issues and motives regarding the use of colonial languages, and Ngũgĩ takes things further by criticizing African scholars for becoming complicit to the use of English in their culture and in politics. However, postcolonial thinkers have made compelling arguments as to why English can still be used to resist the dominant culture and create space for formerly colonized people. For Achebe (1965), there is no other option but to use the new language of English. However, he notes that it does not mean it is the same English as the oppressor. Instead, he suggests a "new English, still in full communion with its ancestral home but altered to suit new African surroundings" (Achebe 1965, p. 30). Even as Césaire (1972) heavily criticizes colonialism, he does not deny the presence of standard French in his work. However, he, too, strives for a "black French" that better represents his people (p. 83). Braithwaite (1984) shares Achebe's sentiments when discussing nation language. He asserts that although there may be English in its lexicons, it is based on and influenced strongly by the people's African heritage in its "contours, its rhythm and timbre, its sound explosions" (Brathwaite, 1984, p. 13). It is not the same English that was imported and forced into schools, but "that of the submerged, surrealist experience and sensibility" that is closely related to the African aspect of the Caribbean experience (Brathwaite, 1984, p. 13). It is a new English - an English with sound and spirit. It is an English that is sometimes simultaneously English and African. Furthermore, Braithwaite (1984) argues that it is not the language, but the people who use language powerfully who can spur revolutions and effect change. In fact, using the master's tools by speaking English and getting educated abroad has been a useful strategy of resistance.

Additionally, Glissant (1989) describes Creole as a diversion and a subversion of linguistic impositions: the slave took the master's simplified pidgin, reduced the "childish babble" even further, and formed a systematic and strategic way of communicating without detection (p. 20). As mentioned earlier, 
Bhabha (1994) argues that mimicking the colonizer is a process of reform, reclamation of power, and a disturbance of the authority of colonial discourse. Slave communities concealed and camouflaged meaning into their seemingly scrambled sentences, using Creole as a form of trickery and confidentiality (Glissant, 1989). In a society where slaves were not afforded the right to remember their past, their nation language was used to disguise their personalities and preserve their culture (Brathwaite, 1979/1981). And as the black population in the Caribbean continued to conform to European culture, and Africa became more distant, Creole remained a form of retainment of roots, and a distant memory of how and why this hybridized language came to be. I apply the concept of mimicry and subversion to the modern day and look at how the Jamaican language is used in GTA slang to create a "profound and disturbing" relationship with English, by disrupting perceptions of how English should look and sound (Bhabha, 1994, p. 124). Within the context of Toronto, I also aim to explore whether the slang is perceived as accessible to all, or if it is similar to Patois in that it is "open to those who do not originate from Jamaica" but "still represents an exclusivity that celebrates the community and uniqueness" of the island (Wilkinson, 2017).

European settlers wrote about their fear of learning the ways of the slave and the horror of witnessing white inhabitants adopting Jamaican Patois (Brathwaite, 1971). Even though white folks refused to conform to the ways of the island, the emerging Jamaican society was so powerful that newcomers became caught up in the new lifestyle. Those who interacted the most with the slavesparticularly women — were the first to begin using the language (Brathwaite, 1971). Following colonialism, Patois and other aspects of Jamaican culture, particularly music, have continued to influence people around the world with much more acceptance, and even embracement and celebration (Gilroy, 1993; Bryan, 2004). That said, when it comes to language, there is still little discussion about what happens when, through cultural encounters and integration, dominant groups adopt the speech of the 'subaltern'. Or, when in some communities, these marginalized languages have so long been incorporated 
into Western localities, that their origins are forgotten. Therefore, in my research I look at the ways in which language symbolizes the acceptance of a new culture and way of thinking, to explore how Patois' infectious nature has been used to define different cultures across space and time.

My research takes these ideas about language, power, and resistance further by looking at a language that began as one which incorporated African and European influences, and then experienced further negotiation and iterations. I investigate the ways in which GTA residents define themselves and their culture partly through the influence of a language that was meant for the Caribbean context and was intended to connect the islands to Africa. This project also looks at Patois' continual evolution beyond its original context, which is a topic that scholars have discussed in little detail when writing about language and culture. Furthermore, whereas Fanon (1967) writes of creole languages as a source of embarrassment or inferiority, Bryan (2004) asserts that Patois has become even more vibrant with many more uses. That said, I also seek to discover whether stigma and discrimination still exist within the community of slang users, and if so, to what extent.

\subsection{Identity and Diaspora}

Diaspora comes from Greek origin and refers to the scattering of seeds. It was used to refer to the movement of Jews outside of Israel before being used to refer to other ethnic groups, particularly nonwhite communities (Karim, 2003). Gilroy (1993) credits Jewish thinkers as a source of inspiration for his ideas regarding diaspora and identity within the Black Atlantic. Although diaspora is usually associated with populations moving from the south to the north, the experiences of European immigrants, for instance, have similarities to traditional diasporic locations (i.e. Asia, Africa, the Caribbean, Latin America) due to cultural identities that still exist within Western continents (Karim, 2003).

Hall's view of diaspora is not necessarily related to the physical scattering of people to different parts of the world, but instead the metaphorical idea of the diasporic experience. By moving away from 
the literal definition of diaspora, Hall asserts that the diasporic experience can then be thought of as the "recognition of a necessary heterogeneity and diversity", and the constant production and reproduction of the self(Hall, 1994, p. 235). That said, in this project, I focus on Jamaicans' diasporic patterns, and the impact of their settlement in Toronto. I examine diaspora in relationship to Jamaica's severed roots and lost history, and the ways in which language was used to retain the country's historical influences. To discuss identity, Hall (1994) borrows from Césaire and Senghor's notions of the three presences in Caribbean culture: Présence Africaine (African Presence), Présence Européenne (European Presence), and Présence Americain (American Presence). I do the same to discuss the historical influences on the Caribbean identity, as well as the ways in which migration and diaspora expand this notion of identity development. I also include examples of cultural production in the GTA by Jamaican descendants and those influenced by Jamaican culture, to demonstrate the visibility and representation of Patois in Toronto slang and culture.

\subsubsection{Présence Africaine and Présence Européenne: origins of identity.}

The Présence Africaine is much contested in the Caribbean. Lamming (1960) describes the relationship between Africa and the West Indies as personal and problematic. West Indians were forced to forget the parts of their history that had anything to do with Africa, and their idea of the continent was thus reduced to menacing rumours and myths made to incite fear (Lamming, 1960). Indeed, there were no history books or archives, no lessons of the "lost kingdoms of names and places" that made this faraway place seem significant (Lamming, 1960, p. 160). The voice of the African presence was rarely allowed to be expressed. Instead, various practices had to be adopted, especially through language, to keep this relationship alive.

Caribbean people have a difficult relationship with their history. Because colonialism is the "very base and structure of the West Indian's cultural awareness", their traditions are not residential, but instead come from external influences (Lamming, 1960, p. 35). The strongest influence is that of Europe, 
and England in particular. This Présence Européenne speaks all the time and is the voice that cannot be turned off in the colonial discourse of power, domination, and history (Hall, 1994; 2015). Caribbean culture revolved around England to the point where "I met the world through England, and if the world wanted to meet me it would have to do so through England" (Kincaid, 1988, p. 33). The more Caribbean folks interacted and observed the actions of the white world, the more they rejected their African roots. Ngũgĩ (1972) discusses “West Indian embarrassment”, quoting a passage from Jamaican, Andrew Salkey's (1959) novel: "We is no slave people, and there is no Africa in we blood the way you would-a like we to believe" (in Ngũgĩ, 1972, p. 83). Caribbean people did not want to be identified by what they perceived as shameful ancestry, and instead chose to align themselves with a more 'reputable' culture: that of the British. Negro slaves appeared to internalize the sentiments made about their inferior position and bestial nature (Brathwaite, 1971). They appeared to have absorbed the European rhetoric and had no choice but to subject themselves to "History with a capital $H$ " (Glissant, 1989, p. 248).

Colonization was never meant to elevate or improve the colonized (Césaire, 1972; 2001). In addition to force and coercion, the ruling class created "subjects who 'willingly' submit to being ruled" (Loomba, 2005, p. 30). African slaves, and especially those who were born into slavery, "absorbed prevailing Establishment ideas about themselves", which weakened, to some extent, the Jamaican society, and kept them from revolting for as long as they did (Brathwaite, 1971, p. 184; Ngũgĩ, 1986). The black man thus feels an "unfamiliar weight" under the white gaze as a result of his internalization of inferiority that occurred during colonization (Fanon, 1963, p. 110). Fanon's $(1963,1967)$ studies of the negative psychological implications of colonialism on the black race also exemplify this stifling European presence. These experiences stemming from the slave trade undoubtedly caused a neurosis, shock, or repression, which often prevents the West Indian people from revisiting the past (Glissant, 1989). As a result, the anglophone West Indian feels a profound connection to England, having been developed by the 
English memory, and thus feeling the "maintained and fertilised" historic ties between the two locations (Lamming, 1960, p. 25).

As time progressed, the Afro-Caribbean identity became more available to people in the West Indies, and the emergence of the Négritude and Rastafarian movements in the 1930s created new connections and awareness of the African diaspora across the francophone and anglophone Caribbean, respectively. Césaire (2001) believed that the restoration of the "lost humanity, dignity, integrity, and subjectivity of black identity" was the key to confronting colonialism, racism, and Western Imperialism (Banoum, n.d.). Similarly, Rastafarianism was based on the reclamation of African identity, as well as resistance of societal structures (Edmonds, 2003). And although many Jamaicans do not acknowledge or practice Afro-centric values, the Présence Africaine still manifests itself in every "verbal inflection, every narrative twist of Caribbean cultural life", every "secret code with which Western text was re-read", and in "every rhythmic and bodily movement" (Hall, 1994, p. 230).

Empirical research may help to identify key characteristics of a particular nation and culture, but Hall (1992) argues that the "fully unified, completed, secure and coherent identity is a fantasy" (p. 277). This is because identities are fluid, dynamic, and rely on the meanings and messages to which they are exposed. In addition, because of the hybrid nature of the country, different groups and communities in Jamaica negotiate different elements of the island's cultural influences in various ways. For example, some individuals have chosen to adopt the respectable system of values and adhere to a historically British lifestyle based on stable homes, involvement in the church, social advancement, and prestigious education (Wilk, 1995). On the other hand, some choose to reject respectability, and instead live a reputational lifestyle built on "indigenous response", promiscuity, and popular culture (Wilk, 1995, p. 116). Certainly, there also exist variations between these two binaries wherein lie many other Jamaican lifestyles. 
Gilroy (1993), through his concept of the Black Atlantic, discusses the avenues of the black identity that resulted from the transatlantic slave trade, and the different contours of black culture following this historical event. He expands upon Du Bois' concept of 'double consciousness', which he believes is the best-known resolution to explain the "core dynamic of racial consciousness", as well as the “fundamental antinomy of diaspora blacks" (Gilroy, 1993, p. 30). Du Bois uses this term to describe the complex feeling of 'twoness' that comes with black internalization of American identity, which Gilroy (1993) suggests also describes the ambivalence of identity among all post-slave populations. That said, some Jamaicans are more knowledgeable and in-touch with their African roots and have chosen to reclaim their racial heritage through practices of Rastafarianism, while others completely reject the notion of African roots, believing they are "more 'civilized' than the African" and perhaps "closer to the white man” (Fanon, 1967, p. 26). However, like many West Indians, Jamaicans often portray dual identities, adopting characteristics from a variety of foreign value systems, and code-switching according to the situation or people with whom they surround themselves. Bryan (2004) also identifies a continuum upon which Patois' phrases may align closer to the African creolized end, or to the end more closely resembling standard English. These identity constructions are evidence that the island is a Third Space of enunciation where Jamaicans negotiate, appropriate, translate, and constantly create new cultural statements and systems (Bhabha, 1994).

I argue that the identity cultivated among Jamaicans draws from both of Hall's (1990) definitions of cultural identity: it acknowledges the difference in lifestyles and historical values and practices - the ways in which individuals choose to adopt, as they negotiate, draw from, and grapple with domestic and foreign signs, symbols, and meanings - while also understanding that there is a "oneness" that unites Jamaica's population through shared memories and a shared experiences (Hall, 1994, p. 223). The latter relates to Gilroy's (1993) 'transatlantic diasporic identity', where those across the Atlantic are a "single, complex unit" of individuals who relate to and share cultural practices because of their shared traumas (p. 
15). A city as diverse as Toronto may also emulate this process of identity formation, as residents adopt signs, symbols, and meanings from a variety of sources, while simultaneously relating to the shared experiences of those who grew up in a similar environment. Language is highly connected to the Jamaican identity because of its amalgamation of ancestral and colonial influences, as well as its continual transformations, which reflect the people of the island at a given time. And for a people so violently detached from their roots, speaking a unified language is a "proclamation of the most profound kind of identification", relating to themes of assertion, affirmation, invitation, and bonding (Bryan, 2004, p. 645).

\subsubsection{Présence Americain: migration, diaspora, and culture.}

Hall (1994) describes Présence Americain as the "most ambiguous presence of all" (Hall, 1994, p. 230). America, the "NNew World' presence" is the "beginning of diaspora, of diversity, of hybridity and difference" (Hall, 1994, p. 235). In this context, the "diasporic site becomes the cultural border between the country of origin and the country of residence" or, the "zone of intense, cutting-edge creativity born out of the existential angst of the immigrant who is neither here nor there" (Karim, 2003, p. 5). In other words, the diasporic site is a Third Space where immigrants negotiate their relationship to their new home and the memories of back home. It allows non-Western elements "mediated by the histories of Afro-America and the Caribbean" to contribute to the formation of "new and distinct black cultures amidst the decadent peculiarities" of more dominant cultures, while also creating a subculture of sorts, which negotiates and combines in "unforeseen ways" with the dominant groups (Clarke, Hall, Jefferson \& Roberts, in Hall \& Jefferson, 1975; Gilroy, 1987 in Gelder and Thornton, 1997, p. 340). Additionally, the ways in which these non-Western elements merge with the West differ based on their geographic sites and various ethnic and cultural compositions, and result in cultural productions that “range on a continuum from 'pure' heritage maintenance and ideological monitoring; to mainstream cultural negotiation; through to assertive hybridity" (Cunningham, 2001, p. 143). 


\subsubsection{Migration and culture.}

Hall (2001) holds that the Caribbean is the "original and the purest diaspora" (p. 28). As such, Jamaicans who migrate beyond this site become "twice diasporized" (Hall, 2001, p. 28). They tend to migrate to areas that already have a substantial number of Jamaicans, most commonly cities such as London, Miami, New York, and Toronto, as well as other Caribbean countries (Jones, 2005). In the United States, Jamaican immigrants feel the pressure to identify and distance themselves from African Americans and Hispanics. However, they may choose to realign themselves with the general black community in different situations and contexts (Jones, 2005; Foner, 2005). In contrast, Sebba's (1993) research revealed that in cities like London, Patois is strongly incorporated into and supports the existing culture, while also reinforcing London-Jamaican culture. Additionally, it is used by young, black Londoners as a "badge of identity" within the wider culture (Bryan, 2004, p. 655).

Bryan (2004) discusses Hewitt's (1986) research on Patois and the ways in which, in certain communities, it can become a 'community vernacular' where white individuals also use the language in their friendship networks. While some black people saw it as parody, others "gave it qualified approval if produced by respected individuals in an Afrocentric context" (Bryan, 2004, p. 655). Hewitt (1986) concluded that Patois could be perceived as a "common property for all young people" as opposed to its ownership lying solely with the original culture (Bryan, 2004, p. 655). This is because the language further transforms in new contexts and is exposed to adolescents from a range of races and ethnicities (Bryan, 2004). In turn, these young people explore the "limits of hybrid identities through the radical intermixing" of terms, phrases, and other cultural practices (Cunningham, 2001, p. 143).

Similar to London, "the black population in Toronto is dominated by West Indians", particularly Jamaicans (Jones, 2005, p. 155). Additionally, in Canada, there is more emphasis placed on ethnicity than race (Jones, 2005). These ideas help to explain the strength of Jamaican culture, and why all black people living in the GTA are often assumed to be Jamaican, or at least included in this identification (Jones, 
2005). In other words, the influence of Jamaican culture in the GTA may be due to the lack of a distinct African-Canadian identity, not unlike the United States'strong African American culture.

Migration invites new modes of identity formation, including the ways in which immigrants engage in productive strategies that 'reterritorialize' and 're-embed' their identities in new imaginings of space (Lull, 1995; Karim, 2003). This is done by combining the customs, practices, and routines of the physical place with that of their homeland (Anderson, 1983). Migrants reterritorialize through sound and action, and the "languages, accents and rituals spoken and performed in a space", which in turn establish cultural connections to its occupants and give it an identity (Karim, 2003, p. 9). Jamaicans have some of the earliest immigration patterns to Canada, and they have a dominant presence among the black population in Toronto. Paired with the inherent vibrancy of Patois, Jamaican immigrants and their offspring continue to carve space in the GTA through language and cultural 'performance' (of both Patois and slang) which is then adopted by adjacent minority and dominant groups, alike.

Jones' (2005) research reveals that although they are generally happy with their lives in Toronto, many Jamaican immigrants still refer to Jamaica as 'home' and have plans to return to the island to live, even as they build their lives in Canada (Henry, 1999; Jones, 2005). They may even identify themselves as Jamaican, Jamaican-Canadian, or if they do not identify as black, they may choose to refer to themselves as their two ethnic backgrounds, such as Jamaican-Chinese (Jones, 2005). These trends weaken as one goes down the family line: first- and second-generation Jamaican-Canadians feel pride in their Jamaican heritage but are more inclined in some instances to refer to Canada as 'home' and to identify as black, Canadian-Jamaican, or Canadian (Henry, 1999). However, regardless of the generation and location, technology and media reflect the transatlantic nature of diaspora by defying space and time and making it easier for Jamaicans to connect with people they consider part of their group. Members of the Jamaican diaspora also connect with 'back home' by consuming similar media content and using social media. These actions help to "maintain the ties with the homeland", as well as connect to its 
cultural practices and ideologies by facilitating the ongoing exchange of language, music, and other cultural symbols (Karim, 2005; Croucher, 2011, p. 259).

As Patois evolves over time, and as a result of its migration to new sites, it becomes culturally transfigured in different ways. Hence, although the Jamaican identity has many different characteristics, the use of language that unites individuals across space and time appears to be a significant contributor to this process of identification. As well, non-Jamaicans and non-Caribbean individuals are simultaneously being exposed to these cultural exchanges via face-to-face interaction and modern technology. As such, Patois stretches and appeals to those beyond the Jamaican context, which raises questions of appropriation, authenticity, and ownership of the language and the dialects from which they develop.

Furthermore, the transformation of Caribbean language in new spatial and figurative contexts allows for the creolization of the dominant culture, especially through the decentering, destabilizing, and carnivalizing of English, "the nation-language of master-discourse" (Hall, 1994, p. 236). Jamaican communities in the GTA also "create material for the process of cultural syncretism from extended and still-evolving relationships between black populations of the over-developed world and their siblings in racial subordination elsewhere (Gilroy, 1987, in Gelder and Thornton, 1997, p. 340). My research expands on these ideas of the diasporic identity and the destabilization of English by applying them to a locality which does not only have strong concentration of Jamaicans in Canada but is also home to a number of immigrants with whom they interact. I explore the ways in which Toronto slang contributes to GTA residents' perception of themselves and their culture, and whether, through language, residents can articulate Jamaica's influence on the area. I also investigate whether Jamaican culture and language has a profound impact on the cultural and individual identity of GTA residents, and the role of race and ethnicity in the use of slang as an identity marker. 


\subsubsection{Visibility of Patois in Toronto slang and culture.}

Young people in the GTA connect with the culture through interactions with family members and friends, as well as through music, art, books, and the internet. This "imaginary reunification" connects those who share similar childhoods and experiences, regardless of geographical location (Hall, 1994, p. 224). They also create cultural products using words, phrases, and symbols of Toronto life. For example, in 2001, Kardinal Offishal, a world-renowned Scarborough-born rapper and music producer, wrote the song, BaKardi Slang, which explains some of the slang terms used in Toronto. Lyrics such as, "We don't say 'you know what I'm sayin' T dot says 'yuh dun know"” and "Yo instead of your boys We talkin about 'di man dem' When talkin about 'your bredrin' Yo we talkin about 'your friend”', Kardinal Offishal makes distinctions between the slang used in Toronto versus the United States (Harrow \& Price, 2001). The song's 2001 release date, as well as its nominations for 2001 MuchMusic Video Award for Best Hip Hop Video and MuchMusic Video Award for People's Choice: Favourite Canadian Artist, also demonstrate the longevity of slang's visibility in mainstream culture.

That said, Denis (2016) regards Drake as the most "globally-visible and well-known representative of the multiethnic adolescent Toronto speech community" (p. 5). Even as he has gained global notoriety, Drake continues to spread the culture of the GTA through his music and online. His recent songs reference Toronto streets and neighbourhoods, and include lines such as, "You know who mans are"; "I'm not afraid of no waste yute neither"; "We need to forward to the islands"; and "“for real, are you dumb?"”, which are all common phrases and terms used in Toronto (Graham \& Bidaye, 2016; Graham, Ritchie, Williams \& Feeney, 2017). He also used slang and exaggerated certain Toronto mannerisms on national television in a Saturday Night Live sketch in 2014.

Toronto slang is displayed online using hashtags such as \#torontomans and \#growingupintoronto, memes, videos, and other social media content, which often highlight words, phrases, and practices to which those living in the GTA can relate, even if they no longer live in the area. Residents have 
demonstrated the distinctive nature of Toronto slang by posting 'educational' and comedic skits online and testing people's knowledge of popular GTA terms (for example, Do Toronto People Know Toronto Slang? (Big Sheng, 2018); Toronto Slang Challenge in Los Angeles (StevieG, 2018); and Atlanta vs. Toronto Slang (Kay and Kosh, 2017)). Video comments come from Torontonians, as well as Londoners, and Jamaicans themselves, who identify with the slang use, and or subsequently accuse Toronto residents of 'stealing' their words.

Another popular online influence is 6ixbuzz TV (6ixbuzz), a Toronto-based social media blog. Co-founder, MB expressed that the account's popularity revealed the "lack of voice to these communities - to the hip-hop culture and what surrounds it" (Weekes, 2018). By curating and sharing memes, videos, news, and music from and by Toronto's youth, 6ixbuzz provides insights into the culture in and around Toronto, in a humorous and entertaining way. Many of the videos also demonstrate the similarities between Toronto slang and Patois through the terms and accents of those in the videos. The brand has a presence on Facebook and YouTube, but its largest following is on its private Instagram account, which has garnered over 960,000 followers in less than a year and a half. The other co-founder, SB made the account private to ensure users wouldn't just "pree the stuff and watch everything" without following them, but he also found that the decision made the account appear more exclusive (Weekes, 2018). Not to mention, Drake follows and has commented on previous content, which has only contributed to 6ixbuzz's rise in popularity. These online depictions and representations of Toronto slang demonstrate neither a public or private sphere; it may represent a 'public sphericule', with users creating a space where "cultural identities can be processed in a self-determining way, where voices other than the official, but constitutive of community sentiment, can speak" (Cunningham, 2001, p. 138).

Furthermore, similar to BaKardi Slang, Toronto slang and culture are visible in partnership with mainstream outlets and public spaces. In January 2019, CP24 tweeted about a web series by 4YE Comedy - a GTA-based YouTube group that integrates both Patois and Toronto slang in their videos- 
beginning with “Attention Toronto Mandem!” (CP24, 2019). This web series, in partnership with Much Music Studios, would be a parody of courtroom shows, where Judge Tyco, a character created by 4YE, determined the fate of young Torontonians using heavy Toronto slang. The duo is also included on the Much Music Creators page online. A couple weeks later, a young CP24 reporter stated that a winter storm would pack a "dutty", or "dirty" punch across the GTA, using a term from Patois that is also used within Toronto slang (Star Gyal, 2019). In each of these recent instances, social media users expressed their love for Toronto and demonstrated their recognition of both Patois and slang. York University also offered a Jamaican Creole course in its Department of Languages, Literatures, and Linguistics.

While certain aspects of Toronto slang and its connections to Jamaica may appear elusive, one of the most visible demonstrations of Jamaica and the Caribbean's strong presence in the GTA is the Toronto Caribbean Carnival, which was first organized in 1967. Originally called Caribana, the Toronto Caribbean Carnival is known as one of the biggest Caribbean festivals in North America. The carnival aims to "showcase originality, culture, and history to millions of spectators attending in downtown Toronto or watching on television and online" (Toronto Caribbean Carnival Online, 2019). The event began as a three-day event, but now holds three weeks of related events and activities throughout the month of August for attendees of all ages to engage even further with Caribbean culture. The CN tower also lights up to kick off the festivities. That said, the grand parade is where much of the popularized action takes place: the Carnival boasts one million-plus attendees, which includes Toronto and Canadian residents, as well as international visitors who wish to see the excitement happen in real time. Thus, those from the GTA and beyond participate in and are exposed to the language and cultural practices of the 346,530 people of Caribbean origins living in Toronto.

Still, writers in the GTA discuss Jamaicans' complex feelings about Patois' popularization in mainstream Toronto culture, and the effects of "bits of the patois language and the accent" filtering down to "much of the rest of the population" (Bascaramurty, 2017). While some residents are proud of people's 
desire to be associated with Jamaican culture, others criticized individuals such as the late Rob Ford, who was filmed speaking in a Jamaican accent (Bascaramurty, 2017). Martis (2016) also explained that while some believe Drake has created his own vocabulary, he actually speaks Toronto slang, which has adopted from Patois. She then questions if those who are not aware of these origins know what they are saying. Indeed, questions of what it means to be "Jafaikan" (a term originating from London, meaning "fake Jamaican'), and the terms upon which the Patois-infused Toronto slang is considered 'authentic' or 'genuine' have become prevalent in public discourse (Bascaramurty, 2017). Hence, my research not only contributes to the scholarship that lacks exploration of the use of Patois to define Canadian cultures, but it also helps to bridge the gap between academic and non-academic approaches to the topic of language and culture in the GTA.

\subsection{Research Gaps and Recent Related Studies}

Many postcolonial academics who focus on Jamaica, black languages, diaspora, and identities, neglect to consider Jamaican experiences in Canada. For example, scholars such as Brathwaite (1971, 1979/1981, 1984), Hall (1990, 1992, 1994, 2015), and Lamming (1960) often oriented their research towards England, and the ways in which the anglo-Caribbean feels a profound, if not extremely complex relationship with its 'Motherland'. Similarly, Fanon $(1963,1967)$ and Césaire's (1972, 2001) works on postcolonialism, racism, the black identity, and its psychological side effects, are based primarily on their experiences in the French Caribbean and France. Glissant (1989) provides commentary on the language and culture in Quebec, but does not explore in greater detail, the unique ways in which these complexities take shape in Canada in general, or Toronto in particular. Additionally, Gilroy (1993) only mentions Canada in passing, and usually only in relation to the United States. His piece draws parallels and comparisons between locations such as England, the Caribbean, and the United States, but Canada is 
often left out of the equation. These examples point to the aforementioned Présence Européenne, and the overwhelming consideration for Europe and its perceptions of the black Caribbean individual.

Likewise, recent studies have followed the trend of forgetting Canada as a place of settlement and discuss Jamaican culture and diaspora primarily in relation to cities in England and the United States (Hewitt, 1986; Sebba, 1993; Bryan, 2004; Thomas, 2007; Sebba, \& Dray, 2012). Additionally, many related studies on slang have taken a linguistic or reference-based approach (Spears, 1981; Patridge \& Beale, 1984; Chapman, Kipfer \& Wentworth, 1995; Simpson \& Ayto, 2008; Widawski, 2015; Denis 2016) or discuss slang within larger discourses regarding urban youth and marginalized subcultures (Widdicombe \& Wooffitt, 1995; Leap, 1996; Livia \& Hall, 1997; Grahn, 2000). Many of these studies are quite outdated and do not necessarily reflect the evolution of subcultural language in recent years as a result of technological and other modern advancements.

Although also under-researched, previous works have focused on Ebonics and other forms of African American slang (Smitherman, 1994; Allen, 1995; Rickford, 1999; Rickford, 2000; Widawski, 2015) The origins of Ebonics and African American Vernacular English (AAVE) share similarities with both Patois and Toronto slang. AAVE, too, was born out of slavery and rooted in racism, discrimination, and violence. Similar to Patois, it is comprised of rules and structures that are often overlooked and cause the user to code-switch between Standard and non-Standard English. In addition to code-switching, users may toggle between "structures that seem more African, more creolized, to those that approximate more closely to English" (Bryan, 2004, p. 643). Between these 'extremes' exist the "intermediate varieties, reflecting the minimal shifts in the structures being used" (Bryan, 2004, p. 643). Users may also alter their speech or resist the pressure to do so, based on their communities, family upbringing, peer groups, and other social factors (Rickford et al., 2015). This is because AAVE's nonstandard and racialized nature causes the language to "trigger discrimination" in various aspects of one's life, including schools, the workplace, and the housing market (Rickford et al., 2015, p. 11817). Similar to Patois and slang, AAVE 
is also "associated with poverty, ignorance and lack of moral character", which is reminiscent of the slave masters' perceptions of West African languages during colonization (DeCamp 1971, p. 26, cited in Bryan, 2004, p. 647). However, the language used in the African American community is also seen as trendy, cool, and coveted, similarly to non-Jamaicans' perceptions of Patois in music and other media outlets (Henry, 2012). This relates to Cunningham's (2001) idea that ethno-specific media, and predominantly black culture, whether African American or Jamaican (which has a majority black population) culture “are mined deeply for social cues (including fashion, language use and so on), personal gossip, public information as well as singing along to the song or following the fictional narrative" (p. 139). Evidently, there are similarities in the ways in which the intersection of race, power, and family and community ties play a role in the extent to which one uses these English alternatives. However, there is still little focus on how these issues may be applied to Canadian cities.

Research which excludes Canada may demonstrate the scholars' constructivist paradigm, that is, they seek to understand the world in which they live and work (Cresswell, 2014). If so, their research is oriented towards the Caribbean, England, or the United States because that is where they lived, worked and observed poignant trends. The lack of consideration for Jamaican culture in Canada may also be attributed to what Andre (1995) calls the "United States hegemony" (Tomlinson, 2012, in James \& Davis, 2012 p. 107). This idea points to the pervasiveness of African American culture in black communities beyond the United States, which has caused the discourse on the uniqueness of black culture in Canada to be unnoticed. However, this does not make the research on migrants to the GTA any less valuable to the scholarship on culture and diaspora. This also does not mean that in recent times, academics have not advanced the research on what it means to be Jamaican in Canada.

Recent works that have attempted to locate Jamaica in the Canadian experience have examined the challenges of integration, as well as themes of migration, language, education, and Jamaicans' contributions to Canadian development (Henry, 1994; Jones, 2005; James \& Davis, 2012). Henry (2012) 
also notes that Canadian youth perceive Patois as "cool" as a result of "popular culture, music and the media" (in James and Davis, 2012, p. 100). Many have studied creole and identity (Bryan, 2004), creole in music and poetry (Leung, 2004; Branca, 2007; Mann, 2016), and creole within the study of linguistics (Bailey, 1966; Sebba \& Dray, 2012; Velupillai, 2015). That said, there are few texts that have examined a combination of these topics through a contemporary lens to understand how Patois has continued to evolve in a new locality, and the ways in which this language is appreciated and used by those within and outside of the diaspora. This project seeks to bridge that gap. 


\section{Chapter 3: Methodological Framework}

My research is grounded in constructivist and transformative paradigms. A constructivist paradigm is concerned with subjective meanings of individuals as they seek understanding and make sense of the world in which they live and work (Creswell, 2014). It is based on interactions and discussions with others, in order to understand their experiences and historical and cultural setting. Researchers with this worldview also acknowledge their own background and experiences as shapers of data interpretation (Creswell, 2014). The transformative paradigm, on the other hand, holds that "research inquiry needs to be intertwined with politics" to "confront social oppression at every level" (Creswell, 2014, p. 9). It examines societal structures and power relations, and addresses social issues like empowerment, oppression, domination, and alienation (Kirby, Greaves, \& Reid, 2006). This paradigm also places emphasis on studying the lives and experiences of marginalized and diverse groups.

Constructivist and transformative paradigms are common approaches used by postcolonial scholars. When studying formerly colonized nations, particularly those in the Caribbean, questions of diverse groups are bound to arise due to the colonial process, which transported and produced peoples of hybrid races, tongues, ethnicities, and identity classifications. Although not always political in the traditional sense, postcolonial scholars must acknowledge the racism, oppression, power struggles, and other social injustices that occurred with such a widespread and violent conquest such as colonization. Many of the aforementioned scholars were affected by the colonial encounter and studied various aspects of its aftermath to better understand its effects on colonized nations. Many also acknowledge and write from the perspective of a Caribbean or Asian individual forced to participate in the Western system.

My research is constructivist because it relies on the meanings, views, and perceptions of participants (Creswell, 2014). This project is transformative because of my intent to discover how Patois - a language which emerged from power, racial, and cultural imbalances — has been integrated so 
deeply into Western nations and used by those within and beyond the Jamaican diaspora. Additionally, my unique position as a member of the group I studied also brought a unique perspective to the project. As a young, black woman of Jamaican descent who grew up in the GTA — specifically in Mississauga and Brampton, I was able to relate to participants' perceptions and experiences. I was aware of the pop culture references made by many of my participants, could recall similar memories, and thus had a strong understanding of many of their views and opinions. Furthermore, as a GTA native, terms and phrases used in slang and Patois were familiar to me, and I was able to contextualize these terms upon hearing them. I was also able to better identify trends in their responses and connect their narratives. Additionally, my years of passively observing language and culture in the GTA allowed me to understand the contrasted and shared opinions that existed among the participants.

Both the constructivist and transformative paradigms are aligned with qualitative research methods because they are more concerned with individuals subjectively make meaning and experiencing life, more so than dealing with objective and or scientific facts. As a result, my research assumes a qualitative dominant mixed methods approach: qualitative research is the dominant approach, with quantitative research "validating and explicating findings that emerge" (Johnson, Onwuegbuzie \& Turner, 2007, p. 121). Qualitative research is based on people's lived experiences, and is "naturalistic, emergent, and evolving" (Marshall and Rossman, 1999 in Kirby, Greaves, and Reid, 2006, p. 13). It consists of approaches such as grounded theory, hermeneutics, phenomenology, and narrative analysis to systematically analyze socially meaningful actions. While they may have slightly different processes of collecting and interpreting data, all qualitative methodologies have a social approach, and share the goal of understanding social life (Strega, 2005). That said, I chose to add a quantitative element to the project because I understand that incorporating numerical data and approaches to my research will likely strengthen my case (Johnson et al., 2007). Overall, qualitative research is a way of interpreting the world 
through meanings and realities created by individuals, and quantitative data will help complement these findings and provide additional validation.

\subsection{Methods}

This project relied heavily on the opinions, stories, and experiences of GTA residents. Therefore, I conducted surveys and interviews. My exploratory online survey employed convenience sampling to gain insights into what the wider population thinks and believes about topics relating to GTA slang and its connections to Jamaican culture. I utilized SurveyMonkey to create and share an online survey via social media, personal networks, and face-to-face approaches. I collected 60 responses, which is within the normal sample range for student projects (Davies \& Hughes, 2007).

Online surveys have been growing in popularity as a social pastime and often result in a high response rate (Baatard, 2012). They are a quick and inexpensive way to obtain information and a general idea of my target group's view on the topic at hand. They allowed me to capture the thoughts and sentiments of those beyond my interview sample. Online surveys are also anonymous, objective, and easy to verify, and helped to create authentic and relatively unbiased opinions (McNeill \& Chapman, 2005). Conducting the survey first and gathering insights from a wider range of individuals helped to inform the direction of my interviews. Furthermore, since I happen to be a part of the community within which I chose to study, the survey provided more impartial insights into the opinions and experiences of a wider population sample.

As mentioned, personal narratives help one understand the ways in which individuals observe and make meaning in their everyday life. Interviews were the appropriate method for this goal, as they allowed for in-depth conversations and rich data to supplement the arguments within my thesis. Interested individuals were required to follow a set of criteria: they needed to have an understanding and experience using or being exposed to Toronto slang; they had to have been living in the GTA for at least five years; 
and if they did not currently live there, they had to have only moved out of the area a maximum of two years ago. These criteria helped to ensure that their stories were based on long-term immersion and observation of the culture. Furthermore, I aimed to recruit participants who resided in areas of the GTA with the highest concentration of Jamaican immigrants and cultural diversity. This included Scarborough, North York, Etobicoke, Brampton, and Mississauga. While the survey participants were anonymous, the majority of my interview participants were a part of my extended social network. My recruitment methods for both the survey and interview resulted in the majority of participants being between the ages of 18 and 35 years old. Thus, the findings were based on the opinions and observations of a young adult demographic. As a token of thanks, each interview participant received a five-dollar Starbucks gift card.

Using purposive sampling, I interviewed 12 participants, as "saturation of most common themes may be reached within 16 participants" in studies with relatively homogeneous groups (Hagaman \& Wutich, 2017). Guest et al. (2006) and Francis et al. (2010) have also suggested minimum interview sample sizes of 12 or 13 . Limiting the number of participants helped to facilitate in-depth conversations about their perceptions and feelings, and gain "authentic insight into people's experiences" (Silverman, 1993, p. 91). Similarly, interviewing individuals from limited regions contributed to the recognition of apparent themes and trends among the participants' stories.

My primary goals in conducting these interviews were to:

1. Understand whether GTA residents are aware of the connection between slang and Patois, and the ways in which they made this connection

2. Discover the ways in which GTA residents describe the culture

3. Understand how GTA residents consciously or unconsciously use language to help define GTA culture, as well as what this usage means to them

The interviews were semi-structured and audio-recorded and conducted over the phone and on Skype. Semi-structured interviews are often more conversational than structured interviews but require more of a 
topical direction than unstructured interviews. They are also used to "delve deeply into a topic and to understand thoroughly the answers provided" (Harrell \& Bradley, 2009, p. 27). Although there were specific questions and areas I aimed to address, follow-up questions were asked in order to probe and encourage participants to elaborate on their responses.

As mentioned, the data collected for this project was obtained from 60 survey participants and 12 interview participants (see Table 3). Survey participants answered 21 questions (see Appendix H), including two voluntary open-ended responses. Many took the opportunity in one or both forms to discuss their opinion, provide insight, and share additional thoughts on the topic. Interview participants answered approximately 14 base questions (see Appendix I), as well as additional questions that related to their responses. Following the collection of 60 responses, SurveyMonkey and NVivo were used to gather qualitative and quantitative insights and make preliminary connections and observations. Transcripts were produced out of the 12 audio-recorded interviews before they were also imported to NVivo.

Thematic and narrative analysis were used to make sense of my findings. Thematic analysis is a flexible approach to qualitative data and can be applied to critical paradigms. It is also used to identify patterns and meaning “within and across data in relation to participants' lived experience, views and perspectives" (Clarke \& Braun, 2017, p. 297). Similar to thematic analysis, narrative analysis is a qualitative technique that draws from personal statements of experiences and individual interpretations of events and relationships, formed by their contextual environment (Duignan, 2016). These two approaches allowed me to discuss trends, patterns, and make connections across my survey and interview data.

I used NVivo to compare stories and categorize themes, quotes, and keywords based on their relation to language, culture, and the GTA. Using the auto-coding feature, NVivo identified 25 themes. With these pre-determined themes as a benchmark, I combined some of the similar and most relevant themes to create the following sections, which have a deeper focus on important elements of my findings: Views of and connections to Jamaican culture; Characteristics of a contagious language; Is Toronto slang 
unique?; Using slang: ownership and appropriation; Stigma around slang; Hybridity 2.0; and Community and belonging. The qualitative information, namely the open responses in the survey and the conversations with interviewees, drove my constructivist-grounded project and allowed me to identify meaningful points in the participants' stories and responses. By reviewing the data, creating markers for quotes and themes, identifying common patterns, and finding meaning in personal narratives, I make a case for why my research is significant to and represents the thoughts and feelings of GTA residents beyond my sample size.

Prior experiences paired with the semi-structured nature of the interviews prompted me to ask probing questions that gave interviewees the opportunity to elaborate on their statements and reflect further on their responses. Evidently, I have a strong relationship to my research sample. Conducting my research within a constructivist paradigm makes this relationship a strength, as I was able to connect with my participants' stories, in addition to connecting key similarities between the participants themselves. That said, I attempted to remain as neutral as possible when participants shared opinions I personally disagreed with. Additionally, I tried to ensure that my questions were not biased or phrased in a way that would sway their responses in my favour. 


\section{Chapter 4: Findings and Analysis}

This chapter communicates my findings based on my data collection methods, as well as an analysis of the data, which is driven by the interview participant responses and open responses given by survey participants. I provide characteristics of my sample, the interpretations and meanings of my findings, and the contribution of those findings to the existing scholarship within which similar topics have been explored (Riffe, Lacy, \& Fico, 2014). I conclude this chapter with a summary of these findings.

\subsection{Survey Findings}

A survey was conducted to gain insights from individuals in the GTA ahead of holding interviews. There were 60 respondents in total. As shown in Table 1 below, most respondents were between 18 and 35 and had lived in the GTA — predominantly in the Peel Region and City of Torontotheir whole lives. Additionally, over half of the respondents were not of Jamaican descent but almost all of them had ties to Jamaican people, and had heard of Jamaican Patois, primarily from face to face contact. These respondents said they notice the connection between Patois and Toronto slang either all the time or sometimes and believe that a lot of the slang terms used in the GTA derive from Jamaican language. This demonstrates that although more than half were unaware or unfamiliar with Patois' history or development, they were still able to identify what it sounds like and the ways in which it is embedded into Toronto language and culture.

Furthermore, although the majority of respondents had visited cities with heavy Jamaican migration, and even Jamaica itself, fewer respondents were able to see a connection between GTA slang and the slang used in these areas. This may indicate that they believe that the unique mix of cultures which reside in the GTA have resulted in a unique way of speaking. Indeed, the majority of participants perceived Toronto to have a distinct culture. What's more, their belief in their ability to tell a story in 
slang, as well as their feelings of inclusion when they can understand it, proves that language is an essential characteristic of the Toronto culture.

Table 1 Quantified Survey Findings

\begin{tabular}{|c|c|}
\hline Criteria & Quantitative Response \\
\hline Age Range & $\begin{array}{l}18-35(\mathbf{9 5 \% )} \\
36-50(\mathbf{5 \% )}\end{array}$ \\
\hline Time Spent in the GTA & $\begin{array}{l}\text { All their lives }(\mathbf{6 5 \%}) \\
\text { 5-7 years } \mathbf{( 1 5 \% )} \\
\text { 8-10 years } \mathbf{( 1 5 \% )} \\
\text { Recently moved out of the GTA } \mathbf{( 5 \% )}\end{array}$ \\
\hline City of Residence & $\begin{array}{l}\text { Peel Region }(\mathbf{3 8 . 3 3 \% )} \\
\text { City of Toronto } \mathbf{( 3 5 \% )} \\
\text { York Region } \mathbf{( 5 \% )} \\
\text { North York } \mathbf{( 3 . 3 3 \% )} \\
\text { Durham Region } \mathbf{( 5 \% )} \\
\text { Other }(\mathbf{1 3 . 3 3 \% )}\end{array}$ \\
\hline Ethnicity & $\begin{array}{l}\text { Jamaican descent } \mathbf{( 2 8 . 3 3 \% )} \\
\text { Caribbean descent } \mathbf{( 6 . 6 7 \% )} \\
\text { Second generation Canadian (One or more parents } \\
\text { born outside of Canada) } \mathbf{( 1 1 . 6 7 \% )} \\
\text { Other } \mathbf{( 5 3 . 3 3 \% )}\end{array}$ \\
\hline Associations with Jamaicans & $\begin{array}{l}\text { Family, friends, are acquainted with someone of } \\
\text { Jamaican descent, or some combination of all } \\
\text { three }(\mathbf{9 5 \% )} \\
\text { Zero associations/Unaware of associations } \mathbf{( 5 \% )}\end{array}$ \\
\hline Awareness of Jamaican Patois & $\begin{array}{l}\text { Yes }(\mathbf{9 0 \%}) \\
\text { No (5\%) } \\
\text { Maybe/Unsure (5\%) } \\
\end{array}$ \\
\hline Awareness of Patois' history/origin & $\begin{array}{l}\text { Yes }(\mathbf{1 3 . 3 3 \% )} \\
\text { A little bit } \mathbf{( 2 6 . 6 7 \% )} \\
\text { No } \mathbf{( 5 6 . 6 7 \% )} \\
\text { Unsure }(\mathbf{3 . 3 3 \% )}\end{array}$ \\
\hline Introduction to Patois & $\begin{array}{l}\text { Face to face interaction }(\mathbf{9 1 . 6 7 \% )} \\
\text { Other }(\mathbf{8 . 3 3 \% )}\end{array}$ \\
\hline $\begin{array}{l}\text { Notice of a connection between Patois and } \\
\text { Toronto slang }\end{array}$ & $\begin{array}{l}\text { Yes, all the time } \mathbf{( 5 3 . 3 3 \% )} \\
\text { Yes, sometimes }(\mathbf{3 3 . 3 3 \% )} \\
\text { No (13.33\%) }\end{array}$ \\
\hline $\begin{array}{l}\text { Visits to Jamaica, Miami, London, or New York } \\
\text { City }\end{array}$ & $\begin{array}{l}\text { Yes (to one, some, or all locations) }(\mathbf{9 3 . 3 3 \% )} \\
\text { No }(\mathbf{6 . 6 7 \% )}\end{array}$ \\
\hline $\begin{array}{l}\text { Notice of a connection between GTA slang and } \\
\text { language used in Jamaica, Miami, London, or } \\
\text { New York City }\end{array}$ & $\begin{array}{l}\text { Yes }(\mathbf{7 0} \%) \\
\text { No }(\mathbf{3 0 \%})\end{array}$ \\
\hline Introduction to Toronto slang & Face to face contact $(\mathbf{9 8 . 3 3 \% )}$ \\
\hline
\end{tabular}




\begin{tabular}{|c|c|}
\hline & Internet/social media (1.67\%) \\
\hline $\begin{array}{l}\text { Perception of the degree to which Toronto slang } \\
\text { derives from Patois }\end{array}$ & $\begin{array}{l}\text { A lot of it }(\mathbf{5 3 . 3 3 \% )} \\
\text { Some of it }(\mathbf{2 8 . 3 3 \% )} \\
\text { A little bit } \mathbf{( 1 0 \% )} \\
\text { I don't know } \mathbf{( 8 . 3 3 \% )}\end{array}$ \\
\hline Ability to tell a story using Toronto slang & $\begin{array}{l}\text { Yes }(\mathbf{5 5 \%}) \\
\text { Maybe (35\%) } \\
\text { No (10\%) } \\
\end{array}$ \\
\hline Perception of inclusion when using Toronto slang & $\begin{array}{l}\text { Yes }(\mathbf{2 6 . 6 7 \% )} \\
\text { Sometimes }(\mathbf{4 1 . 6 7 \% )} \\
\text { No }(\mathbf{3 1 . 6 7 \% )}\end{array}$ \\
\hline $\begin{array}{l}\text { Perception of inclusion when able to understand } \\
\text { Toronto slang }\end{array}$ & $\begin{array}{l}\text { Yes }(\mathbf{8 3 . 3 3 \% )} \\
\text { Sometimes }(\mathbf{8 . 3 3 \% )} \\
\text { No }(\mathbf{8 . 3 3 \% )}\end{array}$ \\
\hline Belief that Toronto has a distinct culture & $\begin{array}{l}\text { Yes, of course }(\mathbf{4 5 \%}) \\
\text { Yes }(\mathbf{2 1 . 6 7 \% )} \\
\text { Probably }(\mathbf{2 0 \%}) \\
\text { No/I don't know }(\mathbf{1 3 . 3 3 \% )}\end{array}$ \\
\hline
\end{tabular}

There were two open ended questions in the survey (see Appendix I, questions 17 and 19). First, participants were asked to elaborate on whether the GTA is unique. The final question asked if they had any concluding thoughts about the topic of language and culture in the GTA. From these responses, there were nine auto-coded themes: culture, Jamaican, influences, words, Patois, white, slang, immigrants, and backgrounds. Within these coded themes were nodes, which contextualized them. For example, within the theme of Culture, items such as 'unique culture', 'strong culture', 'Jamaican culture', 'immigrant cultures', 'Canadian culture', and 'black culture' were recorded. Under the Influences theme, items included 'Patois influences', 'Jamaican influences', ‘Asian influences', ‘American influences' and 'noticeable influences'. Table 2 displays the themes recorded and their aggregated themes below:

Table 2 Auto-coded Themes: Survey

\begin{tabular}{|l|l|}
\hline \multicolumn{1}{|c|}{ Theme } & \multicolumn{1}{c|}{ Aggregated Themes } \\
\hline Culture & - White culture \\
& - Unique culture \\
& - Strong culture \\
& - Multiple cultures \\
& - Jamaican culture \\
& - Immigrant culture \\
\hline
\end{tabular}




\begin{tabular}{|c|c|}
\hline & $\begin{array}{ll}\text { - } & \text { Different culture(s) } \\
\text { - } & \text { Black culture } \\
\text { - } & \text { Authentic culture } \\
\text { - } & \text { Canadian culture } \\
\text { - } & \text { Diasporic cultures }\end{array}$ \\
\hline Jamaican & $\begin{array}{ll}\text { - } & \text { Little Jamaicans } \\
\text { - } & \text { Jamaican pride } \\
\text { - } & \text { Jamaican Patois } \\
\text { - } & \text { Jamaican influences } \\
\text { - } & \text { Jamaican descent } \\
\text { - } & \text { Jamaican culture } \\
\text { - } & \text { Jamaican immigrants }\end{array}$ \\
\hline Influences & $\begin{array}{ll}\text { - } & \text { Patois influences } \\
\text { - } & \text { Noticeable influence } \\
\text { - } & \text { Jamaican influences } \\
\text { - } & \text { Asian influences } \\
\text { - } & \text { American influence }\end{array}$ \\
\hline Words & $\begin{array}{ll}- & \text { Specific words } \\
\text { - } & \text { Slang words } \\
- & \text { Google words } \\
- & \text { Certain words }\end{array}$ \\
\hline Patois & $\begin{array}{ll}\text { - } & \text { Religion Patois } \\
\text { - } & \text { Patois slang } \\
\text { - } & \text { Patois influences } \\
\text { - } & \text { Jamaican Patois }\end{array}$ \\
\hline White & $\begin{array}{ll}\text { - } & \text { White students } \\
\text { - } & \text { White cultures } \\
\text { - } & \text { Perhaps whiter } \\
\end{array}$ \\
\hline Immigrants & $\begin{array}{ll}\text { - } & \text { Jamaican immigrants } \\
\text { - } & \text { Immigrant cultures } \\
\text { - } & \text { Black immigrants } \\
\end{array}$ \\
\hline Backgrounds & $\begin{array}{ll}\text { - } & \text { Ethnic backgrounds } \\
\text { - } & \text { Different backgrounds }\end{array}$ \\
\hline Slang & $\begin{array}{ll}- & \text { Slang words } \\
- & \text { Patois slang } \\
- & \text { Different slang } \\
\end{array}$ \\
\hline
\end{tabular}

Those who chose to elaborate on the uniqueness of Toronto culture talked about multiculturalism and the different influences on Toronto culture, such as Arabic, Somali, and East and South Asian cultures, in addition to Jamaica. Other respondents stated that the GTA is unlike anywhere else in the world. The only other cities they mentioned were London and New York while discussing the influence Jamaican culture has had on many different regions in the world. When asked to provide any additional 
thoughts on the topic, respondents wrote that Jamaicans are rarely acknowledged for the influence and impact they have had on the language in Toronto. On the other hand, they reflected on the fact that the slang is so heavily integrated into both Toronto culture and their personal identity, that they don't really think about it too much: it's just one of the "many things that makes Toronto what it is" (Anonymous Survey Participant, Online Survey, 2018).

\subsection{Interview Findings}

Following the launch of the survey, 12 interview participants were recruited to take part in the project. Brief summaries of each participant are located in Table 3. Participant 3, Derek Denis, a sociolinguistics professor at the University of Toronto requested that he be identified. All participants were between 18 and 35 years old and graduated from or are studying for a postsecondary diploma or degree. There were nine female and three male interviewees. 11 out of 12 participants have either lived in the GTA their whole lives or spent the majority of their lives in the area. For example, Participant 11 was born in Vancouver, lived in the GTA for half of his childhood before moving back, and has been living in the Peel Region since he was 12. As mentioned, I aimed to recruit participants who grew up and or lived in areas with heavy Jamaican influence. As such, 10 out of 12 interview participants were raised and or currently reside in Brampton, Mississauga, North York, or Scarborough. Only four interview respondents were of Jamaican descent, but all participants had affiliations with Jamaicans through their friendships, work colleagues, or both.

\section{Table 3 Interview Participant Summaries}

\begin{tabular}{|l|l|}
\hline & \multicolumn{1}{|c|}{ Theme } \\
\hline Participant 1 & This participant is a black male of Jamaican descent in \\
& his early 20s. He recently moved to Vancouver to \\
& pursue further education following graduating from an \\
& undergraduate university program in Toronto. Before \\
& this, he lived in Brampton all his life, spending time in \\
& various areas within Toronto and the GTA. He \\
\hline
\end{tabular}




\begin{tabular}{|c|c|}
\hline & $\begin{array}{l}\text { volunteered to participate in the project via personal } \\
\text { communication. }\end{array}$ \\
\hline Participant 2 & $\begin{array}{l}\text { This participant is an Indo-Caribbean female of } \\
\text { Guyanese descent in her early } 20 \mathrm{~s} \text {. She grew up in the } \\
\text { Rexdale district of Toronto before moving to } \\
\text { Brampton in } 2009 \text {. She graduated from an } \\
\text { undergraduate program in Toronto and currently } \\
\text { works in downtown Toronto. She volunteered to } \\
\text { participate in the project via social media. }\end{array}$ \\
\hline Participant 3 - Derek Denis & $\begin{array}{l}\text { Denis is a white male in his mid-30s. He grew up in } \\
\text { Scarborough and went to a predominantly white high } \\
\text { school. That said, he was aware of the Jamaican } \\
\text { influences in the city. He currently works at University } \\
\text { of Toronto as a sociolinguistics professor, studying } \\
\text { language in urban spaces. He recently wrote an article } \\
\text { about the term "mans", a popular slang in Toronto. He } \\
\text { agreed to participate in this project after being } \\
\text { contacted via email communication. }\end{array}$ \\
\hline Participant 4 & $\begin{array}{l}\text { This participant is a black female of Jamaican descent } \\
\text { in her early } 20 \text { s. She recently moved to Vancouver } \\
\text { because of a relocation opportunity through her } \\
\text { occupation. Before this, she lived in the GTA, and } \\
\text { spent temporary periods of time in Montreal, Jamaica, } \\
\text { and the United States. She volunteered to participate in } \\
\text { this project via social media. }\end{array}$ \\
\hline Participant 5 & $\begin{array}{l}\text { This participant is an east Asian female in her early } \\
\text { 20s. She grew up in Pickering before moving to North } \\
\text { York, where her neighbourhood and high school was } \\
\text { predominantly east Asian. She graduated from an } \\
\text { undergraduate program in Toronto and currently } \\
\text { works in Toronto. She volunteered to participate in } \\
\text { this project via social media. }\end{array}$ \\
\hline Participant 6 & $\begin{array}{l}\text { This participant is a black female of Jamaican descent } \\
\text { in her early 20s. She lived in Brampton until she was } \\
\text { six years old but grew up and lives in the Weston area } \\
\text { of Toronto. She currently works as an urban planner in } \\
\text { Toronto, performing tasks all over the city, including } \\
\text { Harbourfront in downtown Toronto, and Black Creek } \\
\text { in North York. She volunteered to participate in this } \\
\text { project via social media. }\end{array}$ \\
\hline Participant 7 & $\begin{array}{l}\text { This participant is an east Asian female in her early } \\
\text { 20s. She grew up in Mississauga and has lived there } \\
\text { her entire life. She went to school in Toronto and has } \\
\text { friends who live and have lived in Toronto, including } \\
\text { what is referred to as "Little Jamaica". She currently } \\
\text { works in Etobicoke, Toronto. She volunteered to } \\
\text { participate in this project via social media. }\end{array}$ \\
\hline
\end{tabular}




\begin{tabular}{|c|c|}
\hline Participant 8 & $\begin{array}{l}\text { This participant is a black female who was born and } \\
\text { grew up in Jamaica. She is in her early } 20 \text { s and moved } \\
\text { to Toronto as a teenager to attend school. She also } \\
\text { completed her undergraduate education in Toronto. } \\
\text { She has lived in Toronto for seven years and lived in } \\
\text { North York before recently moving to East York. She } \\
\text { currently works in downtown Toronto. She } \\
\text { volunteered to participate in this project via social } \\
\text { media. }\end{array}$ \\
\hline Participant 9 & $\begin{array}{l}\text { This participant is a Jewish female in her early } 20 \text { s. } \\
\text { She grew up in York Region in the Vaughan area. She } \\
\text { grew up in a predominantly Russian-Israeli } \\
\text { neighbourhood. She attended university in Toronto } \\
\text { and recently moved to Israel. She volunteered to } \\
\text { participate in this project via social media. }\end{array}$ \\
\hline Participant 10 & $\begin{array}{l}\text { This participant is an east Asian female in her early } \\
\text { 20s. She grew up and has lived most of her life in } \\
\text { Mississauga. She completed her undergraduate } \\
\text { education in Mississauga and currently works in } \\
\text { downtown Toronto. She volunteered to participate in } \\
\text { this project via social media. }\end{array}$ \\
\hline Participant 11 & $\begin{array}{l}\text { This participant is a black male of Jamaican and } \\
\text { Congolese descent in his early } 20 \mathrm{~s} \text {. He was born and } \\
\text { spent the first few years of his childhood in Vancouver } \\
\text { but has lived the majority of his life in Mississauga } \\
\text { and Brampton. He went to school in Toronto. He is a } \\
\text { content creator who writes skits and music for social } \\
\text { media, often based on Toronto slang, culture, and } \\
\text { personalities. He agreed to participate in this project } \\
\text { after being contacted via social media. }\end{array}$ \\
\hline Participant 12 & $\begin{array}{l}\text { This participant is a black female of Somali descent in } \\
\text { her early } 20 \text { s. She grew up in the Jane and Finch area } \\
\text { of Toronto before moving to Brampton for high } \\
\text { school. She moved to North York during her time } \\
\text { completing her undergraduate degree in a different } \\
\text { area than her childhood neighbourhood and now lives } \\
\text { and works in downtown Toronto. She volunteered to } \\
\text { participate in this project after hearing about it through } \\
\text { a mutual friend and reaching out via email } \\
\text { communication. }\end{array}$ \\
\hline
\end{tabular}

Next, 11 out of 12 participants had heard of Patois, and had been exposed to it by their families, friends, or in Jamaican establishments. Approximately one third of participants had only heard of Patois in passing or admitted they would be unable to identify it on their own. That said, nine out of 12 
participants had noticed a strong connection between Patois and Toronto slang and believed that a lot of the slang in the GTA has been influenced by Jamaican language. Six participants also compared and noticed the similarities between the culture and slang used in the GTA to that of London because of their similar Jamaican influences.

All 12 interview participants were introduced to slang during elementary and high school. This was done primarily through face-to-face interaction, although most were unable to pinpoint the specific time of exposure. While they had all heard of and grew up with Toronto slang for some period of time, only five felt comfortable enough to tell a story about their day using Toronto slang. Of those who declined, three felt like they would not know which words to use, two explained that it would not be a 'natural' or authentic thing to do, and two said they would not be able to use the slang consistently. However, nine participants shared terms or phrases they believed to be considered Toronto slang. Of these terms and phrases, 'mans', 'mandem', 'cheesed', 'wha gwaan', and 'ting' were the most frequently used.

Many themes were identified using NVivo's auto-code feature. Therefore, they were narrowed down to the top nine most common and relevant themes in order to compare to the survey results and keep the data concise. The top nine auto-coded themes in the interviews were: words, language, people, culture, area, group, slang, appropriation, and media. Table 3 illustrates these themes, as well as the nodes that were connected to these themes. Both the open-ended survey and interview responses are discussed in-depth in the next section.

Table 4 Auto-coded Themes: Interview

\begin{tabular}{|l|l|}
\hline Theme & \multicolumn{1}{|c|}{ Aggregated Themes } \\
\hline Words & - Certain words \\
& - Slang words \\
& - Slang word \\
& - Random words \\
& - Using words \\
& - Somali word \\
\hline
\end{tabular}




\begin{tabular}{|c|c|}
\hline & $\begin{array}{ll}\text { - } & \text { Individual words } \\
\text { - } & \text { Ghanian word } \\
\text { - } & \text { Actual word } \\
\text { - } & \text { Short words } \\
\text { - } & \text { French word } \\
\text { - } & \text { Specific words } \\
\text { - } & \text { Curse words }\end{array}$ \\
\hline Culture & $\begin{array}{ll}\text { - } & \text { Different culture } \\
\text { - } & \text { Jamaican culture } \\
\text { - } & \text { Caribbean cultures } \\
\text { - } & \text { Culture shock } \\
\text { - } & \text { Cultural appropriation } \\
\text { - } & \text { Resistant culture } \\
\text { - } & \text { Jamaican culture influence } \\
\text { - } & \text { Indian culture }\end{array}$ \\
\hline Slang & $\begin{array}{ll}\text { - } & \text { Slang words } \\
\text { - } & \text { Slang thing } \\
\text { - } & \text { Slang word } \\
\text { - } & \text { Ghetto slang } \\
\text { - } & \text { Slang conversation } \\
\text { - } & \text { White slang } \\
\text { - } & \text { Home slang } \\
\text { - } & \text { Slang video } \\
\text { - } & \text { Hearing slang } \\
\text { - } & \text { Different slang }\end{array}$ \\
\hline Language & $\begin{array}{ll}\text { - } & \text { Language change } \\
\text { - } & \text { Different languages } \\
\text { - } & \text { Source language } \\
\text { - } & \text { Ambient language } \\
\text { - } & \text { Language variety } \\
\text { - } & \text { Body language } \\
- & \text { Language accent } \\
\end{array}$ \\
\hline Area & $\begin{array}{ll}\text { - } & \text { Poor areas } \\
\text { - } & \text { Income housing areas } \\
\text { - } & \text { Different areas } \\
\text { - } & \text { Making area } \\
\text { - } & \text { Low income area } \\
\text { - } & \text { Surrounding area } \\
- & \text { Certain area } \\
- & \text { Jewish area } \\
\end{array}$ \\
\hline Appropriation & $\begin{array}{ll}\text { - } & \text { Cultural appropriation } \\
- & \text { Culture appropriation }\end{array}$ \\
\hline People & $\begin{array}{ll} & \text { White people } \\
\text { - } & \text { Caucasian people } \\
\text { - } & \text { Seeing people } \\
\text { - } & \text { People kind } \\
\text { - } & \text { Obviously people } \\
\end{array}$ \\
\hline
\end{tabular}




\begin{tabular}{|l|l|}
\hline & - Non-black people \\
& - Somalian people \\
& - Different people \\
& - Putting people \\
& - Jamaican people \\
\hline Group & - Ethno-linguistic group \\
& - Grouping understanding concepts \\
& - Closed group \\
& - Social groups \\
& - Certain group \\
& - Subsequent migrant groups \\
\hline Media & - Following group \\
& - Friend groups \\
\hline & - Social media \\
& - Public media \\
\hline
\end{tabular}

\subsection{Data Analysis}

This section identifies and discusses the primary themes that arose from my 12 interviews, supported by survey participants' open responses. Though the participants were quite diverse, their responses had surprisingly similar themes and ideas. These shared themes demonstrate the common experiences and observations made by a number of individuals. Additionally, their responses relate, confirm, challenge, and contribute to the literature discussed in Chapter Two.

Seven key themes were identified from my findings and as such, seven sections follow. The first section looks at the ways in which participants are connected to Jamaican culture. This includes familial and social relationships, music, and food. Section two examines the characteristics of a contagious language, and participants' perceptions of how these characteristics apply to both Patois and Toronto slang. Next, the third section discusses the ways in which Toronto slang is unique, while looking at the cultural makeup of the GTA compared to cities in Canada and elsewhere. Section four grapples with the concept of ownership and appropriation in relation to slang. Ideas of authenticity, media influences, and acknowledgement of slang's influences are discussed in depth. Section five then looks at the stigma that remains prevalent among participants and the wider society when individuals are either unable or choose 
not to speak Standard English. Section six discusses hybridity and the concept of multi-ethnolects to examine the ways in which Patois, a hybrid language, continues to transform and embed itself within the GTA. Finally, section seven examines the significance of slang within social settings and among personal and virtual relationships and communities.

\subsubsection{Connections to and views of Jamaican culture.}

My findings show that GTA residents were exposed to certain aspects of Jamaican culture through a number of avenues. First, participants connected with Jamaican culture through familial and social relationships. Most of them had Jamaican friends, knew people of Jamaican descent, or were Jamaican themselves. Participants in both interview and survey noted that these social interactions are the primary way in which language spreads most effectively. Music is another way in which participants were made aware of Jamaican culture. For example, one participant (Denis) stated that even though he went to a predominantly white school in Scarborough, he would listen to some Dancehall music in addition to other genres. Participant 7 also shared that she listened to Dancehall music growing up. Participant 12 explained that listening to Sean Paul, Gyptian, Vybz Kartel, and other Jamaican-born music artists was an initial way that she became familiar with the culture. She also mentioned Caribana's influence on the GTA, which she described as, "so prominent that it's so hard not to be influenced by the culture if you grew up in Toronto" (Participant 12, Personal Communication, November 18, 2018).

Food was a more curious tale of their initial contact. Multiple participants (participants 5, 7, 9, and 12) discussed the role of Jamaican food in their cultural exposure growing up. Participant 7 noted that she was exposed to Jamaican language in part by eating at Jamaican restaurants. Participant 5 recounted her experiences with Jamaican coworkers, and their advice on where to get the most authentic cuisine. Participant 12 also explained that her Somali mother would cook Jamaican dishes because their family lived close to many Jamaican restaurants and found the food accessible while living in Toronto's Jane and 
Finch neighbourhood. All three participants also mentioned Jamaican beef patties as a marker of convenience and interaction with the cuisine.

Furthermore, Participant 4, who is of Jamaican descent, expressed her dissatisfaction with the limited Jamaican food options, having moved to Vancouver in 2018. She explained that she is unable to find Jamaican food restaurants and was forced to learn to cook her favourite dishes herself. She also added that there is one Trinidadian restaurant that she is aware of that is run by a man who is originally from the GTA. Over five percent of survey participants also indicated that their first exposure to Jamaican Patois was by visiting a Jamaican restaurant or listening to reggae music. Therefore, while the majority of participants were first exposed to the language and culture through face-to-face interactions, their indirect contact also contributed to their perceptions of what it means to act, eat, or sound like a Jamaican.

A small number of respondents, although aware of Toronto slang and perhaps how it sounds and is constructed, were unaware that there was any affiliation to another culture or ethnicity. Participant 5 stated that while she knew the slang had to come from somewhere, she would not know enough to make a connection or say that there is a definite connection to one place. Participant 9, on the other hand, had "no idea" what Patois was, though had heard of Creole. These perspectives appear to be outliers within this study, as the majority of all participants had heard of Jamaican Patois, and believed it is the source of some, if not most of GTA slang. For example, many survey participants discussed the ways in which Toronto slang is unique and has been influenced by a number of predominantly immigrant languages, but that it is "clearly derived from Patois for the most part" (Anonymous Survey Participant, Online Survey, 2018). Additionally, a respondent thought the slang is "very based on Jamaican patois", another claiming that it is “"englishified' patois” (Anonymous Survey Participants, Online Survey, 2018).

Of those who had at least a general understanding of the language, all interview participants expressed that they had noticed a connection between Patois and Toronto slang to varying extents. For example, while Participant 10 stated that she makes some connection, usually from what people tell her, 
Participant 4 passionately stated that she "one hundred percent" notices the connection, explaining that when she recently tried to prove to a friend that there are other influences on Toronto slang than Patois, a quick internet search revealed that approximately $80 \%$ comes from the Jamaican language (Participant 4 , Personal Communication, November 1, 2018). Participant 11 remarked that Patois is "basically (laughs) the slang of Toronto", and Participant 7 believed that not only has Patois been "absorbed into Toronto slang", but she is also able to understand select words in Patois due to her engagement with slang (Participant 11, Personal Communication, November 15, 2018; Participant 7, Personal Communication, November 6, 2018).

\subsubsection{Summary.}

There were many takeaways while assessing participants' connection to Jamaican culture and language. First, although participants did not share an equal amount of knowledge or familiarity with Jamaican culture or Patois, their exposure to immigrant culture speaks of the diversity that exists within the GTA. The hybridity in Toronto is exemplified through relationships, music, and food, and demonstrates Kraidy's (2005) notion that cross-cultural contact by way of the movement of both people and cultural products is crucial to the hybridization process. These acts also pay homage to the Caribbean slaves' cultural expression, which continues to inadvertently provide observants with a general sense of their culture (Brathwaite, 1971).

Additionally, participants' lack of knowledge about Patois' history or its connection to Toronto slang may be due to the Présence Européenne that has caused Standard English to act as an indicator of intelligence, success, and race, both in the Caribbean and in the Western world (Hall, 1994; Rickford et al., 2015; Bryan, 2004). Similar to Jamaica, there is often heavy stigma and little discussion regarding the alternate ways in which people may express themselves linguistically in Canada. Patois, slang, and other dialects are usually considered inferior. As a result, participants — especially non-Jamaicans—-have less opportunity to learn and understand the origins of the slang. On the other hand, those who were familiar 
with Patois were aware of the pervasiveness of Patois within Toronto slang, and most were quick to comment on this entanglement between Patois and Toronto slang. They consciously and subconsciously noticed the ways in which Patois has transformed and adapted to the Toronto context, demonstrating its lack of fixity in this Third Space (Bhabha, 1994). This prompted the question of why Patois is such a staple within slang, and which characteristics make a language appeal to a wider population or community.

While Spivak (1988) questions the power of the subaltern in the colonial context, it is evident that through language and other means, Jamaicans have found pockets of opportunity through which to 'speak' of the diverse components of their culture, practices, and lifestyle, and as such, make an impact on the GTA culture. These outward expressions and celebrations of Jamaican culture allow immigrants and their descendants to connect with their homeland, while also sharing these practices with new communities (Karim, 2003). This can also be exciting to those who are introduced to and experience the culture in the Canadian context (Croucher, 2011). Jamaican immigrants' history of migrating to Toronto and tendency to migrate to areas with existing Jamaican settlement also makes Torontonians susceptible to the absorption and celebration of the culture.

\subsubsection{Characteristics of a contagious language.}

In investigating what participants believe makes a language popular or 'contagious' in a locality, and more specifically, why Toronto slang is so appealing, my findings reveal three explanations, namely: the majority of responses associated the slang's appeal with number of people, sound and expression, and origin of the language. It is important to note that these explanations appear to be similar to colonizers' reasons for speaking Patois. During colonialism, Caribbean slaves were forced to abandon their African languages, in favour of languages such as English, French, and Portuguese. However, in Jamaica, female settlers could not avoid its appeal, and ended up incorporating the language of the island into their own speech (Brathwaite, 1971). Through strategies of mimicry and subversion, nation language evolved into 
something not unlike English — at least, in its lexicons. However, with its oral expression and blasts of sound, Patois remains connected to Jamaicans' African heritage (Achebe, 1965; Braithwaite, 1984). In the following sections, I will discuss each of these three explanations in detail.

\subsubsection{Number of people.}

One of the agreed explanations for a language's adoption by a community, as expressed by most of the participants, is the number of people who live in that community. As mentioned, Jamaicans were one of the earliest immigrant groups to Canada after changes to strict legislations occurred in the 1960s, and the GTA had a population of 5,928,040 in 2016. Of this population, six percent had Caribbean origins and $58 \%$ originated from Jamaica (Statistics Canada, 2018a). Hence, one of the participants (Denis) attributes the strong Jamaican influence on the GTA to Founder's Effect. Founder's Effect is the idea that early communities have an important influence on all subsequent generations, and since the Jamaican community is "a much older...maybe the oldest...visible minority community in the GTA", as well as one of the largest, it has likely impacted the migrant groups that followed (Denis, Personal Communication, October 29, 2018). As such, "the more speakers or more people who have parents who are speakers of the language, the more likely that those languages are going to influence, the general slang in the area, right? It's, that's just a matter of numbers" (Denis, Personal Communication, October 29, 2018). Participants 7, 8, 10 and Participant 12 agreed that the number of users is an essential way in which language, or in this case, Jamaican-based slang is adopted. Participant 12 explained that when she lived in areas where there were more Jamaican people, "it was more likely for people to speak in Toronto slang that was heavily influenced by Patois", but when she moved to Brampton, which has a heavy South Asian influence, the slang was different than that of her Jane and Finch neighbourhood (Personal Communication, November 18, 2018). Participant 8 also believed that the more people in an area who speak a certain language, the more likely the language will spread. 
Participant 9 focused on the notion of power when it comes to language. She held that in addition to having people care for and carry the language, the elites are responsible for the influence a language may have on a locality. She discussed the ways in which a language may begin with the elite before it "goes towards the masses" and causes the majority of people in the land to then adopt that way of speaking (Personal Communication, November 8, 2018). This was certainly the case during colonialism, when imperial languages and cultures played an essential role in the "silencing of the postcolonial voice" (Ashcroft et al., 1995, p. 4). However, on local terms, she said that areas with larger populations of people of a certain ethnicity will cater to those majority groups. For example, "let's say you go to Markham right now. There would be areas [where] there are no English signs. You feel like you're an outsider" (Participant 9, Personal Communication, November 8, 2018). She refers, here, to the predominant Chinese population in the city of Markham, and the prominence of Chinese street and business signs to accommodate the dominant group, which happens to be immigrants. Participant 7 also mentioned Richmond Hill as an example of the number of people belonging to a culture directly influencing how the neighbourhood or city is run. She noted that in Richmond Hill, “there won't even be, like, an English translation. It's just in, like, Mandarin or Cantonese or something. And...there's no English or French, which are [Canada's] official languages. But it's just because of the high population of Chinese people in the area" (Participant 7, Personal Communication, November 6, 2018). Because of the high population, it "makes more sense to bring in that language" (Participant 7, Personal Communication, November 6, 2018). Participant 4 also thought the cultural majority "has a hundred percent to do with, like, especially the popularity and the widespread of our Toronto slang" (Personal Communication, November 1, 2018).

Participants appeared to discuss the strategies used by immigrants throughout the diasporic process to adjust and adapt to their place of residence. Evidently, the cultures that migrate to the GTA seek to reterritorialize and re-embed their identities by incorporating the "languages, accents and rituals spoken and performed" in their homeland, into the physical space of their new homes (Karim, 2003, p. 9). 
East Asian languages are not English-based, which may make, in some ways, their presence in areas such as Markham and Richmond Hill more visible. However, largely due to their early immigration and large numbers, Jamaicans, too, assert their culture through the incorporation of foreign and local customs, practices, and idioms. In turn, these customs have been shared with and adopted by both dominant and minority groups.

\subsubsection{Sound and expression.}

When asked why they think Jamaican language has been so popular with residents of the GTA, participants suggested that it may be to do with its sound and oral expression. For example, Participant 8 asserted that the language "just randomly sounds really interesting to them" (Participant 8, Personal Communication, November 7, 2018). Participant 7 also believed expression contributes to the popularity of a language. She explained that "there's certain times that, like, English words fail but, like, kissing your teeth...it's such an emotion that is totally unique and speaks for itself. Just how it's expressed, how it's used" (Participant 7, Personal Communication, November 6, 2018). Additionally, Participant 12 felt that "if there's a large number of people who are Jamaican and very expressive, then I think that language is going to prevail, and that's going to have a strong influence on the culture" (Personal Communication, November 18, 2018).

The sound and expression were also described as humorous. For example, Participant 11 stated that he likes to highlight Toronto slang in his videos because he sees it as comedy. Participant 1 also said he speaks in slang when he is trying to be funny. When discussing the humour that comes with slang use, Participant 7 mentioned watching 4YE Comedy. She explained that "for their [video] with Drake. I just...love it so much. It's so funny (laughs) to me...I'll re-watch those over and over again for some reason. And it, like, always makes me laugh" (Participant 7, Personal Communication, November 6, 2018). Participant 12 reinforced this idea, stating that people want to speak in slang because "they like 
that feeling of being able to speak in a way that's, like, expressive and clever and funny. Most of the time, a lot of Toronto slang is actually very funny" (Personal Communication, November 18, 2018).

Another trend among the interviews was that of the 'coolness' associated with speaking in Toronto slang. Participant 2 said she thinks slang use begins with whatever is perceived as being cool to say, and whatever people hear the most. Participant 11 explained that "Jamaica and Jamaicans in general just, like, have their own sauce...And I think when you grow up around it, you just have that in you" (Personal Communication, November 15, 2018). He mentioned that there are certain traits that only come with being Jamaican, but there is also "just a vibe coming from Jamaica and Jamaicans that it's in you when you're around it for so long" (Participant 11, Personal Communication, November 15, 2018). Because of this infectious vibe which Participant 11 described as being associated with Jamaicans, the language also becomes influential when people are around it. Participant 4 had similar sentiments when it came to Jamaican culture, as well as black culture in general. She explained that Toronto slang is like broken telephone because "one man says it, another man says it and every man just ends up saying it...[it] kept on being said and then it's cool, and also black people being the pinnacle of coolness influenced a lot of that...especially Jamaicans" (Personal Communication, November 1, 2018). She also stated that Patois and Toronto slang are like "foreign cousins", making it easy for Jamaican descendants to spread the slang widely (Personal Communication, November 1, 2018).

As Denis mentioned, face-to-face contact is an important factor in the discussion of influence. He explained that while lexical items and individual words may spread easily throughout the media, he and other linguists do not think "media can truly spread language change on a structural level. I think that requires face-to-face contact" (Denis, Personal Communication, October 29, 2018). Although one can identify words and phrases online, it is difficult to gain and understand the essence and context of those terms. For example, Denis and I discussed the ways in which the term, "mans" is predominantly used in 
the GTA to reference the first person, but in less local contexts, "it's almost always... a third person reference... like, "him" or that "guy over there" (Denis, Personal Communication, October 29, 2018).

Participant 1 also touched on this idea, stating that although there is a lot of exposure to Toronto slang in music and online, in-person contact plays more of a role in the extent to which people are influenced. He believed that if you "just read something it doesn't necessarily mean that you'll use it in a sentence when you're speaking to people" (Participant 1, Personal Communication, October 24, 2018). However, when people are using the terms and phrases aloud, they are "most likely to [speak that way] more often" and more accurately (Participant 1, Personal Communication, October 24, 2018). Furthermore, face-to-face exposure is important because "there's body language to it, there's a certain way of speaking”, including one's accent, intonation, and what Participant 1 describes as 'upspeak' that is added to the end of each sentence (Participant 1, Personal Communication, October 24, 2018). This idea relates to Brathwaite's (1979/1981) explanation of the nation language being a "total expression" that requires the participation of sounds and noise of the entire community - if one ignores the noise, one also misses part of the meaning the noise signified (p. 273). Although Toronto slang is not as expressive as Patois, there is evidently more to it than simply knowing some of the terms.

Additionally, Participant 11 believed that "when, like, slang was created, I think the Jamaicans were the ones who made it" and "everyone picked up on it" (Participant 11, Personal Communication, November 15, 2018). Participant 2 explained that she had long been familiar with GTA slang, as well as its origins, because being Guyanese, "my parents say certain things in certain ways and pronounce things differently" (Personal Communication, October 28, 2018). She also described her high school in Rexdale as being primarily children of Caribbean descent and first-generation Canadians. Likewise, Participant 12 grew up in the Jane and Finch area, which is home to numerous racialized people in addition to Jamaican immigrants, descendants, and businesses. The participants of Jamaican descent, as well as those who grew up in predominantly black and Caribbean neighbourhoods, thus had the opportunity to gain a deeper 
understanding of the culture and language in the GTA, as well as the context within which terms and phrases were used. Indeed, the sound and expression often associated with slang was primarily experienced through face-to-face interactions with family and friends, particularly early on in life.

\subsubsection{Origin of the language.}

My research findings confirm that origin also plays a role in the contagious nature of a language. Participant 5 believed that a language that originates from an English-speaking country is easier to integrate into an English context. Therefore, it is easier to insert a language such as Patois into the GTA, than Japanese or Korean, for instance. Participant 5 also alluded to the idea that the language has to go through somewhat of a transformation before it can be adapted. She stated that "the girls at work from Trinidad and Tobago use a lot of lingo and it's really long and fast and not everything can be incorporated into the English context" (Participant 5, Personal Communication, November 4, 2018). Because the language in Trinidad is similar to Jamaica, it is safe to say she would feel the same way about Patois. Therefore, as she explained, the words need to be short and quick in order to be used in a locality such as the GTA. This could explain why certain straight Patois terms and phrases stand out more easily and are used most often within the slang.

Many other participants also compared Patois and Toronto slang with Asian languages and slang. Participant 10 is Filipina, and she explained that it appears to be a "very North American thing", and perhaps a "very English thing" to have slang, since she does not think the Filipino language has slang, other than words that have been shortened for convenience (Personal Communication, November 8, 2018). However, this has not been proven and requires further investigation. Participant 7 also stated that compared to Patois, it would be difficult to “mimic someone speaking Vietnamese. I wouldn’t know where to begin; it's just not as approachable of a language I think" (Personal Communication, November 6, 2018). However, she speculated that the Korean language, Hangul, might be more appealing because it originates from a country that has been growing in popularity due to the rise of K-Pop music and Korean 
dramas (Participant 7, Personal Communication, November 6, 2018). That said, even with the constantly changing demographics of the GTA, Participant 7 doubted Korean or Chinese would have as big of an influence on the language in the area, at least for now.

Participants 4 and 8 also noted the current lack of slang from other immigrant groups. Participant 4 believed a language's influence "definitely has to do with the cultural origin of it and who created it because I don't, I never heard no, no, like, Punjabi slang being cool around Toronto, you know" (Personal Communication, November 1, 2018). Likewise, Participant 8 explained that she has "never heard anyone going crazy over wanting to use any, like, Korean slang terms or Mandarin slang terms, or even, like, Portuguese slang terms" (Personal Communication November 7, 2018). She went on to say that it is not only Jamaican language, but all Caribbean creole languages that seem to be attractive to people in the GTA.

Some participants discussed the appeal of Jamaican culture in general. For example, Participant 1 described the long-standing influence Jamaica's culture has had on the rest of the world, primarily through music and language. Participant 12 echoed this sentiment, stating that she thinks "Jamaican culture is very prominent on a global scale. And I think it has, just never-ending influence in the same way that blackness is really influential in popular culture" (Participant 12, Personal Communication, November 18, 2018). She believed that this influence has a lot to do with Jamaica's history as a resistant culture. Black culture shares a similar history, which may be why she believed Toronto slang is also “more resistant than anything else (Participant 12, Personal Communication, November 18, 2018).

Furthermore, those who are of Jamaican and Caribbean descent may use the slang because it connects them to their roots. At the very least, they understand the terms from a different perspective. Participant 4 described slang and Patois as distant cousins because of their similarities in certain respects, and their vast differences in other respects. Participant 2 also described Toronto slang as "a mix of your parents' generation and your generation growing up" (Participant 2, Personal Communication, October 
28, 2018). Furthermore, Participants 1, 2, 4, 8, and 11-individuals who speak or whose family members speak Patois or another form of creole- - heavily understood and described the ways in which Patois differs from slang, the various interpretations of slang in contrast to their original meanings, and the significant extent to which Toronto slang borrows from the language.

\subsubsection{Summary.}

The survey and interview participants raised many important ideas about the appeal of certain languages. First, the notion of the contagious nature of Jamaican language due to its expression and origin is not new. Colonizers, though disgusted by the culture of the black slaves, could not help but adopt some of the language and other aspects of the island's budding society; it was too infectious. Glissant (1989) and Brathwaite (1986) note that creole languages are characterized by their orality, "blast of sound", and their total expression, (Glissant, 1989 p. 124). Similarly, oral storytelling, which stems from African oral tradition, embraces rhythms, sounds, sights, and tones in the environment. Thus, the importance of expression is historical and ancestral, connecting the African storyteller to their audience and to the community within which the story is being told. It also provides authenticity to the story.

Slang, on the other hand, may not be storytelling, per se, but many participants noted its performative nature, as well as its ability to entertain friends and listeners and make them laugh. Furthermore, individuals may gravitate towards slang not only because it contains words and phrases often found in the Standard English language, but because the English upon which much of the Toronto slang is based, is heavily influenced by the "contours, its rhythm and timbre, its sound explosions..." found in African languages and storytelling (Brathwaite, 1984, p. 13). It is an English which encompasses the soul and spirit of natural storytellers who took the English language and made it their own. 


\subsubsection{Ts Toronto slang unique?}

When asked, "what makes the culture and language in the GTA unique", survey participants discussed themes such as multiculturalism, mentioning Caribbean, Asian, and African influences. They also compared Toronto culture and slang to that of the United States and London. For example, a survey participant noted that "although a lot of slang words used are of Jamaican descent or can be heard in other parts of the world, some of the slang words used in Toronto are only heard in Toronto therefore making it culturally unique" (Anonymous Survey Participant, Online Survey, 2018). Therefore, regardless of the similarities and influences from other nations, many respondents concluded that the GTA is unlike anywhere else in the world. Jamaican culture is one of the most dominant because of immigrants' tendency to migrate where there is already a heavy population of their people (Jones, 2005). Additionally, similar to Hall's (2001) assertion that no Caribbean island looks the same in terms of its ethnic composition, language, and cultural tradition, each site of the Caribbean diaspora is also unique regarding the cultures with which it has encountered and intermingled. As such, while they share similarities with other diasporic locations, Toronto culture and language still possess distinguishable features. That said, some participants were still weary of praising the multiculturalism and diversity wholeheartedly, which is reminiscent of critics' debates on the process of hybridity.

\subsubsection{Multiculturalism.}

The majority of participants touched on the diversity and multiculturalism in the GTA to describe its culture. This diversity is believed to be a major contributor to the uniqueness of Toronto slang. After mentioning that slang draws from a number of sources, including Somalia and South Asian culture, a survey participant stated that "Toronto is just so rich with diversity that there are so many different slangs derived from so many different backgrounds" (Online Survey, 2018). Another survey participant noted that while they do not know how distinct Toronto slang is from Patois, they do notice that the slang is 
diffused into other areas of Ontario and Canada two to three years after they become popular in the GTA. They attributed this to the multilingual and diverse culture in Toronto. Seven other survey participants cited the diversity of the GTA, explaining that the multiculturalism and mesh of ethnicities are what make the area so unique from other locations in Canada.

Two survey participants mentioned that the lack of diversity where they currently live (outside of the GTA) makes it difficult to identify with or describe a strong culture there. Likewise, Participant 1 explained that living in Vancouver, it is rare to see a black person because of the high concentration of white and East Asian residents. During his childhood and formative years in school, there were always people of different backgrounds, races, and nationalities, that the mentality was that "'we're all from the GTA' instead of being like, 'this person is from, Jamaica, and this person is from Ethiopia' or whatever. Like as a result of there being so many cultures...it kind of, like, becomes, like one culture" (Participant 1, Personal Communication, October 24, 2018). Participant 4, who also lives in Vancouver, expressed the privilege that comes with living in the GTA, where one's culture is represented through food, music, and retail. When describing the culture in the GTA, she enthusiastically explained that "we are the only genuine...definition of a melting pot. Like, I'm able to go get, like, Chinese hot pot, all while hearing reggae down the street. And then seeing, like, Little Greece...from over here, and then seeing my Japanese brejin eating jerk chicken" (Participant 4, Personal Communication, November 1, 2018). She stated that she is educated about numerous cultures from countries she has never visited simply because she lived in Toronto. Participant 7 said "diversity is our strongest quality living in Toronto. And I'm proud to say I'm from here" (Personal Communication, November 6, 2018). She explained, "going to other cities, you just assume that the demographic make-up is gonna' include, like, people who look like you most of the time" (Participant 7, Personal Communication, November 6, 2018). However, in locations outside of the GTA, particularly in Midwestern America or even the West Coast—an area known for its liberal beliefs - participants expressed that they are less likely to see people of different 
cultures. This also appears to be true for other areas in Canada. Participant 8 noted that other than being multicultural, the GTA has been heavily influenced by immigrants such as herself. She also stated that the GTA is "one of those places that's really just taken from all of us to develop their culture" (Participant 8, Personal Communication, November 7, 2018).

Some participants were not completely convinced of the genuineness of Toronto's diversity. Although it is one of the most diverse areas in the country, Participants 3 and 5 pointed to the lack of people of colour, especially in executive positions, in various industries and institutions. Denis believed the GTA wants to be perceived as a multicultural place "on the surface" but "in practice, it's less multicultural in that sense than people...often admit" (Personal Communication, October 29, 2018). He clarified that by "people" he means white people, as many would prefer to say Toronto is multicultural without questioning the still predominantly white government systems and organizations. Aside from perhaps eating at cultural restaurants or participating in shallow demonstrations of the diversity in the GTA, this idea of multiculturalism "comes from a particular gaze and, um, there's...a lot more going on under the surface" (Denis, Personal Communication, October 29, 2018).

Participant 12 stated that she believes the GTA is both diverse and divisive, noting that racialized communities cluster together, and "there could be someone who grew up in Toronto, who might not understand Toronto slang whatsoever, because they're removed from cultures that speak in Toronto slang" (Personal Communication, November 18, 2018). Participant 9 also noted that the GTA is very neighbourhood-divided. However, Participants 3, 5, and 9 acknowledged that although their neighbourhoods were predominantly white, Asian, and Russian-Jewish, respectively, they have noticed that their childhood communities have become more diverse as the years have progressed. Participant 6 , on the other hand, believed that the GTA is so diverse that it does not have one distinct culture that can be identified at all. 


\subsubsection{Toronto culture versus elsewhere.}

I honestly feel like it's so comfortable for me because I've grown up in it, so...(laughs)... when you leave Toronto, I guess that's when you kind of see that, like, not everyone understands the slang, or what you're saying. Or, they have different ideas of it (Participant 2, Personal Communication, October 28, 2018).

When participants were asked to describe a time when they travelled outside of the GTA and experienced a different culture, many described trips to the United States. They identified that the main difference between the GTA and various places in the United States was the lack of diversity, as well as the lack of Americans' conceptions of diversity. For example, Participant 2 told the story of her high school band trip to Ohio. She played the steel pan, an instrument that originated in Trinidad, which demonstrates the multicultural nature of her school. When her classmates conversed with the American students, she noticed that although they were open-minded, “they just acted like they weren't as aware of...specific cultures and the difference in the Caribbean cultures" (Participant 2, Personal Communication, October 28, 2018). She continued that "a lot of people, um, were asking me if I was Pakistani or, like, any other, like East Indian, and when I said my...my parents were Indo-Guyanese, they were kind of like...'I... don't know what that is, or where that is" (Participant 2, Personal Communication, October 28, 2018). Travelling from an area that is home to hundreds of thousands of immigrants, Participant 2 and her classmates noticed that unlike the GTA, the other students were fifth and sixth-generation American. Whereas she and her friends might identify as being from the Caribbean or another nationality, even though they are Canadian citizens, the American students had to "go deep down the roots into, like, Scottish, English, whatever" (Participant 2, Personal Communication, October 28, 2018).

Participant 7 described her trips to visit her cousin in Santa Cruz. She explained that when she visits, they exchange different slang terms, with her cousin asking, “'what does 'pree' mean?' and I'd be like, 'what does, like, 'gnarly' actually mean?'” (Participant 7, Personal Communication, November 6, 
2018). She continued that Santa Cruz has very few black people, let alone a black community, and as such, her cousin would have little frame of reference as to where terms from Toronto originate. That said, even black communities in the United States may still be unaware of Toronto slang's heavy Jamaican influence. This is because of the African American culture which dominates in the United States and encompasses a different experience from that of the Jamaican immigrant and their descendants.

Participant 4 explained, "I lived in America for a little bit...and that's when I experienced how 'other' [it is to be] a Caribbean black person in any other space" (Personal Communication, November 1, 2018). She also stated that, "even Miami has a good, big concentration of Jamaicans, but because they have African-American culture...that takes over. Same with New York. Like, African-American cultures, obviously [they're] the big influencer...if anything Jamaicans are assimilating to them" (Participant 4, Personal Communication, November 1, 2018).

Participant 11 echoed this sentiment by sharing his experience visiting family in the States and realizing that Americans' perceptions of culture are limited. African Americans are often unable to trace their roots beyond the United States, and often consider themselves "just African American. Like, they don't know which country their family is actually from" (Participant 11, Personal Communication, November 15, 2018). His cousins had never heard Dancehall music or Afro-beats before and stick to their American culture. Participant 12 also shared that her family members in the Midwest would say she has an accent. Furthermore, while they had a general Midwestern accent, she believes GTA accents "range from someone who grew up in Scarborough, versus someone who grew up in Forest Hill. There was a big difference there" (Participant 12, Personal Communication, November 18, 2018). She also remembered American slang being very different from the Jamaican-influenced slang in Toronto.

Participant 9 discussed her trips to Prospect Park in Brooklyn, New York, in a predominantly Filipino and black neighbourhood. That said, she did not notice a distinct slang in Brooklyn or even in the Bronx, which also has a heavy Jamaican and Latino immigrant population. She was unsure if it was 
because she did not stay long enough to overhear conversations or become aware of a particular way of speaking. However, "I swear, like, as soon as you go into Toronto, you can be here for, like, a week, [and] will at least know some slang [even] if they're not comfortable talking” (Participant 10, Personal Communication, November 8, 2018). Therefore, to Participant 10, the slang in areas such as New York are less pervasive, but upon visiting certain neighbourhoods in Toronto, even for a few days, one is likely to hear slang at some point.

Similar memories were evoked by those who travelled to other destinations outside of the United States. Participant 7 studied in Paris for a semester and would "watch what I say in order to not confuse them and just speak as clearly and non-colloquially as possible" (Participant 7, Personal Communication, November 6, 2018). She also did this so as not to be misinterpreted. Similarly, Participant 5 told the story of her friend who travelled to Southeast Asia with her boyfriend for a month and a half, and upon living among the locals, they realized that the way they spoke was unique to the GTA. Participant 9, who has travelled to nearly 20 countries, noticed that in each place she visited, there were phrases and terms that appeared to only be understood by those who were native to the area. That said, people would take interest in her when they found out she was from Toronto, asking her if she was from the "Six" and feeling a sense of familiarity with some of the terms they had previously heard in Drake songs.

Participants 3 and 5 recounted recent trips to Newfoundland. Denis visited Saint Pierre, an island off Newfoundland still under French Colonial Administration. His experience was not only unlike the culture in Toronto, but also unlike all of North America. The French they spoke differed from Quebecois French, and the residents had a lifestyle that was more closely aligned with Europeans (e.g. closing businesses between 12 and 2pm to enjoy lunch and socialization). Participant 5's visit to Newfoundland was more familiar, but although she knew she was in Canada, "it's a totally different atmosphere" (Personal Communication, November 4, 2018). In addition, when Participant 8 visited Montreal for four days in 2017, "I didn't feel that it was as multicultural, even though I didn't really go all around Montreal. 
But I didn't feel that multicultural vibe that I feel here. And also, I found the people weren't necessarily as nice-slash-polite, you know?” (Personal Communication, November 7, 2018).

As mentioned, Participants 1 and 4 find Vancouver culture drastically different from that of the GTA because of its lack of diversity, cultural symbols and establishments, and the inability for their peers to understand their Toronto-based colloquialisms. For example, Participant 4 has to remember to " "unToronotonize' myself [around my roommates]. 'Cause we'll be talking, and they'll be like "Huh?” Like I said 'bare' the other day, [and] she's like, 'Like a bear?' And I'm like, 'No, no, no...a lot'” (Personal Communication, November 1, 2018). Participant 1 also expressed that:

Here in Vancouver, something will happen, and I'll want to be like, "ahlie?" or, like, "say word?" but I know that if I were to say that, people here would be like, "What are you saying?" Like they wouldn't understand it, so I just... or, in the moment, when things like that happen, it's always evident that, like, it is a Toronto thing (Personal Communication, October 24, 2018).

Although the majority of participants touched on the uniqueness of the GTA, many also identified similarities between the culture in Toronto and London. Participant 7 noticed the connection between Patois, Toronto slang, and the slang used in South London. Participants 1 and 6 believed that both London and Toronto are multicultural and share a similar melting pot landscape. Participant 1 told the story of someone he met who was born in Jamaica and had recently moved to Toronto from London, but “fit in really easily, ‘cause, I don’t know, I guess maybe London's culture is kind of similar in certain ways" (Participant 1, Personal Communication, October 24, 2018). Participants 2, 3, 4, 7, and 11 also identified similarities between Toronto and London slang. During her undergraduate education, when Participant 2 and her friend discussed Toronto slang terms with a British exchange student, the student would exclaim, "No way, we say that too!" (Personal Communication, October 28, 2018). Denis also pointed out the use of words such as 'ahlie', which are shared among Toronto and London residents.

After personally observing the comment sections of a number of Toronto slang and Torontoinspired social media content, I asked some of the participants what they thought of London residents 
accusing Torontonians of 'stealing' their slang. Their responses were quite similar. The majority of participants who brought up London also discussed the similar immigrant patterns between London and Toronto. Denis said he does not believe Toronto residents have stolen the slang, but "I think it's just been an interesting confluence of really similar immigrant populations" (Personal Communication, October 29, 2018). He suspected that Toronto and London have the highest concentration of Jamaicans apart from Jamaica itself. As a result, 'it's not that surprising that, you know, Toronto and London both have 'ahlie'. That makes perfect sense because they have...the same source populations. It's entirely possible...in fact it's probable that they're mutually reinforcing each other" (Denis, Personal Communication, October 29, 2018). Participant 4 also believed London and Toronto to be home to the most Jamaican immigrants, which is demonstrated in their similar ways of speaking. Participant 1 stated that "I think, maybe, it's just a result of the two cultures just being similar, and being influenced by the same things, that they think that we're stealing their culture. But we've really just evolved from something similar" (Participant 1, Personal Communication, October 24, 2018).

\subsubsection{Summary.}

These stories demonstrate that not only is the culture in the GTA distinct from other places in the world, it also differs from other locations within the country. First, non-GTA residents may be unaware of the slang until it spreads beyond communities of immigrants, their descendants, and their social circles. Indeed, immigrants' tendency to settle where their kinfolk already reside explains why cities such as Vancouver lack Caribbean restaurants and grocery stores: the number of Jamaicans are not yet high enough to need to accommodate these desires (Jones, 2005).

Some of the interview participants' sentiments also replicated both sides of scholars' longstanding debates on hybridity. Said (1994) states that cultures include more foreign elements and differences than they consciously exclude, and participants echoed this by identifying Toronto as a true melting pot or cultural mosaic. These beliefs are also true of the process of creolization within which 
diversity is a key component (Hall, 2015). While diaspora was not mentioned here, participants certainly pointed out the inherent "heterogeneity and diversity" present within diasporic sites, and the ways in which this cultural diversity helps them to connect with others and understand themselves (Hall, 1994, p. 235). However, negative opinions on diversity are not foreign, as many critics, too, believe that positive views of hybridity overlook its relationship hegemony and power imbalances (Chow, 1993; Toumson, 1998). Furthermore, under the guise of hybridity and now, diversity, only the fun and least controversial aspects of these immigrant cultures, such as food and music, are embraced or accepted, while dominant ideologies and views remain imposed upon them (Kraidy, 2005). That said, it appeared participants were celebratory of Toronto's diversity because on a local level, cultural products, whether language, food, or otherwise, is often owned and produced by individuals from the culture in question and are therefore considered more authentic.

Participant 4's experience and other recounts of American interaction demonstrate an element of the United States hegemony, which dominates over minority immigrant groups. As discussed, while Jamaican immigrants to the United States may feel pressured to either identify and distance themselves from African American and Hispanic minority groups, the GTA's black community is primarily from the Caribbean, which reduces the pressure to conform to other cultures and practices (Jones, 2005; Foner, 2005). Instead, Jamaicans and other Caribbean immigrants stand out due to their expressive language and culture and Toronto's large immigrant population.

Evidently, London is perceived as being closest in comparison to Toronto, due to their similar histories of Jamaican migration (although London's history of Jamaican settlement is much longer). Similar to Sebba's (1993) findings regarding Patois’ presence in London, Patois has been heavily integrated into and supports the culture in the GTA, while also connecting people of Jamaican and Caribbean descent with 'back home'. Stories of participants' travels outside of the GTA demonstrate the ways in which young — and often marginalized — people living in Toronto consider slang as a "badge of 
identity" not only within the Canadian landscape, but globally as well (Bryan, 2004, p. 655). Indeed, although a survey participant said speaking slang does not make them feel more or less a part of the culture, they also noted that speaking that way and joking around with friends is simply a part of who they are. Patois is still a staple among Jamaicans and within Jamaican culture, and its integration into Toronto culture demonstrates the ways in which language continues to evolve and produce new forms and practices as the older ones continue to exist (Ashcroft, Griffiths \& Tiffin, 1995). And through its translation into this unique context, it appears to have had a profound impact on the ways in which individuals perceive themselves within the GTA, and the ways in which they perceive the GTA in relation to localities near and far.

\subsubsection{Using slang: ownership and appropriation.}

Through numerous avenues, members outside of the Jamaican diaspora are exposed to the ongoing exchange of language, music, and other cultural symbols used by Jamaican descendants to maintain ties to 'back home' (Karim, 2005; Croucher, 2011). As such, both Jamaicans and non-Jamaicans are exposed to the ways in which Patois has transformed and translated into the slang used in Toronto. This raises issues of ownership and appropriation: while slang originates from black communities and is rooted in the resistance and subversion tactics used by black slaves, it is, like any other language or dialect, fluid, flexible, and hybridized (Glissant, 1989; Bhabha, 1994). Furthermore, similar to the ways in which colonizers adopted Patois because of their close vicinity to the slaves, non-Jamaicans and nonpeople-of-colour (POC), may also pick up on and use slang due to their relationships, area of residence, and more (Brathwaite, 1971). Therefore, questions regarding what constitutes as cultural appropriation when it comes to Toronto slang is quite complex.

Many interview participants and even a couple of survey participants either alluded to or discussed cultural appropriation, and some found the use of Toronto slang to be more problematic than others. For example, one survey participant explained that now that they have a better understanding of 
cultural appropriation, "I'm not sure if it's appropriate for me to use 'GTA slang' because it's basically just cherry picked from patois, similar to how we cherry pick parts of other cultures (like bindis, head dresses) and appropriate those 'palatable' or 'desirable' parts of a culture” (Anonymous Survey Respondent, Online Survey, 2018). On the other hand, some reflected on slang's deep integration in Toronto culture and connection to who they are. They explained that they do not often think about the language too much, as it is just one of the "many things that makes Toronto what it is" (Anonymous Survey Respondent, Online Survey, 2018). Generally, those who associated Toronto slang primarily with age or multiculturalism did not believe that cultural appropriation was as big of an issue. In contrast, those who associated the slang more closely with race, Patois, or immigrant culture in general, perceived the use of slang to be an act requiring further reflection.

\subsubsection{Authenticity of use.}

Authenticity became a central, although indirect topic within discussions of cultural appropriation. When asked to tell a story using Toronto slang, only five participants attempted to do so. Those who declined made statements relating to their lack of knowledge of the slang, including not having enough vocabulary; not being well-versed in the slang; their inability to tell a whole story; and their uncertainty regarding which words to use and when. Others expressed their discomfort with using the slang because it would not feel genuine. They felt they would be appropriating the slang; that it has never felt 'natural'; or that it is only when they are around someone who shares lived experiences that they are compelled to effortlessly speak in slang. These responses resulted in further questioning regarding what it means to speak slang 'naturally' or 'genuinely'.

To some, the culture within which one grew up is a critical factor when evaluating authentic slang use. Discussions of ownership and cultural appropriation arise in Denis' research, and he expressed the difficulty of defining cultural appropriation. He explained that if Toronto slang is seen as "truly a multiethnolect —emphasis on the multi here" that involves linguistic elements from various places, "then it's 
hard to say what appropriations is" (Denis, Personal Communication, October 29, 2018). That said, he stated that using the slang would be appropriation for him because he is "definitely not in that speech community" (Denis, Personal Communication, October 29, 2018). Therefore, it appeared that it was less his identity as a white male, and more of his lack of connection to the community, that indicates whether it would feel normal for him to speak in GTA slang. Participant 4 also denied, to some extent, that there was a heavy case of 'racial appropriation' with the use of slang because if a white person grows up in Scarborough around Jamaican people, it would be unfair to tell them that they are not allowed to speak a certain way because they are white. She explained that "if it's genuine, if...you genuinely understand the culture and you grew up around that culture your whole life, you are allowed a piece of that...you didn't choose where you grew up" (Personal Communication, November 1, 2018).

Participant 2 believed people who use slang are a product of their environment. She saw authentic use as more of a geographical issue, stating that to "fully speak like that as if you were...you grew up with this type of slang...I feel like that's more like appropriating the culture" (Participant 2, Personal Communication, October 28, 2018). When asked if Toronto slang has an owner, she replied that although there may not be an owner, "I do feel like it derived, from, like, the different areas of...the hoods! Of the more impoverished side of the hood of Toronto areas...those are where the Jamaican people really immigrated to" (Participant 2, Personal Communication, October 28, 2018). As such, she also explained that in some situations, growing up in areas where people speak slang allows one to speak more authentically:

So I feel like when you hear it used enough and when you're around a certain group of people...you kind of pick it up, it's natural, so it's like, “oh, I know when to use 'mandem', I know when to use 'marved', I know when to say... 'say less' and 'more times'... and um...like 'dunnoe', like I know when to say these things" 'because it's like, you've been in [those] situations... (Participant 2, Personal Communication, October 28, 2018). 
She continued that slang and the entertainment that comes with it can be enjoyed without "having to, like, act like you're from there..." because "I feel like they don't realize they're mocking it. But they kind of are because it's not really that genuine" (Participant 2, Personal Communication, October 28, 2018).

Race came up many times when discussing authenticity of slang use. Participant 7 often discussed Patois and Toronto slang in relation to race. She acknowledged that a non-black person may not be able to 'get away' with using slang or Patois because they are less connected to the communities who do so. Participant 12 's views on the authentic use of slang were also aligned with race and culture: those who are more closely related to black or Jamaican culture are able to identify more deeply with the slang and use it more genuinely. She noted that the city of Toronto has a "very specific relationship to black culture", and because she perceives slang as part of black culture, she described it as a "resistive language" that may not be understood by those who are not marginalized (Participant 12, Personal Communication, November 18, 2018). She explained that language is more authentic when used by those who are a part of the culture and share similar lived experiences. In this way, she echoes Ngũgĩ's (1981) idea that language is a "collective memory bank of a people's experience in history" (p. 15-16). She also believed that for the most part, people either speak in slang in an authentic way or a mocking way (Participant 12, Personal Communication, November 18, 2018). To demonstrate this, she explained that when people use Somali language, “they might say the word, 'Hoyo' for example. And they're saying something like, 'Oh, your Hoyo is looking for you'. I think the way that they might say the word 'Mom' in Somali might be mocking" (Participant 12, Personal Communication, November 18, 2018). She continued that she finds people often joke around when they speak in Toronto slang, and that is often seen as making fun of the culture from which a term derives. However, there are also people who "speak that way when they're upset, and that's authentic to them. So, I think there's a really clear divide. And it's easier to tell when you are closer to that language that's being spoken" (Participant 12, Personal Communication, November 18, 2018). 
Indeed, Participant 12 also had strong thoughts about appropriation related to geography and community at the intersection of race. To her, communities from which Toronto slang originates are places with heavy Jamaican and visible minority influences. Because of Toronto's distinct connection to black communities, and specifically Jamaican communities, she felt that appropriation takes place when people who are not from these areas partake in the culture. This is taken to a more extreme level when someone who grew up in Waterloo, for example, is "speaking in Toronto slang because they lived here for a year. And they're so removed from the kids who live in neighbourhoods that people would describe as a hood", but "get the fun part of the culture, which is the language, but you don't have to deal with any of the consequences of being a racialized person" (Participant 12, Personal Communication, November $18,2018)$.

Participant 8 had a different perspective on why Toronto slang may be appropriation. As a Jamaican immigrant to Canada, she stated that Patois and slang are "very different", because when her Patois "slips out", it is not guaranteed that someone from Toronto will understand what she is saying (Participant 8, Personal Communication, November 7, 2018). She also believed that there is a delay between the terms that develop and become cool in Jamaica, and their integration into Toronto culture. Participant 8 was adamant that slang does have an owner because of its clear connection to Patois. When she hears terms which derive from Patois, there is an element of trend-setting by Jamaica, but for the most part, "I feel more just like our stuff are being taken. You know what I mean? Like that's ours. That's something that we created" (Participant 8, Personal Communication, November 7, 2018). She continued that there are a number of Caribbean creole languages, but "they're just taking from us. That was our thing. And now they're taking it and they're using it to try and sound cool or be cool? Like, they're just taking our stuff!" (Participant 8, Personal Communication, November 7, 2018).

On the other hand, some participants believed the use of Toronto slang to be less problematic, and more of a simple demonstration of the migration and hybridity that exists in the GTA. Participants 
believed slang use has to do with people being a product of their environment. Participant 1 stated, "I think mostly it's from immigrants moving to Toronto and then using [phrases] around their peers who aren't from the same culture as them, and them using it as well"' (Personal Communication, October 24, 2018). Similarly, Participant 11 said he does not believe there is any element of cultural appropriation within slang. He held that Jamaicans started the slang and people around them picked up on it. He described the generational aspect of Toronto slang, "if you're white, black, or Asian, and you all grew up together, you're all gonna' talk the same way...even the, like, the richest, rich, like, bougie white girls try to talk in the same slang as hoodmans" (Participant 11, Personal Communication, November 15, 2018). From his perspective, authentic slang use does not come from race or ethnicity but is associated with the age and generation of the user.

Participant 6 stated that at this point, the slang used in Toronto has "become, like, for everyone" (Personal Communication, November 5, 2018). Similarly, Participant 9 noted that it "I think it's just one of the things that is very fluid. I don't think anybody could take it, per se" (Participant 9, Personal Communication, November 8,2018 ). She also differentiated between language and slang: a culture can claim ownership over a language, but slang cannot be appropriated because it involves picking and choosing "whatever kind of fits their personality and fits the conversation of their group and adds to it", (Participant 9, Personal Communication, November 8, 2018). Participant 1 added that “I don't think that's damaging to the culture that they originate from in any way" (Participant 1, Personal Communication, October 24, 2018). Similar to Participant 9, he also attributed the use of slang by people in the GTA not as a way to mock others, but as a tool with which they can express themselves, which he does not see as an issue. As a person of Jamaican descent, he noted that he interprets the words spoken to him by someone in the GTA differently than if they are spoken by a Jamaican person because it is within a different context. Instead of claiming ownership of the language or telling others "you're not allowed to, 
like, say stuff like that "cause you're not from Jamaica", he sees it as, "I understand why you're saying that to me because you're from Toronto" (Participant 1, Personal Communication, October 24, 2018).

\subsubsection{Ambivalence towards modern media influences.}

Although participants believed Drake's international fame has helped to put Toronto slang on the world stage, many did not see him as inventive, creative, or even authentic with slang use. Participant 1 noted that Drake uses slang that has been around for a while and that he simply repeats "what he's hearing or what people say, instead of, like, making his own phrases" (Participant 1, Personal Communication, October 24, 2018). Denis also stated that Drake, a product of his environment, did not start anything new. For example, in their stories and examples of slang terms and phrases, participants mentioned 'mans', ‘forward', and 'are you dumb?', which Drake has also used in his songs, as demonstrated in section 2.4.2.2. Additionally, Kardinal Offishal's BaKardi Slang, which debuted approximately five years before Drake's first mixtape demonstrates that Toronto slang has been popular before Drake brought it to the foreground.

Participant 4 displayed mild resentment of him when she expressed that with "the internet now and, like, with (hesitates)...God forbid Drake", more and more residents in Canada and the United States are beginning to use slang terms popularized in Toronto (Participant 4, Personal Communication, November 1, 2018). Additionally, while she credited him for the positive impact he has had on the reduction of the stigma attached to Toronto slang, Participant 2 was not convinced that Drake's usage is genuine. In fact, she stated that she feels it is forced. She explained that "it's kind of weird to hear him speak like that. Even though he-I feel like, again, he's doing it, like, correctly, but I don't feel like it's natural (laughs) coming from him" (Participant 2, Personal Communication, October 28, 2018). Here, too, is the issue of authenticity, and whether someone as famous and well-known as Drake is seen internally as an example of genuine language use. 
Drake has also used a lot of terms, references, and inspiration straight from Jamaican culture. However, participants were ambivalent at times about whether he is an appropriator. For example, Participant 7 explained that Toronto slang is appropriation when it is used for profit, but that Drake "gets a pass" because Patois is so deeply integrated into the slang that it would be difficult for him to constantly acknowledge the origin of each term he uses (Participant 7, Personal Communication, November 6, 2018). She also believed that being half black makes his slang use more acceptable (Participant 7 , Personal Communication, November 6, 2018). Participant 8 believed that Drake is a "culture vulture to a certain extent", but acknowledged that he grew up in Toronto, a place with a large diaspora, and is also friends and makes songs with Jamaican artists such as Jamaican singer, Popcaan. That said, she noted that people use slang and Patois because it is "advantageous to them" (Participant 8, Personal Communication, November 7, 2018). His Canadian citizenship, money, and other privileged factors allow him to speak in whichever way he desires, but growing up in Jamaica, if "one of my aunts or uncles or even myself, if I were to use that in a formal setting or an interview, one of the things they'd probably mark me down for is, 'Oh, she didn't speak properly', or 'She was unprofessional'” (Participant 8, Personal Communication, November 7, 2018). Therefore, while she is a Drake fan and understands his ties to Jamaican culture, she believes it to be unfair, and even annoying that on the island where the language originated, "it's going to work against you" in certain settings, but in Toronto, "people are using it all willy-nilly, not even really knowing what some of the words mean" (Participant 8, Personal Communication, November 7, 2018).

The most popular online influence and, at times, representation of Toronto culture among participants, was that of 6ixbuzz. However, while Participant 7 described 6ixbuzz as a Toronto-based Worldstar, Participant 4 was not convinced that 6ixbuzz has any noble objectives. Instead, she stated that it is an exploitative account that profits off black culture and the slang used by people of Jamaican descent. She was passionate about her opposition to the account, explaining that "they're profiting off this Instagram page, talking like us and doing relatable content for us and showing black people to be the 
damn fool" (Participant 4, Personal Communication, November 1, 2018). She continued saying, Like, you're not part of the f------ culture 'cause you're an op, like, you're just not part of the culture" (Participant 4, Personal Communication, November 1, 2018). Although it appears the founders are, in fact, black (as of July 2018, MB worked at a non-profit mentorship organization that caters specifically to black youth, and SB was one of the mentees who had registered), Participant 4 stated "I know it's like some little brown kid in Castlemore running 6ixbuzz". Evidently, even influencers that have originated from the GTA are still met with skepticism when it comes to deciphering which slang use is authentic, and which requires more investigation.

\subsubsection{Acknowledgement of Jamaican culture.}

Acknowledgement of Toronto slang's origins seemed to be the most pressing issue among participants. For example, Participant 1 did not perceive slang use as appropriation, but he also added that it is not damaging to the culture "if you're aware of where these things are originating from", or at least understand that the terms did not originate from Western culture (Participant 1, Personal Communication, October 24, 2018). Similarly, Participant 6 stated, "we just call it slang but, like, no one acknowledges that it's actually Patois", and cultural appropriation may occur when "we're not honoring the space that it came from" or why it is used (Participant 6, Personal Communication, November 5, 2018). A survey participant also shared that they believe Toronto slang is "very based on Jamaican patois but a lot of people don't give patois the credit it deserves" (Anonymous Survey Participant, Online Survey, 2018). Another said, "A lot of [sic] not most comes from Jamaican culture but it's interesting how very little Jamaicans are credited" (Anonymous Survey Participant, Online Survey, 2018). Participant 7 identified with the fun that comes with using slang but encouraged anyone who is using the language to "acknowledge where it comes from and pay respect to that. Otherwise, you run the risk of sounding like an idiot" (Participant 7 Personal Communication, November 6, 2018). 
Denis, who analyzes YouTube videos as part of his research mused over the fact that in videos where Toronto residents test strangers on their knowledge of slang, "the term 'Toronto slang' is an extremely neutral term. It just...you know, it's just Toronto (laughs). Yeah, it's not, like, 'Toronto Jamaican slang' or 'Jamaican slang in Toronto' or something like that" (Denis, Personal Communication, October 29, 2018). He also noticed that, "even in the context of some of these videos, the source of a lot of these terms is almost never discussed" (Denis, Personal Communication, October 29, 2018). The YouTube interviewers simply believe that terms are "part of Toronto slang and if you're from Toronto then you know it, but if you're from, I don't know, Pickering, then maybe you don't....I mean, I just find that super interesting that it is talked about so, so neutrally" (Denis, Personal Communication, October 29, 2018).

That said, while some respondents appeared to be aware of the history and etymology of the language used in the GTA—-for example, a survey participant believed words from Patois are first imitated by non-Jamaican people of colour, before eventually being adopted by white cultures and commercialized - others were not privy to the connection between the two cultures. One survey participant even commented that they "never associated [Toronto slang] with any ethnic group before" and were interested in learning more (Anonymous Survey Participant, Online Survey, 2018). Furthermore, both Participants 4 and 11 told stories of being 'educated' by non-Jamaican and non-black individuals who were unaware of the origins from which the slang came. First, Participant 4 recounted:

...one of my Jamaican friends retweeted this white guy's tweet [and] he's like, "wha' does white boi know 'bout 'wha gwaan'?" Or, something like that. He said something 'bout 'blem' or, like 'wha gwaan' or something... and then the white guy opened up his dirty mouth to say, "It's Toronto slang. You wouldn't get it." I'm like (sarcastic laugh)...they literally think they have dibs over the way we talk or the slang we created... and they think that somehow, they own it and it's for them to gatekeep, even though the people who created it could not. Yeah, so it's a very gray area, like, it's...partially cultural appropriation. But it's not...but it is at the same time (Participant 4, Personal Communication, November 1, 2018). 
Participant 11 shared a similar story:

There was someone in one of my comments tryna' have an argument with me, saying that people from London created the word "mandem". And I told him that that comes from Jamaica. And he's tryna' give me a whole background, like, breakdown of the word, and why people from London created the word "mandem" (Participant 11, Personal Communication, November $15,2018)$.

Both participants expressed that there is a lack of awareness that so much of London and Toronto slang come from Jamaica. However, people who are neither Jamaican, nor have direct connections to Jamaican culture "literally think they have dibs over the way we talk or the slang we created. And that's when it becomes an issue" (Participant 4, Personal Communication, November 1, 2018). Participant 4 added that, "I just really wish the people who are using our slang...I wish we could get the credit that we need, and that Toronto slang can be recognized — it needs to be recognized as, like, something important" (Participant 4, Personal Communication, November 1, 2018).

\subsubsection{Summary.}

Evidently, there exists a divide in opinions pertaining to issues of cultural appropriation, ownership, and use of slang. First, race must be considered, simply because any marginalized language that has survived colonialism has had to endure, address, and challenge the oppression of European imperialism. These languages have developed out of struggles with slavery, suppression, resistance, representation, and more, which began because of racial hierarchical claims by colonizers (Ashcroft et al., 1995). Today, slang still develops in communities dominated by racial minorities, marginalized groups, and immigrants of colour. Therefore, race remains a factor when analyzing when and why slang use is deemed acceptable or unacceptable for those with little connection to the origin group.

Although Participant 8 was unhappy with what appears to be the 'theft' of Jamaican language, through the Third Space, languages move and are transported over time. No language is completely pure, nor can it be "disaggregated or restored to their originary forms" once multiple cultural elements have 
fused together (Hall, 2015, p. 15). In fact, Bhabha (1994) argues that the Third Space places no fixity on cultural symbols or meanings at all. As a result, they are free for others to translate and appropriate in new ways. Furthermore, while understanding its origins is productive, language's fluidity and constant encounters with young people from a wide range of races and ethnicities makes it difficult to name a sole owner of a vernacular such as Toronto slang (Bryan, 2004).

Indeed, similar to Bryan's (2004) discussion, while some participants agree that the slang rooted in Patois belongs to the local community within which it is being spoken, and others believe it is "common property for all young people", many still think there is an element of mocking or parody that exists when individuals who do not relate to the language attempt to use it as their own (p. 655).

Additionally, although Glissant (1989) holds that language should be accessible to all, he also notes that learning a language requires apprenticeship. Some participants appear to believe this 'apprenticeship' is missing, as they described the ways in which people who use slang seem to be unaware of its origins, history, or significance. Therefore, while slang may be open to any and everyone who comes across it online or through music and other means, users miss the understanding and acknowledgement of its significance when they adopt slang terms without deeper thought or reflection.

\subsubsection{Stigma around slang.}

My findings from both surveys and interviews demonstrate that although Patois, slang, and even AAVE are widely used, this does not mean that negative stereotypes have disappeared. As discussed in the Chapter 2, Standard English alternatives, such as AAVE and Patois emerged out of marginalization and oppression and are still met with discrimination in a number of settings (Rickford et al., 2015).

Therefore, various stigmas regarding slang recall past suppressions of the Présence Africain and confirm Fanon's (1963) argument that the use of pidgin languages can cause black and Caribbean people's internalized inferiority to resurface. These feelings are often passed down through generations, and thus prevent dialects such as Toronto slang from being celebrated wholeheartedly. 
Toronto slang and Patois both face stigma in certain contexts. Although participants celebrated the positive aspects of using slang, there were still times when they noted its drawbacks, demonstrating the public's, as well as their own judgements when others speak in the dialect. Participant 1 said he will sometimes use slang in a sarcastic way or to be funny, and he and 12 discuss the ways in which using slang makes their utterances sound more entertaining or expressive. Participant 11, who uses slang heavily in his creative content online, stated that he does so because "it's funny to me when people that talk in slang only know how to talk in slang. Like, obviously the majority of us could talk properly if we want to talk properly. But there's some people that literally cannot do it. And I just find that hilarious" (Participant 11, Personal Communication, November 15, 2018). He also mentioned that, "like when you talk to certain girls, and they have, like, that...super Toronto accent, and it's just, like, shocking and a turn off. That is hilarious" (Participant 11, Personal Communication, November 15, 2018). Sentiments such as, 'You still speak like that?' or 'You only speak like that?' were also prevalent in Participant 2's responses. After telling a story in Toronto slang, she was asked what went into deciding which words to say and why, and while she explained that people are a product of their environment, she added that "the thought process is more like...you really have to think like a 'hoodman'. You have to think like a Toronto man who doesn't know how to speak" or at least, does not know "any other way to speak" (Participant 2, Personal Communication, October 28, 2018).

Participant 2 also critiqued those who did not grow up in "the hood" for appropriating the language because they "know better" (Participant 2, Personal Communication, October 28, 2018). When asked to elaborate on the notion of 'knowing better', she was noticeably conflicted. On one hand, she responded that it is "not really knowing better, but I feel like...they normally, like, they didn't grow up speaking like that. So, not necessarily knowing better, but also, in a sense, like, knowing the difference" (Participant 2, Personal Communication, October 28, 2018). She explained that there are people, often from lower income neighbourhoods, who truly do not know how to speak any other way than slang, due 
to lack of exposure to areas outside of the GTA. As a result, their speech is not considered 'proper', and is often viewed with a negative connotation. On the other hand, although she believes the slang does not necessarily need to be perceived negatively, she understands it "to a certain extent. Because honestly there are people who I've grown up with that I'm like 'you still speak like this? Come on, like, you're so grown now, and you speak like this and you're trying to get a job"” (Participant 2, Personal Communication, October 28, 2018). She reiterated this sentiment later in the interview:

I personally even, like, I think of people that I've grown up with in high school I'm like, 'Why do you still talk like that? Like, you know better'. And like...it's always —it's just a thing that's like looked down upon. Like, I'm even like, 'Ew, like, why are you speaking like that. Like you don't talk like that anymore. Like, there are better ways-like, you can speak more civilized or whatever' (Participant 2, Personal Communication, October 28, 2018).

When asked if slang is still seen in a negative light, she responded that it may not be completely negative anymore, but because it stems from low income areas and “...derives from a dialect that's not considered to be...good enough and proper", this means the slang is "still not proper, it's still not what is thought of as proper...it'll never be, like, thought of in a positive light" (Participant 2, Personal Communication, October 28, 2018).

The topic of negative associations with slang was particularly prevalent during discussions of its use in professional settings. For example, Participant 5 explained that "working in agriculture, I have to be cautious about what I say. Even though I don't have any type of Toronto accent, if I had any hint of an accent, they wouldn't be able to understand me, even though English is their first language" (Personal Communication, November 4, 2018). Participant 6, who is of Jamaican descent, never experienced her family members using Patois outside of the household. She believed this was because many of her family members had highly ranked positions at companies where they were the only black individuals in an allwhite space. Therefore, they were forced to adjust in order to move up at work or to merely be accepted. When asked if she believes the opposite (that white people are assimilating to black culture) is happening more commonly now, she explained: 
I do have, like, white friends that have assimilated into black culture because they just want to be immersed and seem cooler. But I think minorities, at a certain point, you do have to assimilate in order to even move up in certain positions...I think when you're not a minority, you have more of a choice with where you want to go and who you want to associate with. When you flip it the other way, you're kind of thinking about, like, "How do I, like, move up and get better? And what does society expect of me?" (Participant 6, Personal Communication, November 5, 2018).

Participant 6 also realized that slang use is more prevalent when she works in certain areas. For example, when she works near Black Creek and Eglinton Road, which has a higher population of Jamaican immigrants, she hears slang more often than when she works near the Harbourfront Centre or by the Yonge-University subway line, which are both located in central areas of the Downtown Core. Although they may speak in slang when in tighter-knit groups, Participant 6 assumed that "in different professional environments, I don't think you do. You scale back on it” (Participant 6, Personal Communication, November 5, 2018). The use of Patois appears to have a similar sense of inferiority to English in Jamaica: Participant 8 explained that using Patois in an interview or as a teacher at school is frowned upon, not recommended, and would probably be criticized. This is because "speaking properly is still equated with speaking Standard English" (Participant 8, Personal Communication, November 7, 2018).

Age also appeared to play a role in people's perception of slang use. Most participants were introduced to slang in grade school or high school. And as demonstrated above, Participant 2 expressed that she is surprised and critical of those who still speak a certain way after high school or even up to university. Participants 3, 6, 9, and 12 commented that they were more aware and in tune with the popular terms when they were younger but are no longer able keep up now that they are older, have moved downtown, or spend more time in professional spaces. A survey respondent noted that they now have to Google words they hear, when before, the slang words used to come naturally to them. Participant 9, who lives in Vaughan, which has a smaller settlement of Jamaicans than other areas in the GTA, was more attentive to slang in high school, and believed it was more present during that time. Her use and attention 
to it began to decline during university, "and now in my daily life, I really don't [use it]" (Participant 9, Personal Communication, November 8, 2018). She added that when teenagers would come to her work in the past, she would notice the differences in their conversation, but "it feels like every two years it's really changing if you're not really in the loop or you're not someone who's kind of within the youth of it" (Participant 9, Personal Communication, November 8, 2018). As mentioned, Participant 11 also believed there to be an age element to slang use, explaining that it is the older people and parents who judge younger folks and “don't like how we talk” (Participant 11, Personal Communication, November 15, 2018). However, while Participant 9 expressed detachment from the young people who speak a certain way, Participant 11 still considers himself a part of this group. Likewise, Denis mentioned that the speech is "restricted to, like, younger people...um...uh, like 25 and under", under which most participants fell (Personal Communication, October 29, 2018). That said, it is evident that the stigma attached to age varies based on social circles, professional life, and participants' own perceptions of when significant use of Toronto slang should be phased out — or at least when it should only be used in more intimate circumstances.

There were also participants who acknowledged but were more critical of the negative stigma attached to Toronto slang. Participant 4 frankly stated that when people hear Toronto slang, they "just think it's uneducated n----- talking, but it's actually very interesting" (Personal Communication, November 1, 2018). Participant 7 explained that slang should be considered appropriation if it is being used as a negative façade. For example, "if they're trying to act, like, ghetto when they're using it. I don't think that's OK...to have that [negative] association with, like, a marginalized community" (Participant 7 , Personal Communication, November 6, 2018). This is because "I don't think that that would be fair or as informed or politically correct to associate that with, like, speaking 'ghetto' which I think is problematic in itself" (Participant 7, Personal Communication, November 6, 2018). A survey participant, noting the perceived negative perceptions of Jamaicans in the GTA, as evidenced in news outlets, shared that "as far 
as language goes, many older Jamaicans are ashamed of jamajcan [sic] creole/patois and they shouldn't be. It's unique and worth acknowledging as it's [sic] own language! Slang has adopted it just fine" (Anonymous Survey Participant, Online Survey, 2018).

Although Participant 2 still had her reservations about the use of slang by the end of the interview, she reflected on the idea that "like, if that's all you know, who said that that's, that's not good enough? Like, why is it not good enough?" (Personal Communication, October 28, 2018). She added that she felt it "goes back down to the fact that it's like an immigrant dialect. So, it's like, because it's an immigrant dialect then it's just not good enough. Yeah...it's unfortunate. Which I think is, like, the root of it" (Participant 2, Personal Communication, October 28, 2018). Participant 12, however, expressed that the negative connotations associated with Toronto slang are problematic and offensive, when it is "actually creative and witty" and has been sustained with little effort (Personal Communication, November 18, 2018).

The negative stigma surrounding slang also appeared to be related to the stigma around its origins. For example, seven of the 12 participants all touched on the idea that much of the slang in the GTA was transported here by immigrants. During this time, many Caribbean immigrants also brought with them the inferiority that came with speaking their languages over Standard English. For example, Participant 2 recounted times when her mother would not let her speak in her native Guyanese dialect, telling her, "you're not Guyanese. You don't need to speak like that like that's not polite—like that's not correct. You don't speak like that", even though the rest of her family used the dialect (Participant 2, Personal Communication, October 28, 2018). Furthermore, they may have experienced the racism and judgement that exists — even in a multicultural area such as the GTA—when someone looks, speaks, or lives life differently from the country's dominant group. Indeed, although Jamaicans make up a large portion of Caribbean migration in Toronto, and their practices are considered trendy by a vast amount of 
the population, they are still a minority in relation to rest of the country's ethnic backgrounds and Eurocentric foundation on which North America was built.

\subsubsection{Summary.}

Evidently, though slang is considered cool and easy to adopt, the stigma and negative stereotypes surrounding non-Standard English still exists. Participants noted the ways in which they may judge those who still or only speak in slang. They also expressed that older people may not be able to understand, identify, or accept this speech, or shut down their children's use of certain languages and dialects. Participant 2 discussed the ways in which she judges former classmates for still using Toronto slang consistently, believing they should be speaking more 'civilized'. The idea of acting civilized was prevalent during colonialism, when formerly colonized people felt removed from their "jungle status" when they rejected their roots and instead emulated Western cultures through language and other practices (Fanon, 1967, p. 18). Additionally, Participant 2's mom's criticism of her use of Guyanese dialect likely stems from Présence Européenne, which speaks all the time, and through its rejection of African and indigenous practices, resulted in internalized inferiority to the white man and white man's English (Hall, 1994; Fanon 1963). In other words, though proud of their culture in many ways, there still exists the remnants of West Indian embarrassment (Ngũgĩ 1972).

The above comments and sentiments echo Fanon (1967) and Brathwaite's (1971) ideas that formerly colonized people were made to feel less bestial and more aligned with civilized cultural standards when they spoke the language of the colonial regime. Although creole languages are not 'extinct', Fanon's statement that speaking like the European makes people of colour feel more equal to them still appears to ring true in certain situations. Many participants used the term 'proper' to refer to the English forced upon slaves. However, in doing so, they unknowingly discredit and undermine efforts to validate the Présence Africaine, and the 'spirit' of the African in reappropriated versions of the language 
(Hall, 1994). In turn, a disservice is done to the people who worked to distinguish their English from that of the colonizer in order to retain their identity and ancestry.

\subsubsection{Hybridity 2.0.}

Many survey and interview participants noted that Toronto slang is derived not only from Patois, but from other distinctive immigrant cultures. One survey participant explained that "you not only find Carribean (sic)/Patois influences but you find Somali and South Asian influences in slang and the way young people speak, which I believe contributes to a different and unique culture compared to other places I've visited" (Anonymous Survey Participant, Online Survey, 2018). Indeed, almost every survey participant who chose to share their thoughts on Toronto's uniqueness discussed this distinct mix of immigrant cultures, which represent the extent to which the GTA is diverse, multicultural, and a hybrid mix of many external influences. Survey participants were ready to explain that although Patois is the most dominant within Toronto slang, it is the unique blend of cultures, in addition to Jamaica, that make the slang in the GTA so unique. Therefore, while no one used the term directly, many identified the process of hybridity as an important element of Toronto culture.

Indeed, Hybridity is a key process, especially in a diverse city such as Toronto, because of the ways in which people "negotiate and translate their cultural identities" over time and in relation to various cultural encounters (Bhabha, 1994, p. 22). Furthermore, Bryan (2004) discusses the linguistic mix that occurs among Jamaican descendants within the diaspora, as they combine Standard English with Patois and other immigrant languages. Many participants acknowledged the blends of culture in the GTA, which then influence and alter the language used in the area. This points to the inevitable transformation of language over time, and points to the GTA as a Third Space of linguistic enunciation. The process appears to continue as slang users move to different areas of Canada and the world and terms combine with those of their new environments. However, hybridity is still contested, and it remains important to 
understand the ways in which the process may be criticized, even as it contributes to the uniqueness of the GTA.

Participants 1 and 12 discussed the fact that the original definitions of certain terms do not necessarily take on the same meaning in their new locality. For example, as mentioned, when Participant 1 hears someone use slang, he does not see it as appropriating the culture. Instead he interprets the term or phrase from a Toronto-based context. He also said he has noticed that there are many words that are “originally said in Jamaica and now, like, they're just in Toronto. But Toronto tends to use it in a different way" (Participant 1, Personal Communication, October 24, 2018). This is similar regarding other foreign cultures. For example, he brought up the phrase "say Walahi", explaining that even though it is not English (it is a Somali term), "I still know what [people] mean when they say that 'cause, like, it's been incorporated into Toronto slang...from another culture" (Participant 1, Personal Communication, October 24, 2018). Participant 12, a Somali-Canadian, also noted the use of Somali terms in Toronto slang. She stated that "sometimes they're being used out of their original context, but there's still connection there, in that this word has meaning in Somali, but it also has a completely different meaning in Toronto slang" (Participant 12, Personal Communication, November 18, 2018).

Participant 8 did not necessarily view Toronto slang as a hybrid transformation resulting from interactions with new cultures and languages. Instead, she believed Torontonians use Patois-based terms incorrectly and are simply unaware of the meanings and contexts within which they should be spoken. She explained that especially with curse words, "we block that out on radio, but they don't block that out on radio here. That's why I wonder sometimes if they, like, totally get what it means" (Participant 8 , Personal Communication, November 7, 2018). While this may be true, it may also be an indication of the fluidity of language and the existence of the Third Space, which allows meaning to be reinterpreted and translated in new ways. Furthermore, she felt like she would not be able to tell a story in Toronto slang because "I feel like it wouldn't really make that much sense. You know what I mean?" (Participant 8, 
Personal Communication, November 7, 2018). Although it was not investigated further, it appears she believes she does not have the desire speak in Toronto slang because she already speaks the the language from which it originates.

Although not labelled 'hybridity', Denis explained a similar process:

So, an ethnolect would be like a variety of language that is predominantly associated with a particular ethno-linguistic group. So, in the States...African American English would be an ethnolect. But what I'm really interested in is what people, predominantly working in Northern Europe...have called a multi-ethnolect. In my own work, they've been described as developing neighborhoods that are somewhat socially or economically, or even physically segregated from the rest of the community. And within these neighborhoods, you have people coming from all over the world. So, what you have is not a neighborhood that is like, you know, little Jamaica or, like, Chinatown or something like that, but rather you have these neighborhoods where you have people from all over the world speaking all kinds of different languages - some of them speaking different varieties of English — all coming together and living in these, somewhat segregated neighborhoods, where they are... where their access to the ambient language - in the case of London in the UK, for example, it would be English - is somewhat reduced or less than in a different kind of neighborhood. And, so, interesting kinds of language change happens, and interesting developments seem to be happening. And so, we called a result like [that] a multiethnolect (Denis, Personal Communication, October 29, 2018).

Evidently, this idea of a multi-ethnolects can be used to describe what many participants appeared to identify. Immigrants who grew up in, perhaps unofficially segregated areas of the GTA had their languages interact and intertwine with the other minority languages in those communities, in addition to English. Following this process, different results occurred, one of which being the emergence of Toronto slang. Participant 9 also touched on this idea of 'back home' slang being influenced by a new locality. She discussed the ways in which the slang from these different communities "would kind of incorporate into regular languages. I can even think about it when I spend time with my friends and we use — speak in English, but then there would be a slang word we'd say in Russian or Hebrew" (Participant 9, Personal Communication, November 8, 2018).

Finally, there was also talk of further evolution and transformation of Toronto slang. For example, a survey participant acknowledged that "every language evolves" and that "our slang seemed to change quite a lot in the last 5 years" (Anonymous Survey Participant, Online Survey, 2018). Participant 
1 also noted that "Toronto slang is always evolving, and it's always gonna' be changing into something new as the population grows and the demographics change" (Personal Communication, October 24, 2018). Participant 7 echoed this idea by hypothesizing the next wave of influence on Toronto slang based on changing demographics. Although she was not completely convinced, she wondered if Asian languages will make more of an appearance in the slang used by young people in the future.

Denis and Participant 12 also went beyond the GTA and briefly discussed the ways in which Toronto slang can be transported to other areas of the world in the same way Patois was transported and transformed in the GTA. As mentioned, Denis explained that through social media observation and other means, individuals and small groups outside of the GTA may choose to adopt certain terms and use them in their communities. And if enough residents catch on, these terms become integrated into new localities. Similarly, Participant 12 noted that there can be an additional transformation that happens when GTA residents travel or move to new locations. She stated that as people move from the GTA, whether to different provinces or to areas in the United States, "they bring that language with them and start speaking in certain ways that people in Toronto do" (Participant 12, Personal Communication, November 18, 2018). She continued that as a Toronto native speaks in the slang, "people there may pick it up, or they may not, or they may mix it with other slang that is innate to the neighbourhoods or cities or areas that they've moved to" (Participant 12, Personal Communication, November 18, 2018).

\subsubsection{Summary.}

Similar to the European and African languages influencing each other in the Caribbean to form Patois, there is evidence of Patois and other immigrant languages and dialects creating a "profound and disturbing" relationship with English, by contributing to and impacting the ways in which English may be understood in different communities across the GTA (Bhabha, 1994, p. 124). The hybridity within Toronto culture and language also speaks to the various diasporas and ethnolects that exist, interact with each other, and continue to evolve as a result of their confrontations in the city. Additionally, the GTA 
may be considered a Third Space where immigrants and descendants of dominant cultures in Toronto negotiate their identities within their current home (Bhabha, 1994). Slang, then, is the result of these negotiations and linguistic and cultural mixtures, which connect to each other through shared experiences.

The celebrated and critiqued aspects of hybridity were also demonstrated within this project. For example, though Césaire (1956) believed hybridity weakened the uniqueness of a nation or culture, it appears to be one of Toronto's perceived strengths. The cultural blending that exists in the GTA allows immigrants to feel welcome and find communities within which they can enjoy their new residence, while remaining close to the place from which they came. In turn, young people who are born in Toronto gain exposure to a number of cultures and ways of living, which do not appear to be as easily gained in other locations in Canada and North America. Many participants believed Toronto to be unique because of this ability to learn from, build relationships with, and get a glimpse of other cultures, while also consciously or unconsciously incorporating foreign words, phrases, or practices into their own lives.

That said, Toronto's hybrid nature often blurs the lines between different cultures. As a result, residents mistakenly claim these practices as their own because of their ignorance to unique cultural histories. As discussed in previous sections, this false ownership of linguistic terms demonstrates the lack of knowledge and education of particular cultural and ethnic features. In this way, Césaire's arguments are still valid and demonstrate the importance of acknowledging that although Toronto may embrace and celebrate its diversity and hybridity, it is not an excuse to forget the distinct nationalities that have contributed to this rich GTA culture.

\subsubsection{Community and belonging.}

Many participants explained that their engagement with different elements of Toronto slang gave them a sense of community and belonging and stated the ways in which slang use makes them feel included in a group. For example, it was described as a way to connect with friends, revisit feelings of nostalgia, and relate to those who, too, use and/or understand the slang used in their community. This was 
not surprising because of language's importance in reflecting one's culture (Okara, 1963; Ngũgĩ, 1981). Many times, slang is used within black communities before expanding to and becoming appropriated by other areas because of its trendiness, coolness, and overall appeal (Henry, 2012). As such, participants explained that individuals use it in various settings in order to be included in the 'in-crowd' or approved by those within black culture (black culture and the 'in-crowd' often intersected). That said, Ngũgĩ (1986) discusses the ways in which language reflects entire bodies of values and contributes to the ways in which individuals perceive themselves and understand their place in the world. Furthermore, languages with African roots value community involvement and participation (Brathwaite, 1979/1981).

\subsubsection{Coolness.}

Many participants noted that non-black, non-POC, and non-Jamaicans use slang to feel included in a group or to simply sound cool. As explored in Chapter 2, coolness is a major factor in the discussion of slang use. Black culture and media are often "are mined deeply for social cues" providing others with the ability to appear knowledgeable about gossip, music, and general trends (Cunningham, 2001, p. 139). Participant 5 described her elementary and high schools as having a "parrot" culture where "people would use certain words and slang and dress a certain way to be on trend and to be cool...' they say it, you say it"” (Personal Communication, November 4, 2018). Although her school in North York was comprised of $80 \%$ Asian students, the black students would "use the slang and non-black people would start using it to be in with the crowd. Everyone wants to be included in a clique" (Participant 5, Personal Communication, November 4, 2018). As discussed, Participant 4 also believed people of other races want to emulate slang because it stems from black culture, the pinnacle of coolness. Therefore, people say, "wha gwaan' and feel cool and they want to go to...talk like the cool kids and they want to be around the cool kids" (Participant 4, Personal Communication, November 1, 2018). Participant 12 shared these thoughts. She stated that using Toronto slang appeals to people's desire to identify with the coolness of being black or marginalized, which ties back to the perception of hip-hop culture and other racialized practices as being 
trendy and fashionable. She stated, "I think Jamaican culture is very prominent on a global scale. It has a never-ending influence just like blackness has a never-ending influence" (Participant 12, Personal Communication, November 18, 2018).

Denis noted that some languages and cultures are considered cooler than others. He believed that it is "definitely the case with Jamaica and Patois...there's an important caché involved there as well...we can think of various ideologies of, like, race and how that interacts with language" (Denis, Personal Communication, October 29, 2018). Similarly, a survey participant "found that in school, the slang began with kids who were POC and then the white students would pick it up to sound cool" (Anonymous Survey Participant, Online Survey, 2018). Indeed, Participant 11 also believed that one may only know little to no people who speak in slang but may pick it up because it sounds like the cool way to speak.

\subsubsection{Friendships and nostalgia.}

Participants were more likely to feel good about understanding the slang more so than speaking it themselves, but this still indicated people's ability to be or at least feel included in certain groups. For instance, for Participant 11, one does not have to speak in slang in order to be friends with or spend time with those who do. However, when someone is able to understand the slang of the group they associate themselves with, there is a feeling of "unanimous understanding" that relates to not having to provide context, background, or explanations for certain words and phrases; it simply feels like home (Participant 9, Personal Communication, November 8, 2018). Participants also explained that they are more likely to speak in slang if they feel comfortable with a particular person or group. Denis will occasionally say "what a gwaan" to his close friend out of irony or as an inside joke, while recognizing that it would be "kind of ridiculous" to use the term out of that specific context, and with anyone other than a close friend (Denis, Personal Communication, November 29, 2018). Participant 12 explained that although she would not be able to speak in complete slang, she finds herself speaking it or using certain terms when she is around friends or people who share similar life experiences. 
Additionally, based on the areas his friends are from or the way they speak, Participant 1 said he will sometimes mirror that back to them. He described this not as a way of speaking disingenuously. In fact, “it's almost, like, kind of natural. Like, when you're with someone, and you know how they are and their characteristics, you automatically know how to speak to them" (Participant 1, Personal Communication, October 24, 2018). Participant 2 had similar thoughts. Part of her issue with the use of slang from people who did not grow up in a certain area, was that they lack the familiarity and sense of home that she connects with when she recalls terms from her childhood. She explained that "I will bring out the Toronto slang here and there with people, but when it's like something that's natural that comes out, if it's something we used to say growing up...it's not as forced"' (Participant 2, Personal Communication, October 28, 2018).

Participant 12 also noted that Toronto slang gives her feelings of nostalgia because having moved to downtown Toronto, she is now removed from her childhood neighbourhoods of Jane and Finch and Brampton. As a result, it makes her feel good to hear the slang that reminds her of her community and evokes her "earliest memories of home, growing up as a kid in the city" (Participant 12, Personal Communication, November 18, 2018). Her friends also experience similar feelings of nostalgia when they come across slang terms from their childhood. This shows that even if they don't feel comfortable speaking and using these words consistently, they still feel a level of inclusivity and belonging when they can decipher what someone is saying in their everyday speech.

\subsubsection{Online connections and communities.}

The majority of interview participants explained that social media and the internet are a huge way in which GTA residents reinforce their understanding of slang, and those outside of the GTA pick up on and integrate it into their own speech. As mentioned, two main sources of exposure arose when discussing this topic: Drake and 6ixbuzz. A survey participant described the culture and language in the GTA as "very Drake-influenced right now" (Anonymous Survey Participant, Online Survey, 2018). Denis, who 
went to a predominantly white high school, noted that one of Drake's high schools "was very much like [mine]" and "he would have been exposed to these kinds of things just exactly the way that I was" (Personal Communication, October 29, 2018). While some question Drake's humble beginnings, he grew up in the "poorer section of Weston" before moving to a more affluent neighbourhood north of Downtown Toronto (Roberts, 2013).

Drake "always gets associated with Toronto slang" even though he is simply a product of his environment (Denis, Personal Communication, October 29, 2018). The self-proclaimed '6ix god' was also credited by most participants for spreading the slang of the GTA internationally. When it comes to those outside of the GTA being exposed to and adopting the slang, Participant 11 stated that “obviously...it mostly started with Drake" (Personal Communication, November 15, 2018). His music, Saturday Night Live sketch, and other public appearances where he unashamedly speaks in Toronto slang have contributed to what Participant 12 sees as an awareness that there is a black community in Toronto. This relates to the idea of the United States hegemony which often stifles others' ability to identify and understand the uniqueness of Toronto culture generally, and the Toronto black culture, specifically. Participant 9 explained that during her travels to almost 20 different countries, people from all over the world would associate her mention of Toronto with Drake. As weird as it was to have people saying, 'the six', Participant 9 acknowledged that "Drake's music actually has quite a bit of impact on...the slang and correlation between how people view Toronto" (Personal Communication, November 8, 2018). People in Vancouver also tell Participant 4 that she sounds like Drake. Evidently, Drake has become the marker of the entire GTA for those who may not know about the area and is "the most dominant ambassador for that kind of language" (Participant 9, Personal Communication, November 8, 2018).

Most interviewees noted that social media has had a significant influence on the ways in which they, as well as those outside of the GTA have learned or reinforced their understanding of various slang terms. Participant 7 noted that "social media is a huge propeller for sharing Toronto slang and culture", 
especially because of the ways in which Twitter and Instagram algorithms share local viral news on the Moments and Explore pages, respectively (Personal Communication, November 6, 2018). Participant 10 believed others' exposure to Toronto slang is “definitely through social media. And overall...not even just social media, but media. I think there are a lot of artists...who kind of...I don't want to say embody Toronto's culture and slang, but they definitely take it with them if they're from here" (Personal Communication, November 8, 2018). Participant 6 also credited social media as a source for learning slang. She shared that her "friends from Aurora speak in slang all the time. And I'm like, 'How did you learn this?' and they're like, 'Instagram and all these Instagram pages'” (Participant 6, Personal Communication, November 5, 2018).

Participant 7 discussed 4YE Comedy's Jamaican and Torontonian characters and subject matter within their skits. Their characters often speak Patois or Toronto slang, but Standard English subtitles are added to the bottom of the screen. The subtitles are usually inaccurate or exaggerated to provide comedic relief. 4YE was one of Participant 7's earlier interactions with Patois and Toronto slang. When explaining some popular slang terms, she noted that "from, like, 4yall, way back, like...it's Tuesday and, like, [we would say] 'saying it's a Popeyes ting at lunch today' (laughs)" (Participant 7, Personal Communication, November 6,2018 ). She also shared that prior to the interview, she had not really considered the influence this YouTube account has had on her perception of Toronto slang and culture, but looking back, it has had a significant impact on her. Denis also noted that even if someone is not exposed to slang in person, they could still learn them through Twitter or YouTube and decide how to "actively adopt them" (Personal Communication, October 29, 2018). However, without direct exposure, there often exists a disconnect between them and the terms being used, compared to the familiarity or communal sense one feels when they hear a phrase they know. As a result, while some viewers may comment, "I have no idea what any of these words are", those who connect to Toronto slang-based videos, will tag their friends, 
share the content with their networks, and comment, "'LOL, that's my high school' or something like that" (Denis, Personal Communication, October 29, 2018).

While Participant 4 had negative opinions on the 6ixbuzz phenomenon, other participants weighed in on the impact the account has had on the culture in Toronto. When asked for final thoughts on language and slang in the GTA, a survey respondent commented that the "6ixbuzztv instagram account probably has a ton of examples of this" (Anonymous Survey Participant, Online Survey, 2018).

Participant 2 noted that her inspiration for telling her story in Toronto slang was basically "all 6ixbuzz TV" (Personal Communication, October 28, 2018). However, she explained that with Drake's fame and the rise of pages such as 6ixbuzz, the slang has become a romanticized idea of what the culture is all about. Participant 7 was even featured on 6ixbuzz after she mistakenly shared personal information online, and was subsequently ridiculed in the comments section, which, by the time she learned about the post's publicity, had thousands of likes and comments. The only reason she discovered the account was because she received messages from friends who told her about the post, demonstrating that 6ixbuzz posts and reposts content without direct consent.

Her personal story aside, Participant 7 stated that although 6ixbuzz is primarily for entertainment purposes, it is viewed by some as a news source, which she does not think is ideal because 6ixbuzz shares minimal awareness about "anything that isn't, like... 'tea', or, like, a fight, you know? Um, but, like, I feel like [the generation after millennials] would probably get their news through, like, memes and meme pages" (Participant 7, Personal Communication, November 6, 2018). That said, she recognized that 6ixbuzz is huge. Even though neither they, nor Instagram provide translations when posting captions and videos that use Patois or Toronto slang, “everyone knows what they're talking about because it's, like, a private, closed, meme page for Torontonians" (Participant 7, Personal Communication, November 6, 2018). Hence, there is still a feeling of community among those approved to follow the account. This is 
also true for those who engage with social media accounts and influencers in order to connect with Toronto natives living across the GTA, the country, and even other parts of the world.

\subsubsection{Finding their people.}

Using slang not only connects people to friends or memories, but it can also cause them to develop or strengthen new relationships. Participant 7 was enthusiastic when she told the story of discovering she and her co-worker both loved 4YE comedy's YouTube videos. This shared interested caused them to bond over their obsession with the videos' content and humour. She explained that "I don't know why, I just showed it to him one day and he's like, "Oh, I've seen this" and we were just, like, quoting everything and yeah. It's fun to quote things and, like, someone else understanding that reference. It makes me really happy" (Participant 7, Personal Communication, November 6, 2018). Participant 12 also enjoys "understanding Toronto slang and being a part of that culture, even though I don't really participate in it anymore" (Personal Communication, November 18, 2018). She laughs when she hears new words, or when people explain the meanings of certain phrases now that she lives farther away. By still engaging with slang, she remains closely related to the culture of the city.

Participant 9, although not an avid user of Toronto slang, touched on the ways in which using slang deeply connects different communities. She echoed Participant 12's earlier ideas that shared experiences and similar identities create stronger ties and make people feel more comfortable speaking a certain way. Participant 9 explained that slang use allows people to recognize their communities and "be like, 'Oh, he fully understands what I'm saying, 'cause he's from the same place I am. And he kind of has the same life story'" (Participant 9, Personal Communication, November 8, 2018). She continued that language is a part of every culture and community, and when one finds their community within the GTA, one has the feeling of finding a home. This is because "they understand, they know your struggle, where you're coming from, and everything that goes with it" (Participant 9, Personal Communication, November 8, 2018). 
Denis' research validated these feelings of home and connection among the other participants. He explained that slang "creates...social solidarity within the group. Like, if you're 'in the know', then...it builds...these bonds between people" (Denis, Personal Communication, October 29, 2018). He also stated that slang is also "a kind of...filtering mechanism, right? It also does the opposite, right? It keeps people who are not inside, it keeps them out" (Denis, Personal Communication, October 29, 2018). This exclusionary element may apply to those outside of the GTA, as well as those who have little connection to slang. However, it may also be used to explain why Participants 3, 6, and 12 believe there exists a difference in the type of slang used, or the extent to which slang is used in different parts of Toronto. Therefore, while there a number of features that unite the area as a whole, there are still unique differences in the neighbourhoods and areas across the GTA.

\subsubsection{Summary.}

Participants' relationship to language proved to be quite complex, as there were multiple ways in which they may use slang to connect with others. First, it is evident that Canadian youth perceive Patois, and in turn, Toronto slang, as 'cool', because of its presence in black and pop culture, as well as on popular social media accounts. Slang use may also subconsciously be considered cool because of the ways in which it can destabilize Standard English by creating a "profound and disturbing" relationship with the dominant culture (Hall, 1994; Bhabha, 1994, p. 124). This is likely done more intentionally by people of colour and those who understand the history of the language, but still may be appealing to those who seek to fit in. Furthermore, social media plays a significant role in connecting Jamaican descendants to their roots, and also allows GTA residents to use technology and media, such as 6ixbuzz, YouTubers, and music artists to connect with those they consider a part of their social circle.

Glissant (1989) states that language should be accessible to all people. However, while people may access and incorporate slang into their speech, Denis explained the ways in which usage can be both inclusionary and exclusionary, as it connects those who live in the GTA through geography, memory, and 
relationships, while remaining somewhat elusive to those outside of the area. As discussed with many participants, it is easy to identify when someone is using slang terms because they want to feel included, as opposed to those who use it because they truly relate to the terms based on genuine experience. However, it is evident that slang plays an important role in the ways in which people feel connected to their peers, their childhoods and memories, and Toronto culture. Slang usage is not simply a way in which people seek to 'fit in', but it is a way in which they build and maintain sincere relationships and feel like they genuinely belong.

\subsection{Summary of Findings and Analysis}

This chapter discussed findings and analyses from both my online survey and interviews. While the survey data was primarily quantitative, the respondents' open responses and interview data analysis took on a thematic and narrative approach in order to understand the perceptions and experiences of my participants. Evidently, though most participants were not of Jamaican descent, they were highly aware of the connection between Jamaican Patois and Toronto slang. Participants interactions through early interactions, restaurant visits, vacations, social groups, and traditional and social media usage, exemplify Kraidy's (2005) idea that hybridization relies on cross-cultural contact via the movement of people and cultural products. These modern interactions connect people with their homeland, while also sharing their culture with new communities, recalling the infectious cultural expression of the Caribbean slaves, and its appeal to and adoption by white settlers (Karim, 2003; Brathwaite 1986; Glissant, 1989; Brathwaite, 1971).

Indeed, their encounters through various avenues and means allowed participants to identify both the ways in which Jamaican Patois has been embedded into the slang used in the GTA, as well as the ways in which GTA culture differs from those around the world. London is popular site for Jamaican settlers and was most comparable to Toronto by participants, likely because both areas are home to a 
largely Caribbean black population, which allows them to feel more comfortable expressing their cultural practices (Jones, 2005; Foner, 2005). However, as Hall (2001) explains that each Caribbean country varies in its features, characteristics, languages, and expressions based on the homeland of its colonizers, each diasporic site also differs in their features and languages because of the unique combination of diverse ethnic populations they encounter.

They also understand that there is still negative stigma attached to speaking a dialect other than Standard English — a stigma they may even hold themselves — that prevents Toronto slang from being accepted in more formal settings or around certain company. Particularly among those of Caribbean descent, this stigma is reminiscent of West Indian embarrassment caused by Présence Européenne, and the long-standing internalization of inferiority to the white man's English (Ngũgĩ, 1972; Hall, 1994; Fanon 1963). That said, slang is perceived as a way of connecting to and relating with people in order to build a community and feel a true sense of belonging, especially with those who share similar experiences. There may be an element of 'coolness' or trend-setting associated with slang use because of its ability to disrupt ideas of 'proper' English, but language is also an important reflection of one's culture and a reflection of values and identity (Cunningham, 2001; Henry, 2012; Okara, 1963; Ngũgĩ 1981; Ngũgĩ, 1986). The community of Patois slang speakers in the GTA is not always visible or identifiable to non-Patois speakers. It indeed represents a 'public sphericule' (Cunningham, 2001), a space that is neither public nor private, where slang speakers create a space to engage with each other, cultivate their collective voices, and share their negotiated identities.

If the GTA is considered a Third Space, immigrants and descendants in Toronto negotiate their identities within their current home (Bhabha, 1994). Additionally, in the Third Space, all languages are considered unfixed, and free to be reappropriated and reused for new purposes. This is because no language is completely pure, nor can it be returned to its original form once multiple cultural characteristics have merged together (Hall, 2015). Additionally, because of its hybridity and the ways in 
which young people from a wide range of races and ethnicities interact it, it is difficult to name a sole owner of a vernacular such as Toronto slang (Bryan, 2004).

That said, Césaire (1956) holds that hybridity weakens a culture's uniqueness, especially since there were some GTA residents who were less aware of the distinctness of immigrant cultures and their contributions to Toronto slang and culture. Therefore, while there were diverse opinions and perspectives about ownership and cultural appropriation pertaining to Toronto slang, the majority of participants were adamant about the importance of understanding and acknowledging its roots before using it without context. This is because the heavy Patois influence is not simply due to people's desire to be cool or entertain others: these languages were born out of slavery, conflict, oppression, resistance, and survival (Ashcroft et al., 1995). Glissant (1989) believes languages should be accessible to all, and while the ease of which people can go online, create digital communities, and travel the world makes this more convenient than ever, slang remains a dialect originating from communities dominated by racial minorities, marginalized groups, and immigrants of colour. And and as such, it is essential for people to engage with Toronto slang genuinely and authentically in order to respect this history. 


\section{Chapter 5: Conclusion}

\subsection{Introduction}

This project sought to discover the significance of a resistive language such as Patois being used in the West, particularly in the GTA, and the perception of this use by both Jamaicans and non-Jamaicans. I specifically asked about the ways in which Patois, a language long used to define Jamaican culture, is now contributing to cultures in locations abroad, through various processes and connections. In this final chapter, I provide an overview of the project, highlight key findings, discuss the project's theoretical contributions, and explain the limitations and recommendations for researchers moving forward. I conclude with final thoughts.

\subsection{Overview of the research.}

This section reviews and summarizes my project in order to demonstrate each chapter's contribution to the investigation of my research question. First, Chapter 1 provided background on my topic, as well as my motivation for performing this research. I looked at the history of migration and current number of GTA residents with Jamaican origins to show the longevity of Jamaican presence, contextualize past observations, and explain the significance of this project. I argued that Jamaican language and culture has been deeply integrated into the GTA culture, but that little research has been conducted on this site. Therefore, I contended that my research would shed light onto Jamaican experiences in Canada, perceptions of Jamaican culture in the GTA, and the ways in which Patois, through slang, is now being used to define localities abroad. I provided a roadmap of the project before moving to chapter two.

Chapter 2 included a theoretical framework and review of the literature, which helped to situate my research within existing knowledge and schools of thought. Postcolonial theory was used to explain 
the Caribbean's severed history and development of a unique culture due to colonialism and slavery. It was also considered the appropriate theory on which to ground this project because it explains the ways in which Caribbean slaves grappled with power structures, hierarchy, and violence, and the emergence of Patois despite heavy oppression.

The literature review was organized into relevant themes to discuss their importance to my project and the ways in which I sought to build on various thinkers' work. Themes such as hybridity, Third Space, language, diaspora, and identity were pertinent to my research and acted as concepts to which I constantly referred, to ensure cohesion and validate my findings throughout the project. I discussed Jamaica's hybrid culture and language as a result of colonialism, as well as its continual transformation over time. I also looked at Patois' development and the ways in which it was used to subvert and challenge imperial languages during slavery. And through the migration and diaspora, I demonstrated how the language has adapted to changes in space and place, eventually contributing to what is now known as Toronto slang.

Additionally, through Présence Africaine, Présence Européenne, and Présence Americain, which often simultaneously exist within the Jamaican individual, I looked at ideas of diaspora in relation to identity formation, to inquire whether the offspring of a language such as Patois should be owned by those of Jamaican descent, or whether it has a wider acceptance due to its fluidity and transformation through time. I also provided insight into the visibility and representation to Patois and Jamaican culture in the GTA in music, online, and in mainstream and public spaces. Finally, I discussed the gaps within the literature, including the lack of consideration of the GTA as a popular settlement location, the lack of research on Caribbean subcultural languages in the GTA, and few modern studies on what it means for a diasporic language to be so deeply embedded into a Western language, especially with the exposure to these languages via music, social media, and more. My research sought to bridge the gap between 
academic research and the public discourse which has produced considerable commentary on the use of Patois within Toronto slang.

Chapter 3 introduced the methodology and data collection methods used to gather and analyze my findings. My research was grounded in a constructivist and transformative paradigm to address questions relating to individuals' everyday lives, as well as issues of social oppression and power relations. As a result, I spoke with people and gained insights and narratives based on their perceptions and life experiences. I gathered these insights through an online survey and interviews. The survey also informed my interview approach and helped me to frame my questions accordingly. Furthermore, while constructivist and transformative approaches are often accompanied by qualitative methods because of their interest in people and experiences, the survey also provided a quantitative element from which to further validate the data I received. Semi-structured interviews were used to gather responses about particular topics, while allowing participants to elaborate, explain, and expand on their responses. Speaking with people who had knowledge of GTA slang and lived in the area for at least five years was critical to understanding the various perceptions people had of the significance of slang and its connection to immigrant languages, primarily, Patois. Their first-hand experiences also allowed for participants to speak more confidently about the significance of Toronto slang to the GTA culture.

Next, Chapter 4 was comprised of data findings and analysis. The chapter displayed the quantitative findings from the survey and discussed observations and conclusions from these numbers. It then looked at the recurring themes as identified by the NVivo auto-code feature. The top nine themes were culture, Jamaican, influences, words, Patois, white, slang, immigrants, and backgrounds. Similarly, the interview findings section also discussed the themes revealed by NVivo. These themes were: words, language, people, culture, area, group, slang, appropriation, and media. Although they shared themes, the survey and interviews provided different insights which helped to provide a fuller picture on the research topic. The Data Analysis section of Chapter 4 was also organized into themes in order to delve deep into 
the primary topics raised within the interviews and, to a lesser extent, the open responses located in the survey. Each theme provided important insights into participants' perceptions of Toronto slang and its relation to Jamaican culture and language. I looked at participants' connections to Jamaican culture; the characteristics of a contagious language; the ways in which participants consider Toronto slang unique; ideas and opinions on slang and cultural appropriation; stigmas that prevent slang from being fully embraced; the continuous hybridization process through slang; and participants' opinions on the ways in which language can foster community and belonging. At the end of each section, I connected the data to relevant literature in order to validate the responses and situate the findings within previous research. Overall, I found that participants' perceptions of Toronto slang and its significance to the GTA's culture is quite complex and is based on a number of factors and criteria, such as race, place, ethnicity, various social interactions, and much more.

Chapter 5 concludes the project by discussing key findings, limitations and recommendations for further research on this topic, and final thoughts on what this research means for both the academic and non-academic world.

\subsection{Key Empirical Findings}

A number of findings resulted from this project to address my research question. This section summarizes five key empirical findings from the project.

\subsubsection{Toronto is uniquely diverse.}

People perceive Toronto as distinct from other cities in Canada. This uniqueness comes from the vast number of diasporic and migrant groups that have moved to the GTA and contributed to the language and culture of the area. The wide variety of minorities and first- and second-generation Canadians have resulted in a distinct hybrid locality where residents are exposed to diverse people, festivals, cuisines, and other cultural objects. Additionally, the vibrancy and strong oral nature of Patois, paired with the fact that 
Jamaicans were early immigrants to Canada, have had a significant impact on the ways in which people in the GTA speak, act, and engage with the culture. Their longstanding residency in the GTA has caused Patois to become entangled with and integrated into the slang of the area and demonstrates the presence of Jamaican culture in everyday life in Toronto. Although London and Toronto are similar in their Patoisinspired slang, their unique hybrid conditions and cultural encounters differentiate the two cities, making them akin in their Jamaican influence but not cultural carbon copies. Furthermore, Toronto's diverse makeup also distinguishes the GTA from cities in the United States because of their overwhelming African American culture to which Jamaican immigrants often feel required to adapt or align themselves.

\subsubsection{Reflection is required before slang use.}

Next, the concept of cultural appropriation is complex in all contexts. Therefore, its relationship to Toronto slang depends on individual perceptions of what it means to use slang authentically. Some believed that Toronto slang is more closely aligned with racialized people who have experienced similar life experiences. Because of the slang's resistive nature, marginalized people are able to relate to notions of subversion, resistance, and contestation of Western practices. On the other hand, some realized that they were more familiar with slang terms and phrases when they were younger, or that their parents and elders are less likely to understand or approve of slang. As a result, the slang may be more popular among youth, before stigma and discrimination causes them to stop using the vernacular as consistently.

Finally, some participants believed that the location of one's childhood or formative years are stronger determinants of authentic use. For example, someone who grew up in an area with heavy Jamaican influence is likely to adopt the terms from Patois and integrate them into their everyday speech more easily than someone who is outside of this group and has only had indirect exposure to the slang, such as through social media or hip hop music. While participants held different opinions on cultural appropriation and authenticity, acknowledgement of the roots and inspiration for this slang is important to most participants regardless of whether they believe slang use should be considered cultural 
appropriation. Therefore, Toronto slang should always be reflected upon and recognized as deriving from much larger and more significant element of Jamaican culture.

\subsubsection{Toronto slang and culture are gaining recognition.}

Due to the ease through which many people in the West can access the internet, they are increasingly being exposed to new slang terms and ways of speaking through social media and other means. Additionally, through social media accounts such as 6ixbuzz, they are also becoming exposed to elements of GTA culture. Famous artists such as Drake incorporate Toronto slang into their music and social media presence, causing awareness of Toronto slang to expand and its usage to increase. Consequently, internet users may pick up on and adopt words from cultures they do not know or with which they are unassociated. Therefore, the internet and social media have allowed non-GTA residents to see the uniqueness of the area but may cause them to use terms out of context. Face-to-face contact is still the primary way in which people learn and effectively use new terms in their everyday speech.

\subsubsection{Toronto slang evokes feelings of community and nostalgia.}

Finally, it appeared slang is more prevalent among youth and people may grow out of it. As mentioned, this may be because of the stigma attached to slang use by adults, as an adult, and in formal and professional settings. It may also be caused by people moving from communities with heavy Jamaican presence and therefore not surrounding themselves with other people who speak the same way. However, even if they choose to no longer speak slang, participants feel a sense of belonging and community when they can identify slang terms and understand the language of the groups who do. This is because they can relate to the group's experiences. Additionally, they may have feelings of nostalgia when they are reminded of their childhoods and a time when they used slang terms more consistently. Those familiar with Patois may also feel nostalgic for their Jamaican households or allow them to make a 
link between their familial and physical location. Feelings of belonging and nostalgia provide participants with a sense of 'home', familiarity, and allow them to connect and foster social relationships with others.

\subsubsection{Summary of empirical findings.}

Many insights were obtained throughout this project. Themes of race, place, authenticity, appropriation, and the significance of slang to both local and diasporic cultures and communities were prominent within this project. Evidently, there is a deep relationship between Toronto slang and Jamaican Patois, and both a conscious and subconscious relationship between GTA residents and Jamaican culture. This is especially true for those who grew up in diverse areas of the GTA and were and or still are connected to the speech communities within which slang is prevalent. Through face-to-face interactions, social media, and other means, slang contributes to young people's identity formation, as well as their social ties between those of similar ethnicities, childhoods, and experiences across the GTA.

\subsection{Theoretical Contributions}

There are a few ways in which this research has contributed to existing theories and concepts. First, it adds to the discourse on Jamaican diaspora by providing insight into experiences in Canada, specifically in the Greater Toronto Area. As discussed, Canada has been left out of postcolonial consideration, and the Jamaican diaspora has been studied primarily in regards to the United States and England. Expanding on past research (Henry, 1994; Jones, 2005; James \& Davis, 2012), this project provides insight into the presence of Jamaican language and culture in a specific area in Canada as a result of migration. It points to and demonstrates the profound long-term connection Jamaicans have had with Canada, and the ways in which this relationship has grown and deepened since their initial migration. This project also provides insight into an under-researched element of the greater Canadian identity: while the concept of diversity is prominent to the Canadian international narrative, the fun parts of minority cultures tend to be the most emphasized, while dominant ideologies pertaining to religion and 
politics are imposed on others (Kraidy, 2005). In the same way, participants questioned the validity of these claims, as Canada's government system and organizations are still primarily homogeneous. Therefore, my research contributes to the ways in which Canadians may understand the history of the integration of immigrant cultures in Canada, the unique cultural process in the GTA, and the ways in which GTA residents understand themselves in relation to diasporic histories, influences, and cultural developments.

Similarly, my research contributes to the understanding of Jamaican culture's influence on both marginalized communities and the wider GTA population. Toronto is a location requiring further investigation upon the linguistic and cultural influences deriving from dominant immigrant groups. That said, this project contributed to the awareness and circulation of Toronto slang. Due to the "United States hegemony" (Tomlinson, 2012, in James \& Davis, 2012 p. 107), many scholars (Hewitt, 1986; Sebba, 1993; Bryan, 2004; Thomas, 2007; Sebba, \& Dray, 2012) have focused on the United States and England as sites of inquiry, while failing to consider Jamaicans' contribution to Canadian culture, especially in Toronto. This project provides a glimpse of the strong black culture that exists in Canada - one that is not simply a duplicate of African American culture. While there are similarities to the United States, its difference in origin, language, and cultural customs that make up the GTA cause Toronto to diverge from that of a solely American influence.

This project also raises questions about ownership and cultural appropriation and the criteria involved in claiming ownership or authentic use. While there has been research on slang use among young people and within subcultures (Widdicombe \& Wooffitt, 1995; Leap, 1996; Livia \& Hall, 1997; Grahn, 2000), as well as whether non-Jamaicans or non-POC can use the languages of minorities (Bryan, 2014; Hewitt, 1986; Sebba, 1993), my research explores the many avenues through which individuals may arrive at the definition of 'authenticity', including through race, age, geography, social groups. I also discussed whether slang should be accessible to all (Glissant, 1989), considered a "common property for 
all young people" (Bryan, 2004, p. 655), or claimed and owned by a particular group. Furthermore, this project contributes to ideas surrounding the complexities of cultural appropriation, and perceptions of whose slang use is considered 'authentic' and why.

I examine some of the reasons for the existing stigma surrounding dialects such as Toronto slang. Patois and slang can "trigger discrimination" in school, work, and business settings because of their association with poverty, illiteracy and lack of a moral compass (Rickford et al., 2015, p. 11817). This traces back to slave masters" perceptions of West African languages as "childish babble" or gibberish (DeCamp 1971, p. 26, cited in Bryan, 2004, p. 647). Black slaves internalized these perceptions as well, and through discussions with some of the participants, it is evident that judgement and negative opinions of 'improper' non-Standard English continue to exist, even among those who understand slang's to minority populations. However, in contrast to scholars such as Fanon (1967) who hypothesized that creole languages would become obsolete, Bryan (2004) asserts that Patois has become even more vibrant with many more uses. In its original state and through slang, it is a source of pride in locations across the Jamaican diaspora and an important aspect of people's identities and culture. This project's investigation of the cause and complexities of these stigmas, as well as the demonstration of its significance hopefully contributes to the mitigation of negative judgement in favour of more genuine cultural understanding.

Additionally, this project contributes to the discourse on the ways in which language transforms over time. My research analyzes and discusses past studies on hybridity, Third Space, creolization, and related processes (Brathwaite, 1971, 1979/1981; Bhabha, 1994; Gilroy, 1993; Hall, 2001, 2015, Glissant, 1989; Bernabé, Chamoiseau, \& Confiant, 1990; Kraidy, 2005), as well as adds to the discourse on what occurs when this hybridization process transports, transforms, and unfolds in new localities. This project demonstrates that hybridity is a continuous process that allows people, through the Third Space, to "negotiate and translate their cultural identities in a discontinuous intertextual temporality of cultural difference" (Bhabha, 1998, p. 22). Because of these constant negotiations, all languages can be 
considered hybrid - especially one like Jamaican Patois. Therefore, Patois can be considered the linguistic Third Space where other positions and structures could emerge during colonialism, demonstrating that both European and West African language could no longer return to its original state (Bhabha, 1994; Hall, 2015). Toronto slang continues this progression, and through the Third Space theory, it is evident that the signs and symbols used within Jamaican culture have experienced further iterations and taken on new meanings to prove that no culture or language is static. That said, similar to critiques of hybridity (Prabhu, 2007; Chow, 1993; Toumson, 1998, Kraidy, 2005; Hall, 2015), concepts of diversity and multiculturalism were critiqued by participants because of the dominant culture's tendency to only draw from the desirable and least controversial elements of Indigenous and immigrant cultures to give the appearance of embracing these cultures. Therefore, my project examines the ways in which the Jamaican language has transformed and taken on new and more relevant meanings in the GTA, while continuing to challenge ideas of hybridity and diversity.

Finally, my research discussed social media, technology, and contemporary music influences as new methods of exposure to different languages, dialects, and cultural practices. Whether through Drake's latest song, YouTube videos testing Toronto slang knowledge, or the rapid growth of social media accounts such as 6ixbuzz, people bond and create virtual subcultural communities, which generate feelings of affirmation, invitation, and bonding (Bryan, 2004). Because of internet, individuals have the opportunity to define themselves, reflect the sentiments of their communities, and have their voices heard (Cunningham, 2001). Indeed, the pervasiveness of the internet means social media must be considered and incorporated into current and future research, in order to gain a more thorough understanding of human interactions and social development. As such, this project contributes to the study of language and culture in relation to internet use and, more specifically, social media use. 


\subsection{Limitations and Recommendations}

Limitations existed in this project that provide opportunities for new research to build on and develop as this topic continues to be explored. First, time was a limitation. With more time, additional interviews could have been conducted, as well as interviews beyond my extended social network. Time constraints also limited my ability to better accommodate the schedules of interview participants and receive as many survey responses as possible. Although it does not appear to have acted as a serious limitation, most interviews were conducted over the phone, with a few over Skype, instead of the face-toface conversations that were initially planned. Face-to-face conversations would have provided insights into body language, facial reactions, hand gestures, and emotions. That said, the Skype interviews, which consist of a visual element, provided little additional information, which indicates visual cues were not particularly significant. In fact, it was change in tone of voice, laughter, and hesitation that provided a better idea of participants' feelings.

Additionally, lack of funds may have acted as a limitation. Monetary incentives were not provided to survey participants and a small incentive was given to interview participants. Furthermore, thought the mention of a five-dollar Starbucks gift card was included in all promotional tools, it was not emphasized when communicating with potential participants. Perhaps this minor acknowledgement of an incentive reduced the level of interest among those who desired more of a reward to get involved in the project. That said, all interview participants were excited and grateful to receive any token of appreciation at all.

Scope was another limitation to this project. Within the time given, it was difficult to acquire a large number of survey and interview participants that would cover a wider sample of the GTA population. Therefore, it is recommended that a similar project be conducted on a larger scale with more interviews, in order to gain a deeper understanding and confirmation of noticeable trends. With a large scope and length of time to conduct this research, it is recommended that future projects perform some 
form of comparative analysis of experiences and stories of GTA residents, with that of another location with a heavy Jamaican immigrant population. Further research may also consider focusing more heavily on race to explore the ways in which race is connected to languages that have developed within marginalized communities. It would likely produce new and additional insights related to slang, community, and cultural appropriation. It would also allow the researcher to discover the strength of social and community ties versus perceived racial alliances when it comes to speech.

Finally, providing more linguistic background would serve as a possible strength. With this approach, one could better analyze participants' negotiation process when interpreting meanings and context, deciding which terms and phrases to incorporate into their everyday speech, and forming their identity based on the ways in which they speak. There are many additional ways in which future research can build upon this project. However, listening to minority voices and those affected by the violent events which sparked hybrid languages will remain crucial, regardless of the direction of further studies. This will ensure their opinions are valued and respected and they are given a platform within academia to share their experiences.

\subsection{Final Thoughts}

Dialects such as slang are technically 'open' for everyone to adopt and integrate into their own speech, but those which originate from nations that have suffered from the violence and oppression of Eurocentric societies retain in subtle ways the subversion that contributed to their survival many decades ago. Therefore, while slang is not always used as a resistive tactic, it is important to acknowledge the resistive origins of subversive languages, as well as its value to marginalized communities. Hence, Toronto slang is more than 'youth talk' or an indicator of a certain level of intelligence; it is a contagious, compelling, and communal way of speaking. It connects people across neighbourhoods, localities, cities, and the vast Jamaican diaspora, and reminds us of the power of language's fluidity and ability to unite us. 


\section{References}

About Toronto Caribbean Carnival. (2019). Retrieved from https://torontocarnival.ca/the-carnival/

Achebe, C. (1965). English and the African writer. Transition. doi:10.2307/2934835

Ashcroft, B., Griffiths, G., \& Tiffin, H. (1989). The empire writes back: Theory and practice in postcolonial literatures. London: Routledge.

- $\quad$ (1995). The post-colonial studies reader. London: Routledge.

Baatard, G. (2012). A technical guide to designing and implementing effective web surveys. European Conference on Research Methodology for Business and Management Studies, 48.

Bailey, B. L. (1966). Jamaican Creole syntax: A transformational approach. Cambridge: Cambridge University Press.

Banoum, B. N. (n.d.). Négritude. Retrieved from http://exhibitions.nypl.org/africanaage/essaynegritude.html

Bascaramurty, D. (2017). Popularization of patois stirs up complex feelings for Toronto's West Indian community. Retrieved from https:/www.theglobeandmail.com/news/toronto/popularizationof-patois-stirs-up-complex-feelings-for-torontos-westindiancommunity/article35884529/

Bernabé, J., Chamoiseau, P., \& Confiant, R. (1990). In praise of creoleness. Callaloo, 13(4), 886.

Bhabha, H. K. (1985). Of mimicry and man: The ambivalence of colonial discourse. The MITPress, 28, 125-133. doi:10.2307/778467

- $\quad$ (1993). Culture's in-between. In S. Hall \& P. du Gay (Eds.), Questions of cultural identity (pp. 5360). London: SAGE Publications Ltd doi: 10.4135/9781446221907.n4

- $\quad$ (1994). The location of culture. New York; London: Routledge.

Big Sheng. (2018, September 16 6). Do Toronto people know Toronto slang? (part 2) [Video file]. Retrieved from https://www.youtube.com/watch?v=vJW5diWXz3o 
Branca, N. (2007). Language, gender and identity in the works of Louise Bennett and Michelle Cliff. Honors Projects Overview. 15. http://digitalcommons.ric.edu/honors_projects/15

Brathwaite, K. (1971). The development of creole society in Jamaica, 1770-1820. Oxford: Clarendon Press.

- $\quad$ (1979/1981). History of the voice. In Roots: essay (1986). Habana: Casa de las Américas.

- (1984). History of the voice: The development of nation language in Anglophone Caribbean poetry. London: New Beacon Books.

Bryan, B. (2004). Jamaican creole: In the process of becoming. Ethnic and Racial Studies, 27(4), 641659.

Césaire, A., Eshleman, C., \& Smith, A. (2001). Notebook of a return to the native land. Middletown, CT: Wesleyan University Press.

Césaire, A., \& Pinkham, J. (1972). Discourse on colonialism. New York: Monthly Review Press.

Charmaz, K. (2008). Constructionism and the grounded theory method. In Holstein, J.A. \& J.F. Gubrium (Eds.). Handbook of constructionist research. New York: The Guilford Press.

Chow, R. (1993). Writing diaspora: tactics of intervention in contemporary cultural studies. Indianapolis: Indiana University Press.

Clarke, V., \& Braun, V. (2017). Thematic analysis. The Journal of Positive Psychology, 12(3), 297-298.

Creswell, J. W. (2014). Research design: qualitative, quantitative, and mixed methods approaches. Los Angeles, CA: Sage.

Croucher, S. M. (2011). Social networking and cultural adaptation: A theoretical model. Journal of International and Intercultural Communication, 4(4), 259-264.

doi:10.1080/17513057.2011.598046

Cunningham, S. (2001). Popular media as public 'sphericules' for diasporic communities. International Journal of Cultural Studies, 4(2), 131-147. doi:10.1177/136787790100400201 
Davies, M., \& Hughes, N. (2007). Doing a successful research project: Using qualitative or quantitative methods. Houndmills, Basingstoke, Hampshire: Palgrave Macmillan.

Denis, D. (2016). A note on mans in Toronto. Toronto Working Papers in Linguistics, 37, 1.

Duignan, J. (2016). Narrative analysis. In A dictionary of business research methods. Oxford University Press.

Edmonds, E. B. (2003). Rastafari: From outcasts to culture bearers. New York: Oxford University Press.

Fanon, F., \& Markmann, C. L. (1967). Black skin, white masks. New York: Grove Press.

Fanon, F., \& Philcox, R. (1963). The wretched of the earth. New York: Grove Press.

Foner, N. (2005). In a new land: A comparative view of immigration. New York: New YorkUniversity Press.

- (2009). Gender and migration: West Indians in comparative perspective. International Migration, 47(1), 3-29. doi:10.1111/j.1468-2435.2008.00480.x.

Francis, J. J., Johnston, M., Robertson, C., Glidewell, L., Entwistle, V., Eccles, M. P., \& Grimshaw, J. M. (2010). What is an adequate sample size? Operationalising data saturation for theory-based interview studies. Psychology \& Health, 25(10), 1229-1245. doi:10.1080/08870440903194015

Gilbert, H. \& Tompkins, J. (1996). Post-colonial drama: Theory, practice, politics. New York; London: Routledge.

Gilroy, P. (1987). Diaspora, utopia, and the critique of capitalism. In Gelder, K. \& Thornton, S. The subcultures reader. (pp. 340-349). London; New York: Routledge.

Gilroy, P. (1993). The black Atlantic: Modernity and double consciousness. Cambridge, Mass: Harvard University Press.

Glissant, E., \& Dash, J. M. (1989). Caribbean discourse: Selected essays. Charlottesville: University Press of Virginia. 
Graham, A. \& Bidaye, M. (2016). Keep the family close. On Views. [Audio file]. Retrieved fromhttps://open.spotify.com/track/7sBwAWyXfiIgrYQ8BaJESH

Graham, A. D., Richie, L., Williams, T. M. C., Feeney, A. K. (2017). Blem. On More life. [Audio file]. Retrieved from https://open.spotify.com/track/2XlHu0HcujBCkWMdIAvrqt

Guest, G., Bunce, A., \& Johnson, L. (2006). How many interviews are enough? Field Methods, 18(1), 5982. doi: $10.1177 / 1525822 \times 05279903$

Hagaman, A. K., \& Wutich, A. (2017). How many interviews are enough to identify metathemes in multisited and cross-cultural research? Another perspective on Guest, Bunce, and Johnson's (2006) landmark study. Field Methods, 29(1), 23-41.

Hall, S. (1992). The Question of cultural identity. In McGrew, A. G., Held, D., \& Hall, S., Modernity and its futures (pp. 273-325). Cambridge, UK: Polity Press in association with the Open University.

- (1994). Cultural identity and diaspora. In Williams, P. \& Chrisman, L., Colonial discourse and post-colonial theory: a reader (pp. 227-237). London: Lawrence \& Wishart.

- (2001). Negotiating Caribbean identities. In Meeks, B. \& Lindahl, F., New Caribbean thought: a reader (pp. 24-39). Kingston, Jamaica: Univ. of the West Indies Press.

- $\quad$ (2015). Creolité and the process of creolization. In Rodríguez, G.E. \& Tate, S.A (Eds.), Creolizing Europe: legacies and transformations (pp. 12-25). Liverpool University Press.

Hall, S. \& Jefferson, T. (1976). Resistance through rituals: Youth subcultures in post-war Britain. London: Hutchinson.

Harrell, M. C., \& Bradley, M. (2009). Data collection methods: Semi-structured interviews and focus groups. Santa Monica, CA: RAND.

Harrow, J. D. N. \& Price, R. (2001). BaKardi slang. On Quest for fire: Firestarter, vol. 1. [Audio file]. Retrieved from https://www.youtube.com/watch?v=a1Q_E3jEVEQ 
Henry A. (2012). Patwa, its power, politics and possibilities. In James, C. and Davis, A (Eds.), Jamaica in the Canadian Experience: A Multiculturalizing Presence. pp.98-105. Halifax: Fernwood Press.

Hebdige, D. (1976). Reggae, rastas and rudies. In Hall, S. \& Jefferson, T. (Eds.), Resistance through rituals: Youth subcultures in post-war Britain (pp. 135-153). London: Hutchinson.

Henry, F. (1999). The Caribbean diaspora in Toronto: Learning to live with racism. Toronto: Univ. of Toronto Press.

James, C., \& Davis, A. (2012). Jamaica in the Canadian experience: A multiculturalizing presence. Halifax, N.S.: Fernwood Pub.

Johnson, R. B., Onwuegbuzie, A. J., \& Turner, L. A. (2007). Toward a definition of mixed methods research. Journal of Mixed Methods Research, 1(2), 112-133. doi:10.1177/1558689806298224

Jones, T. (2005). Comparative diasporas: Jamaicans in South Florida and Toronto. (PhD Dissertation). Dissertations from ProQuest.

Karim, K. H. (2003). The media of diaspora. London: Routledge.

Kay and Kosh. (2017, Feburary 26). ATLANTA vs. TORONTO SLANG ft. Osh \& Akela [VideoFile]. Retrieved from https://www.youtube.com/watch?v=WiGlzT15Rgs

Kincaid, J. (1988). A small place. New York: Penguin.

Kirby, S. L., Greaves, L., \& Reid, C. (2006). Experience research social change: Methods beyond the mainstream (2nd ed.). Peterborough, Ont: Garamond Press.

Kachru, B. B. (1986), The power and politics of English. World Englishes, 5: 121-140. doi:10.1111/j.1467-971X.1986.tb00720.x

Kraidy, M. (2005). Hybridity, or the cultural logic of globalization. Philadelphia: Temple University Press.

Lamming, G. (1960). The pleasures of exile. London: Michael Joseph Ltd. 
Leung, G. A. E. (2009). Negotiation of Trinidadian identity in ragga soca music. World Englishes:

Journal of English as an International and Intranational Language, 28(4), 509-531.

Loomba, A. (2005). Colonialism/postcolonialism (2nd ed.). London; New York, NY: Routledge.

Lull, J. (1995). Media, communication, culture: A global approach. Columbia University Press.

Mann, L. K. (2016). White faces in intimate spaces: Jamaican popular music in global circulation. Communication, Culture \& Critique, 9(2), 266-283.

Martis, E. (2016). How the language Of Jamaica became mainstream. Retrieved from https://www.thefader.com/2016/09/01/how-jamaican-patois-became-mainstream

Matheson, K., \& Edwards, C. M. (2016). Perspectives on knowledge mobilization: An introduction to the special issue. Technology Innovation Management Review, 6(9): 4-8.

McNeill, P., \& Chapman, S. (2005). Research methods. London: Routledge.

Morse, J. M., Barrett, M., Mayan, M., Olson, K., \& Spiers, J. (2002). Verification strategies for establishing reliability and validity in qualitative research. International Journal of Qualitative Methods, 1(2), 13-22.

Ngũgĩ, T. (1972). Homecoming: Essays on African and Caribbean literature, culture and politics. London: Heinemann.

- $\quad$ (1986). Decolonising the mind: The politics of language in African literature. Portsmouth, N.H; London: J. Currey.

Okara, G. (1963). The voice. London: Fontana.

Prabhu, A. (2007). Hybridity: Limits, transformations, prospects. Albany: State University of New York Press.

Riffe, D., Lacy, S., \& Fico, F. (2014). Data analysis. In Analyzing media messages: Using quantitative content analysis in research (3rd Ed.). New York: Routledge, p. 138-161. 
Roberts, S. (2013, October 17). Drake: I didn't have it easy growing up in a wealthy Toronto neighbourhood. Retrieved from https://ca.news.yahoo.com/blogs/north-stars/drake-didn-t-easygrowing-wealthy-toronto-neighbourhood-165446063.html

Said, E. W. (1978). Orientalism (1st Vintage Books ed.) Vintage Books.

- $\quad$ (1994). Culture and imperialism (1st ed.). Vintage.

Sebba, M. (1993). London Jamaican: Language systems in interaction. London: Longman.

Sebba, M., \& Dray, S. (2012). Making it real: 'Jamaican', 'Jafaican' and authenticity in the language of british youth. Zeitschrift Für Anglistik Und Amerikanistik, 60(3), 255-273.

Silverman, D. (1993). Interpreting qualitative data: Methods for analysing talk, text and interaction. London: Sage.

Spivak, G. C. (1988). Can the subaltern speak? Basingstoke: Macmillan.

Statistics Canada. (2018a). Census profile, 2016 census Toronto [Census metropolitan area], Ontario and Ontario [Province]. [Catalogue number 98-316-X2016001]. Retrieved April 5, 2019 from Statistics Canada: https://www12.statcan.gc.ca/census-recensement/2016/dp$\mathrm{pd} /$ prof/details/page.cfm?Lang=E\&Geo1=CMACA\&Code1 $=535 \&$ Geo2=PR\&Code2=35\&Data $=\mathrm{C}$ ount\&SearchText=Caledon\%20East\&SearchType=Begins\&SearchPR $=01 \& B 1=A 11$

- $\quad$ (2018b). 150 years of immigration in Canada. Retrieved April 5, 2019 from Statistics Canada: https://www150.statcan.gc.ca/n1/pub/11-630-x/11-630-x2016006-eng.htm

StevieG. (2018, August 6). Toronto slang challenge in Los Angeles | Hollywood BLVD [Video file]. Retrieved from https://www.youtube.com/watch?v=vnpNglQb4OM\&t=283s

Strega, S. (2005). The view from the poststructural margins: Epistemology and methodology resistance. In Brown, L. and Strega, S. (eds.)., Research as resistance: Critical, Indigenous and antioppressive approaches. Toronto: Canadian Scholars' Press, p.199-235. 
Tomlinson, L. (2012). I remember. In James, C., \& Davis, A. (2012). Jamaica in the Canadian experience: A multiculturalizing presence. Halifax, N.S.: Fernwood Pub.

Toumson, R. (1998). Mythologie du métissage. Paris: Presses universitaires de France.

Valero Sancho, J.L., Domínguez, C. \& Ochoa, B. E.M. (2014). An approach to the taxonomy of data visualization. Revista Latina de Comunicación Social, 69, p. 486-507.

Velupillai, V. (2015). Pidgins, creoles and mixed languages: An introduction. Amsterdam; Philadelphia: John Benjamins Publishing Company.

Weekes, J. (2018, July 11). The rise of 6ixBuzz TV from wasteman memes to Toronto's hip-hop centre. Retrieved from https://noisey.vice.com/en_ca/article/xwk8y3/6ixbuzz-tv-toronto-rap-interview

Wilk, R. (1995). Learning to be local in Belize: global systems of common difference In Miller, D., Worlds apart: Modernity through the prism of the local (pp. 110-133). New York; London: Routledge.

Wilkinson, R. (2017). Patois: Language of identity and resistance in the development and perpetuation of Jamaican culture. Unpublished manuscript. 


\title{
Appendices
}

\section{Appendix A Ethics Approval}

\author{
Carleton \\ Pontestity \\ Cenade's Capital University
}

Pffice of Research Ethics

5110 Human Computer Interaction Bldg | 1125 Colonel By Drive

Ottawa, Ontario K1S 5B6

613-520-2600 Ext: 2517

ethics@carletonca

\section{CERTIFICATION OF INSTITUTIONAL ETHICS CLEARANCE}

The Carleton University Research Ethics Board-A (CUREB-A) has granted ethics clearance for the research project described below and research may now proceed. CUREB-A is constituted and operates in compliance with the Tri-Council Policy Statement: Ethical Conduct for Research Involving Humans (TCPS2).

Ethics Protocol Clearance ID: Project \# 109645

Project Team Members: Raven-Paige Wilkinson (Primary Investigator) Dr. Merlyna Lim (Research Supervisor)

Project Title: Diaspora's Dialect: Cultural Exchange and the Transformation of Jamaican Patois in the Greater Toronto Area

Funding Source (If applicable):

Effective: October 11, 2018

Expires: October 31, 2019.

Please ensure the study clearance number is prominently placed in all recruitment and consent materials: CUREB-A Clearance $\# 109645$.

\section{Restrictions:}

This certification is subject to the following conditions:

1. Clearance is granted only for the research and purposes described in the application.

2. Any modification to the approved research must be submitted to CUREB-A via a Change to Protocol Form. All changes must be cleared prior to the continuance of the research.

3. An Annual Status Report for the renewal of ethics clearance must be submitted and cleared by the renewal date listed above. Failure to submit the Annual Status Report will result in the closure of the file.If funding is associated, funds will be frozen. 
4. A closure request must be sent to CUREB-A when the research is complete or terminated.

5. Should any participant suffer adversely from their participation in the project you are required to report the matter to CUREB-A.

Failure to conduct the research in accordance with the principles of the Tri-Council Policy Statement: Ethical Conduct for Research Involving Humans 2nd edition and the Carleton University Policies and Procedures for the Ethical Conduct of Research may result in the suspension or termination of the research project.

Upon reasonable request, it is the policy of CUREB, for cleared protocols, to release the name of the PI, the title of the project, and the date of clearance and any renewal(s).

Please contact the Research Compliance Coordinators, at ethics@ carleton.ca, if you have any questions.

\section{CLEARED BY:}

Date: October 11, 2018

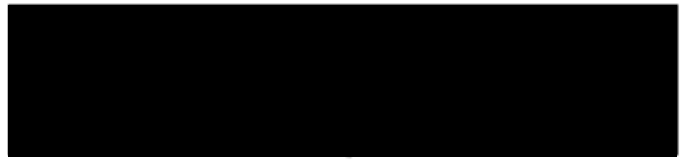

Bernadette Campbell, $\mathrm{PhD}$, Chair, CUREB-A

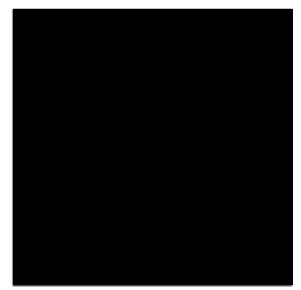

Natasha Artemeva, $\mathrm{PhD}$, Vice-Chair, CUREB-A 


\section{Appendix B Email Invitation}

\section{Carleton universitr}

Canada's Capital University

Subject: Invitation to participate in a research project on language and culture in the Greater Toronto Area

Dear Sir or Madam,

My name is Raven Wilkinson and I am a master's student in the Journalism and Communication department at Carleton University. I am working on a research project under the supervision of Prof. Merlyna Lim.

I am writing to you today to invite you to participate in a study entitled "Diaspora's Dialect: Cultural Exchange and the Transformation of Jamaican Patois in the Greater Toronto Area". Funded by the Social Sciences and Humanities Research Council (SSHRC), this study aims to discover the ways in which Jamaican Patois, a language used to define the Jamaican identity, is now being used to define locations abroad, through various cultural processes and connections.

This study involves one 60-minute interview that will take place over Skype, or in a mutually convenient, safe location. With your consent, interviews will be audio-recorded. Once the recording has been transcribed, the audio-recording will be destroyed.

While this project involves minimal emotional risks (i.e. feelings of distress, embarrassment, or solemnness that may come with recalling past experiences and telling deep, personal stories), care will be taken to protect your identity. This will be done by keeping all responses anonymous and allowing you to request that certain responses not be included in the final project.

You will have the right to end your participation in the study at any time, for any reason, up until 30 days after the end of your participation. If you choose to withdraw, all the information you have provided will be destroyed.

As a token of appreciation, I will be providing you with refreshments during the interview along with a $\$ 5$ Starbucks gift card (the compensation is yours to keep, even if you choose to withdraw).

All research data, including audio-recordings and any notes will be encrypted in password-protected files. Any hard copies of data (including any handwritten notes or USB keys) will be kept in a locked cabinet at Carleton University. Research data will only be accessible to the researcher and the research supervisor.

The ethics protocol for this project was reviewed by the Carleton University Research Ethics Board, which provided clearance to carry out the research. (Clearance expires on: October 31, 2019.)

If you have any ethical concerns with the study, please contact Dr. Bernadette Campbell, Chair, Carleton University Research Ethics Board-A (by phone at 613-520-2600 ext. 2517 or via email at 
ethics@carleton.ca).

If you would like to participate in this research project, or have any questions, please contact me at raven.wilkinson@carleton.ca.

Sincerely,

Raven Wilkinson 


\section{Appendix C Online Invitation}

\section{Carleton \\ U N I V R S I T Y}

Canada's Capital University

\section{Volunteers needed for study on language and culture in the Greater Toronto Area}

We are looking for volunteers to participate in an interview on language and culture in the Greater Toronto Area (GTA). Participants will receive a \$5 Starbucks gift card. The interview takes place at Carleton University.

This project is on entitled "Diaspora's Dialect: Cultural Exchange and the Transformation of Jamaican Patois in the Greater Toronto Area". This study aims to discover the ways in which Jamaican Patois, a language used to define the Jamaican identity, is now being used to define locations abroad, through various cultural processes and connections. You will be asked to participate in an individual interview, to be audio-recorded for transcription purposes; Answer questions about your experiences, perception, and knowledge of GTA culture and slang; and participate in the interview in person (in a mutually agreed upon space with enough privacy and confidentiality to conduct the interview), or via Skype or telephone. To be eligible, you must be English-speaking, have lived in the GTA for five or more years (or left the area up to two years ago), be familiar with GTA slang, and be at least 18 years of age.

The interview will take place on campus and will take approximately 60 minutes to complete.

If you are interested, please email Raven Wilkinson at raven.wilkinson@carleton.ca for more details on participating.

The ethics protocol for this research has been reviewed and approved by the Carleton University Research Ethics Board.

If you have any ethical concerns with the study, please contact Dr. Bernadette Campbell, Chair, Carleton University Research Ethics Board-A (by phone at 613-520-2600 ext. 2517 or via email at ethics@,carleton.ca). 


\section{Appendix D Social Media Script Carleton \\ Canada's Capital University}

\section{Calling all Greater Toronto Area residents!}

I am looking for volunteers to participate in an interview for my thesis project on language and culture in the Greater Toronto Area (GTA). My study aims to discover the ways in which Jamaican Patois, a language used to define the Jamaican identity, is now being used to define locations abroad, through various cultural processes and connections.

You will be asked to participate in a 60-minute individual interview, to be audio-recorded for transcription purposes; Answer questions about your experiences, perception, and knowledge of GTA culture and slang; and participate in the interview in person (in a mutually agreed upon space with enough privacy and confidentiality to conduct the interview), or via Skype or telephone. Participants will receive a $\$ 5$ Starbucks gift card.

To be eligible, you must be English-speaking, have lived in the GTA for five or more years (or left the area up to two years ago), be familiar with GTA slang, and be at least 18 years of age.

If you are interested, please email me, Raven Wilkinson at raven.wilkinson@carleton.ca for more details on participating.

The ethics protocol for this research has been reviewed and approved by the Carleton University Research Ethics Board.

If you have any ethical concerns with the study, please contact Dr. Bernadette Campbell, Chair, Carleton University Research Ethics Board-A (by phone at 613-520-2600 ext. 2517 or via email at ethics@,carleton.ca). 


\title{
Appendix E Poster
}

\section{Carleton \\ universitr}

\section{Participate in a study on Language and Culture in the Greater Toronto Area!}

To participate in this study, you must be:

\author{
$\checkmark$ At least 18 years old \\ $\checkmark$ Living in the GTA for at least five years (or left the area within two years) \\ $\checkmark$ Familiar with GTA slang \\ $\checkmark$ Comfortable in the English language
}

This is a 60-minute interview. You will be asked a series of questions about your experiences and perceptions about GTA culture and language.

Participants will be compensated with a \$5 Starbucks gift card.

The ethics protocol for this project has been reviewed and cleared by the Carleton University Research Ethics Board. If you have any ethical concerns with the study, please contact Dr. Bernadette Campbell, Chair, Carleton University Research Ethics Board-A (by phone at 613-520-2600 ext. 2517 or via email at ethics@carleton.ca).

Please contact the researcher, Raven Wilkinson, for more details on this study at raven.wilkinson@carleton.ca. 


\section{Appendix F Research Consent Form}

Carleton

U N I V E R S I T Y

Canada's Capital University

\section{Name and Contact Information of Researchers:}

Raven Wilkinson, Carleton University, School of Journalism and Communication

Tel.:

Email: raven.wilkinson@carleton.ca

Supervisor and Contact Information:

Merlyna Lim, Carleton University, School of Journalism and Communication

Email: merlyna.lim@carleton.ca

\section{Project Title}

Diaspora's Dialect: Cultural Exchange and the Transformation of Jamaican Patois in the Greater Toronto Area

Project Sponsor and Funder (if any)

Social Sciences and Humanities Research Council (SSHRC)

Carleton University Project Clearance

Clearance \#: TBD

Date of Clearance: TBD

\section{Invitation}

You are invited to take part in a research project because you have lived in the Greater Toronto Area (GTA) for five years or longer (or moved out of the GTA up to two years ago), have a good understanding of GTA culture and slang, and are over the age of 18. The information in this form is intended to help you understand what we are asking of you so that you can decide whether you agree to participate in this study. Your participation in this study is voluntary, and a decision not to participate will not be used against you in any way. As you read this form, and decide whether to participate, please ask all the questions you might have, take whatever time you need, and consult with others as you wish.

\section{What is the purpose of the study?}

Toronto has been the most popular destination for Jamaican immigrants since the mid- to late 1900s. In fact, a Statistics Canada study showed that in 2016, Jamaicans made up $41 \%$ of Caribbean origins in Canada, and 54\% in Toronto, and that the GTA was also home to over 200,000 people of Jamaican origin. As such, Toronto and the GTA have been influenced by many aspects of the Jamaican culture through migration and diaspora. For example, Patois, the unofficial language of the island, has been spoken and spread throughout the Jamaican diaspora in various ways and by those who may not even be of Jamaican 
descent. In fact, through slang, Patois' vibrant and contagious nature has long been integrated into the linguistic and cultural fiber of the GTA, with residents with little to no knowledge of the island or the language's history of violence, oppression, and cultural tension. Therefore, this research looks at the new ways in which Patois has heavily contributed to a culture and age unlike that in which it originated, primarily because of migration. This project aims to discover what it means for a resistive language such as Patois to be used in the West, how this usage is interpreted by both Jamaicans and non-Jamaicans, and what it means for the city. Particularly, this research asks, what are the ways in which Patois, a language used to define the Jamaican identity, is now being used to define locations abroad, through various cultural processes and connections?

\section{What will I be asked to do?}

If you agree to take part in the study, we will ask you to:

- Participate in a 60-minute individual interview, to be audio-recorded for transcription purposes

- Answer questions about your experiences, perception, and knowledge of GTA culture and slang

- Participate in the interview in person (on Carleton University campus, or in a mutually agreed upon space with enough privacy and confidentiality to conduct the interview, such as a conference room or library study room), or via Skype or telephone

\section{Risks and Inconveniences}

Although it is not expected that interview participants will experience psychological harm, you may find some of the questions to be sensitive and to cause you to feel distress. If you do feel distress as a result of answering any of these questions, we invite you to contact Carleton Health and Counselling Services.

\section{Possible Benefits}

You may not receive any direct benefit from your participation in this study. However, your participation may allow researchers to better understand the relationship between migration, language, and the significance of cultural interactions.

\section{Compensation/Incentives}

You will receive a $\$ 5$ gift card to Starbucks for participating in the interview.

\section{No waiver of your rights}

By signing this form, you are not waiving any rights or releasing the researchers from any liability.

\section{Withdrawing from the study}

If you withdraw your consent during the course of the study, all information collected from you before your withdrawal will be discarded. After the study, you may request that your data be removed from the study and deleted by notice given to the Principal Investigator (named above) within one month after your completion. You are permitted to keep your compensation should you decide to withdraw. 


\section{Confidentiality}

We will treat your personal information as confidential, although absolute privacy cannot be guaranteed. No information that discloses your identity will be released or published without your specific consent. Research records may be accessed by the Carleton University Research Ethics Board in order to ensure continuing ethics compliance.

All data will be kept confidential, unless release is required by law (e.g. child abuse, harm to self or others).

The results of this study may be published, but the data will be presented so that it will not be possible to identify you, unless you give consent. All research data will be encrypted in password-protected files.

\section{Data Retention}

Your audio-recorded data will be saved on a password-protected USB and encrypted in password protected files on the researcher's laptop. All data will be deleted once the content has been transcribed, verified for accuracy, and de-identified of any personal information. The transcribed information will also be encrypted in password protected files on the researcher's laptop. Your de-identified data will be retained for a period of two years and then securely destroyed. All data will be coded or anonymous, and as such, a data breach presents only a minor risk.

\section{New information during the study}

In the event that any changes could affect your decision to continue participating in this study, you will be promptly informed.

\section{Ethics review}

This project was reviewed and cleared by the Carleton University Research Ethics Board A. If you have any ethical concerns with the study, please contact Dr. Bernadette Campbell, Chair, Carleton University Research Ethics Board (by phone at 613-520-2600 ext. 2517 for CUREB A or by email at ethics@carleton.ca).

\section{Statement of consent - print and sign name}

I voluntarily agree to participate in this study.

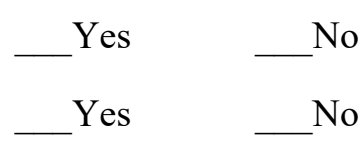

I agree to be audio-recorded No

(Note: if audio-recordings are not permissible, the research will take typed notes)

I agree to be contacted for follow up research Yes No 


\section{Research team member who interacted with the subject}

I have explained the study to the participant and answered any and all of their questions. The participant appeared to understand and agree. I provided a copy of the consent form to the participant for their reference. 


\section{Name and Contact Information of Researchers:}

Raven Wilkinson, Carleton University, School of Journalism and Communication

Tel.:

Email: raven.wilkinson@carleton.ca

Supervisor and Contact Information:

Merlyna Lim, Carleton University, School of Journalism and Communication

Email: merlyna.lim@carleton.ca

\section{Project Title}

Diaspora's Dialect: Cultural Exchange and the Transformation of Jamaican Patois in the Greater Toronto Area

\section{Project Sponsor and Funder (if any)}

Social Sciences and Humanities Research Council (SSHRC)

\section{Carleton University Project Clearance}

Clearance \#: $109645 \quad$ Date of Clearance: October 11, 2018

\section{Invitation}

We ask you to complete this survey if you have lived in the GTA for five years or longer (or moved out of the GTA up to two years ago), are aware of the slang used in the GTA and are over the age of 18. This survey is being conducted by Raven Wilkinson of Carleton University School of Journalism and Communication (raven.wilkinson@carleton.ca, 416-587-0257), working under the supervision of Professor Merlyna Lim (merlyna.lim@carleton.ca). The study is funded by SSHRC.

\section{Objectives and Summary:}

The aim of this study is to better understand the integration of Jamaican Patois into GTA culture and language, and how it has helped define locations abroad, through various cultural processes and connections. 
We estimate that the survey will take about 10 minutes to complete. Your participation in this survey is voluntary, and you may choose not to take part, or not to answer any of the questions. You may withdraw your participation in the survey until you click submit, after which point your answers will be anonymous and unable to identify.

\section{Risks and Benefits:}

Your participation will occupy approximately 10 minutes of your time. We do not anticipate any physical or psychological risks from taking the survey, nor do we anticipate that you will derive any benefit.

\section{Confidentiality and Data Storage:}

We will treat your personal information as confidential, although absolute privacy cannot be guaranteed. No information that discloses your identity will be released or published without your specific consent. Research records may be accessed by the Carleton University Research Ethics Board in order to ensure continuing ethics compliance.

All data will be kept confidential, unless release is required by law (e.g. child abuse, harm to self or others).

The results of this study may be published, but the data will be presented so that it will not be possible to identify you, unless you give consent. All research data will be encrypted in password-protected files.

Although they are in the process of rolling out a Canadian Data Centre, at this time, the account information and metadata will be stored in the United States. SurveyMonkey encrypts users' data in transit using secure TLS cryptographic protocols, although there is risk that data may be disclosed via a court order or data breach.

Your data will be retained for a period of two years and then securely destroyed.

\section{REB Review and Contact Information:}

This project was reviewed and cleared by the Carleton University Research Ethics Board. If you have any ethical concerns with the study, please contact Dr. Bernadette Campbell, Chair by phone at 613-520-2600 ext. 2517 or by email at ethics@carleton.ca.

\section{Implied consent:}

By completing the online survey, you are agreeing to participate in the study. 
1. Which age-range do you fall within?

$\square \quad 18-35$

$\square \quad 36-50$

$\square \quad 51-70$

$\square 71+$

2. How long have you lived in the GTA?

$\square$ 5-7 years

$\square$ 8-10 years

$\square \quad$ I have lived here all my life

$\square$ I recently moved out of the GTA (up to 2 years ago)

3. Where in the GTA do you live?

$\square$ Peel Region

$\square$ York Region

$\square$ North York

$\square$ City of Toronto

$\square$ Durham Region

$\square$ Other

4. Have you ever travelled to a different area of Canada outside of the GTA?

$\square$ Yes, a year ago or less

$\square$ Yes, 2-5 years ago

$\square$ Yes, 5+ years ago

$\square$ No

5. Have you ever travelled to Jamaica, Miami, London, or New York City? Click all that apply:

$\square$ Jamaica

$\square$ Miami

$\square$ London

$\square$ New York City

$\square \quad$ I have never been to these places 
6. Are you of Jamaican descent?

$\square$ Yes

$\square$ No, but I am of Caribbean descent

$\square$ No

7. Do you know/are you friends with individuals of Jamaican or Caribbean decent?

$\square$ Yes, I am friends with individuals of Jamaican descent

$\square$ Yes, I know individuals of Jamaican descent

$\square$ Yes, I have family of Jamaican descent

$\square$ No/I don't know

8. Have you ever heard of Jamaican Patois?

$\square$ Yes

$\square$ No

$\square$ Maybe

9. When were you first introduced to Jamaican Patois?

$\square$ I grew up with it

$\square$ At school

$\square$ In reggae music

$\square$ In current music (e.g. Drake, Partynextdoor, Tory Lanez, Nav, etc.)

$\square$ On the Internet/Social Media (e.g. YouTube, Facebook, etc.)

$\square$ At Jamaican restaurants/businesses

10. Do you know the history of Patois' development?

$\square$ Yes

$\square \quad$ A little bit

$\square$ No

$\square \quad$ I am not sure

11. Do you use Toronto slang words?

$\square$ Yes

$\square$ Sometimes

$\square$ No

12. When were you first introduced to Toronto slang? Check all that apply:

I grew up with it 
At school

$\square \quad$ In my neighbourhood

$\square$ In current music (e.g. Drake, Partynextdoor, Tory Lanez, Nav, etc.)

$\square$ On the Internet/Social Media (e.g. YouTube, Facebook, etc.)

13. Have you ever noticed a connection between Patois and the slang used in the GTA?

$\square$ Yes, all the time

$\square$ Yes, Sometimes

$\square$ No

14. Have you ever noticed a connection between slang used in the GTA and the slang used in locations such as Jamaica, Miami, London, or New York City?

Yes, all the time

$\square$ Yes, Sometimes

$\square$ No

15. How much of the slang used in the GTA do you think derives from Jamaican language?

$\square$ A lot of it

$\square$ Some of it

$\square$ Maybe a little

$\square$ None

$\square$ I don't know

16. Do you believe the GTA has a distinct culture?

$\square$ Yes of course

$\square$ Yes

$\square$ Probably

$\square$ No/I don't know

17. If yes, what about the culture and language used in GTA makes the culture unique?

18. Do you feel more included in the GTA culture when you use slang words?

$\square$ Yes

$\square$ Sometimes

$\square$ No 
19. Do you have any additional thoughts on language, slang, and culture in the GTA?

Thank you for your participation in this survey. If you are interested in participating in an interview to further discuss your responses and experience with slang and GTA culture, please contact raven.wilkinson@carleton.ca. 


\section{Appendix I Interview Questions}

Canada's Capital University

1. Did you grow up in the GTA? If so, in which area?

2. Are you of Jamaican descent?

3. Have you ever been to Jamaica?

4. Describe your experience during a time when you travelled outside of the GTA and experienced a different culture.

5. How would you describe any influences or interactions with Jamaican culture?

6. Have you ever heard of Jamaican Patois? If so, when?

7. Have you ever noticed a connection between Patois and the slang used in the GTA?

8. Can you describe the culture in the GTA?

9. How would you describe the slang in the GTA?

10. Would you be able to tell a simple story in Toronto slang? And if so, can you do so?

11. How, if at all, do you think others are being exposed to the culture and language in the GTA?

12. What do you think makes a language more influential on a locality? Number of people? Nature of the language? Origin? Expression?

13. Do you think there is an any element of cultural appropriation within Toronto slang? Does it have an owner?

14. Do any stories or thoughts come to mind when I say the words, language, slang, culture, and GTA? 